LBNL - 51328

\title{
ENERGY-RELATED INDOOR ENVIRONMENTAL QUALITY RESEARCH: A PRIORITY AGENDA
}

August 12, 2002

\author{
W.J. Fisk ${ }^{1, *}$, G. Brager ${ }^{2}$, H. Burge ${ }^{3}$, J. Cummings ${ }^{4}$, H. Levin ${ }^{5}$, V. Loftness ${ }^{6}$, M.J. Mendell ${ }^{7}$, A. \\ Persily $^{8}$, S. Taylor ${ }^{9}$, J.S. Zhang ${ }^{10}$ \\ ${ }^{1}$ Indoor Environment Department, Lawrence Berkeley National Laboratory \\ ${ }^{2}$ Department of Architecture, University of California, Berkeley \\ ${ }^{3}$ Department of Environmental Health, Harvard School of Public Health \\ ${ }^{4}$ Florida Solar Energy Center, Florida State University \\ ${ }^{5}$ Building Ecology Research Group, Santa Cruz, CA \\ ${ }^{6}$ School of Architecture, Carnegie Melon University \\ ${ }^{7}$ Office of Building Research and Standards, U.S. Department of Energy \\ ${ }^{8}$ National Institute of Standards and Technology, U.S. Department of Commerce \\ ${ }^{9}$ Taylor Engineering, Alameda, CA \\ ${ }^{10}$ Department of Mechanical, Aerospace, and Manufacturing Engineering, Syracuse \\ University
}

Preparation of this report was supported by the California Institute for Energy Efficiency (CIEE) using support from the California Energy Commission. Publication of these research results does not imply CIEE endorsement of or agreement with these findings, nor that of any of its sponsors.

This report was prepared as a result of work sponsored by the California Energy Commission (Commission) and the University of California (UC). It does not necessarily represent the views of the Commission, its employees, or the State of California. The Commission, the State of California, its employees, and UC make no warranty, express or implied, and assume no legal liability for the information in this report; nor does any party represent that the use of this information will not infringe upon privately owned rights. This report has not been approved or disapproved by the Commission nor has the Commission passed upon the accuracy or adequacy of the information in this report.

This work was also supported by the Assistant Secretary for Energy Efficiency and Renewable Energy, Office of Technology Development, Building Technologies Program of the U.S. Department of Energy under Contract ACO3- -76SF00098.

Participation by some core team members was supported by one or more of the following organizations: New York State Energy Research and Development Authority; Florida Solar Energy Center; North Carolina Advanced Energy Center; Iowa Energy Center; Energy Center of Wisconsin.

\footnotetext{
* contact author email: WJFisk@LBL.GOV
} 
This document was prepared as an account of work sponsored by the United States Government. While this document is believed to contain correct information, neither the United States Government nor any agency thereof, nor The Regents of the University of California, nor any of their employees, makes any warranty, express or implied, or assumes any legal responsibility for the accuracy, completeness, or usefulness of any information, apparatus, product, or process disclosed, or represents that its use would not infringe privately owned rights. Reference herein to any specific commercial product, process, or service by its trade name, trademark, manufacturer, or otherwise, does not necessarily constitute or imply its endorsement, recommendation, or favoring by the United States Government or any agency thereof, or The Regents of the University of California. The views and opinions of authors expressed herein do not necessarily state or reflect those of the United States Government or any agency thereof, or The Regents of the University of California. 
August 12, 2002

\title{
ENERGY-RELATED INDOOR ENVIRONMENTAL QUALITY RESEARCH: A PRIORITY AGENDA
}

\author{
W.J. Fisk ${ }^{1, *}$, G. Brager ${ }^{2}$, H. Burge ${ }^{3}$, J. Cummings ${ }^{4}$, H. Levin ${ }^{5}$, V. Loftness ${ }^{6}$, M.J. Mendell ${ }^{7}$, A. \\ Persily $^{8}$, S. Taylor ${ }^{9}$, J.S. Zhang ${ }^{10}$ \\ ${ }^{1}$ Indoor Environment Department, Lawrence Berkeley National Laboratory \\ ${ }^{2}$ Department of Architecture, University of California, Berkeley \\ ${ }^{3}$ Department of Environmental Health, Harvard School of Public Health \\ ${ }^{4}$ Florida Solar Energy Center, Florida State University \\ ${ }^{5}$ Building Ecology Research Group, Santa Cruz, CA \\ ${ }^{6}$ School of Architecture, Carnegie Melon University \\ ${ }^{7}$ Office of Building Research and Standards, U.S. Department of Energy \\ ${ }^{8}$ National Institute of Standards and Technology, U.S. Department of Commerce \\ ${ }^{9}$ Taylor Engineering, Alameda, CA \\ ${ }^{10}$ Department of Mechanical, Aerospace, and Manufacturing Engineering, Syracuse \\ University
}

\begin{abstract}
A multidisciplinary team of IEQ and energy researchers has defined a program of priority energy-related IEQ research. This paper describes the methods employed to develop the agenda, and 35 high priority research and development (R\&D) project areas related to four broad goals:

1) identifying IEQ problems and opportunities;

2) developing and evaluating energy-efficient technologies for improving IEQ;

3) developing and evaluating energy-efficient practices for improving IEQ; and

4) encouraging or assisting the implementation of technologies or practices for improving IEQ.
\end{abstract}

The identified R\&D priorities reflect a strong need to benchmark IEQ conditions in small commercial buildings, schools, and residences. The R\&D priorities also reflect the need to better understand how people are affected by IEQ conditions and by the related building characteristics and operation and maintenance practices. The associated research findings will provide a clearer definition of acceptable IEQ that is required to guide the development of technologies, practices, standards, and guidelines. Quantifying the effects of building characteristics and practices on IEQ conditions, in order to provide the basis for development of energy efficient and effective IEQ control measures, was also considered a priority. The development or advancement in a broad range of IEQ tools, technologies, and practices are also a major component of the priority research agenda.

Consistent with the focus on "energy-related" research priorities, building ventilation and heating, ventilating and air conditioning (HVAC) systems and processes are very prominent in the agenda. Research related to moisture and microbiological problems, particularly within

\footnotetext{
${ }^{*}$ contact author email: WJFisk@LBL.GOV
} 
hot and humid climates, is also prominent within the agenda. The agenda tends to emphasize research on residences, small commercial buildings, and schools because these types of buildings have been underrepresented in prior research. Most of the research areas apply to both new construction and existing buildings.

Nearly all of the recommended priority R\&D project areas include tasks intended to facilitate the communication and implementation of the research results. In addition, the priority agenda includes several projects specifically designed to facilitate or stimulate the use of existing energy-efficient technologies and practices for improving IEQ.

To assure that the research program continues to meet the needs of stakeholders and to facilitate the coordination of research among sponsors, the core team recommends an annual meeting attended by sponsors, a balanced group of stakeholders, and a selection of researchers implementing the agenda.

\section{INTRODUCTION}

Indoor environmental quality (IEQ) and building energy use are both strongly influenced by a building's design, construction, operation, and maintenance, by the activities of occupants, and by outdoor environmental conditions. Consequently, energy-efficiency measures may degrade IEQ, improve IEQ, or be IEQ neutral. Similarly, IEQ improvement measures may increase or decrease energy consumption or be energy neutral.

Given the many interactions between building energy performance and IEQ, these two issues must be addressed and researched in a coordinated manner. The U.S. Department of Energy (DOE) recognized the linkage of IEQ and energy use in the late 1970s and has since supported an important program of energy-related IEQ research. With the growing evidence that large health and productivity gains could be attained from practical improvements in IEQ, a group of state energy organizations represented by the Association of State Energy Research and Technology Transfer Institutions (ASERTTI) has recently expressed their support for an expanded and coordinated program of energy-related IEQ research. As a first step, ASERTTI members and DOE jointly supported the development of this agenda for priority energyrelated IEQ research. Among ASERTTI members, the California Energy Commission, with assistance from the California Institute for Energy Efficiency, has taken a lead role in supporting the development of this research agenda. This paper describes the draft priority R\&D agenda.

\section{METHODS}

In conjunction with the sponsors, a scope for the R\&D agenda was established. The agenda was to define the highest priority research needs pertaining to the interrelationships among IEQ conditions (excluding lighting and acoustics), health, occupant satisfaction, worker performance, building energy use, and the building systems and practices affecting energy use. The scope was to include residences, non-industrial commercial buildings (excluding health care buildings) and schools, and to consider the design, construction, and operation phases of buildings. The agenda was to include a balanced portfolio of R\&D products, ranging from new information to applied products for implementation by industry.

A multidisciplinary "core team" of leading IEQ and energy professionals (see list of authors) developed this agenda. Core team members were approved by a steering committee of the 
project's sponsors. An advisory team representing the buildings industry and other stakeholders reviewed and commented on a draft of the agenda presented in this paper.

To provide a background for the identification of priority R\&D needs, the following activities were undertaken:

1. Given the focus on energy-related IEQ research, the processes that link IEQ with energy use, and the IEQ conditions closely linked to energy use, were tabulated (see Appendix 1).

2. The core team reviewed several existing documents that propose IEQ research agendas (DOE, 2000; EPA, 2000; Fisk, 2000; Mendell et al., 2002; Wyon, 2000).

3. To enable the core team to identify $R \& D$ needs that are not being adequately addressed in existing programs, the existing IEQ research activities of several U.S. professional and government agencies were investigated and summarized, including: the Air Conditioning and Refrigeration Technology Institute (ARTI); American Society of Heating, Refrigerating and Air-Conditioning Engineers (ASHRAE); California Air Resources Board (ARB); U.S. Dept. of Energy (DOE); U.S. Environmental Protection Agency (EPA) - Indoor Environment Management Branch (IEMB) and Indoor Environments Division; Dept. of Housing and Urban Development (HUD); National Institute for Occupational Safety and Health (NIOSH); National Institutes of Health (NIH); National Institute for Standards and Technology (NIST); and National Science Foundation (NSF). Information was obtained from web sites and/or provided by representatives of each sponsor (see Appendix 2).

4. The following criteria were identified for qualitative judging of the priority of proposed R\&D activities: potential health benefits; potential comfort or odor benefits; potential productivity benefits; potential energy benefits or strength of the linkage to energy; need for expanded public support of R\&D; potential for R\&D success; expected overall benefit to $R \& D$ cost ratio; likelihood that R\&D results will be used; extent to which project advances science or technology.

With the background materials developed and reviewed, the research agenda was developed by completing the following tasks:

1. The core team developed and discussed a set of 80 candidate priority R\&D areas. Through a process of discussion and voting, the core team selected the top 35 and, among them, the top 22 priority R\&D project areas.

2. Each of the top 35 priority R\&D areas was summarized in one to three pages of text that:

- describes the objectives and general approach

- incorporates tasks that broadly communicate or otherwise facilitate implementation of findings

- explains why the research area is considered a priority

- indicates how the research results could be used

- assigns a research term; i.e., estimated time period before the research could start to affect practice (short term is $<5$ years; mid term is $6-10$ years; long term is $>10$ years)

- identifies opportunities for potential co-funding 
3. Priority R\&D areas were linked to the following four broad research goals ${ }^{1}$ (with some of the 35 areas linked to more than one category)

- Identifying IEQ problems and opportunities

- Developing and evaluating energy-efficient technologies for improving IEQ, health, comfort and productivity

- Developing and evaluating energy-efficient practices for improving IEQ, health, comfort and productivity

- Stimulating or assisting implementation of energy efficient technologies or practices for improving IEQ.

4. Priority R\&D areas were also linked to the following application categories and interest areas:

- Schools

- Residences

- Commercial buildings

- Codes and standards

- Children's health

- Moisture and microbiological problems

The core team distributed a draft research agenda to sponsors and to an advisory committee representing the building industry and stakeholders. Based on comments received in writing and at a one-day workshop, the core team reorganized and revised the agenda. Revisions included:

a) changing the original ten R\&D goals (Fisk et al. 2002, Appendix 4) to the set of four broader R\&D goals identified above;

b) revising text to better indicate how the recommended research would help bring about practical changes to technologies and practices;

c) linking research project areas to various application and interest areas;

d) adding an additional priority R\&D area related to emissions of VOCs;

e) narrowing the scope of some priority research areas; and

f) adding a recommendation for an annual meeting of sponsors, stakeholders, and researchers that would facilitate rapid communication of research findings, provide an opportunity for stakeholder input, and facilitate coordination among sponsors.

In addition, the agenda was also modified to address numerous specific comments from the advisory committee; for example, suggestions on the content of research in specific project areas.

\section{RESULTS}

The linkages between IEQ and building energy use are summarized in tabular form within Appendix 1. Processes that influence both IEQ and building energy performance include ventilation $^{2}$ of conditioned and unconditioned (e.g., crawlspaces attics) spaces, heating, air conditioning, air distribution, air recirculation, humidification, dehumidification, HVAC maintenance, air cleaning, space pressure control, water leakage and condensation, and indoor pollutant source exclusion, removal, or isolation. Most of the linkages of these processes to

\footnotetext{
${ }^{1}$ Initially, a larger set of ten research goals was identified as described in Appendix 4.

${ }^{2}$ In this document the term "ventilation" refers to all processes that bring outside air into buildings, i.e., mechanical ventilation, air infiltration, and natural ventilation through open doors and windows.
} 
both energy and IEQ are widely recognized. Water leakage and condensation can affect building energy performance by degrading the thermal performance of building envelopes. Condensation risks depend on the level of dehumidification by energy-using HVAC systems and on the thermal characteristics of building envelopes. Pollutant source exclusion, removal or isolation can save energy because they reduce the quantity of outdoor air ventilation needed to maintain acceptable IEQ. For example, in a survey of 100 U.S. office buildings, the estimated median ventilation rate in 25 buildings with tobacco smoking was about four times higher than the estimated median ventilation rate in 75 buildings without tobacco smoking ${ }^{3}$.

The IEQ conditions linked to building energy performance (Appendix 1) include concentrations of pollutants in air and on indoor surfaces, temperature, humidity, air movement, thermal radiation, and sound and vibration levels (not addressed in this plan).

Appendix 2 provides summaries of the existing IEQ research activities of several U.S. professional and federal agencies, including ARTI, ASHRAE, ARB, DOE, EPA, HUD, NIOSH, NIH, NIST, and NSF. These summaries also provide, if available, the approximate annual spending on IEQ research by the sponsor.

Table 1 on the following pages lists, by title ${ }^{4}$, the top 35 priority R\&D areas. Several of the priority $R \& D$ areas support multiple $R \& D$ goals. Within these tables, the top 22 priorities are indicated, as are the original project numbers coded to the original ten R\&D goals listed in Appendix 4.

\footnotetext{
${ }^{3}$ Personal communication, H. Brightman, Harvard School of Public Health.

${ }^{4}$ The number assigned to each priority research area, $1-35$, does not indicate relative priority.
} 


\section{Table 1. Priority R\&D Areas.}

Clicking on the project number will take you to a project description (to be implemented).

\section{Research Goals:}

1. Identifying IEQ problems and opportunities.

2. Developing and evaluating energy-efficient technologies for improving IEQ, health, comfort and productivity.

3. Developing and evaluating energy-efficient practices for improving IEQ, health, comfort and productivity.

4. Stimulating or assisting implementation of energy efficient technologies or practices for improving IEQ.

\begin{tabular}{|c|c|c|c|c|c|c|c|}
\hline & \multirow[b]{2}{*}{ Priority R\&D Area } & \multirow{2}{*}{$\begin{array}{l}\text { (Appx.4) } \\
\text { Original } \\
\text { project \# }\end{array}$} & \multicolumn{4}{|c|}{ Research Goals } & \multirow[b]{2}{*}{ Top 22} \\
\hline & & & 1 & 2 & 3 & 4 & \\
\hline (1) & $\begin{array}{l}\text { Collect benchmark data on ventilation rates and IEQ } \\
\text { in small }\left(<2500 \mathrm{~m}^{2}\right) \text { commercial buildings. }\end{array}$ & $1 \mathrm{e}$ & $\mathbf{X}$ & & & & $\mathbf{X}$ \\
\hline (2) & $\begin{array}{l}\text { Collect benchmark data on IEQ conditions, ventilation } \\
\text { rates, and energy use in energy efficient and } \\
\text { conventional new housing. }\end{array}$ & $1 \mathrm{~g}$ & $\mathbf{X}$ & & & & $\mathbf{X}$ \\
\hline (3) & $\begin{array}{l}\text { Collect benchmark data on ventilation and air-flow } \\
\text { performance in existing buildings as a function of } \\
\text { region, building type, HVAC system type. }\end{array}$ & $1 \mathrm{~h}$ & $\mathbf{X}$ & & & & $\mathbf{X}$ \\
\hline (4) & $\begin{array}{l}\text { Compare health outcomes among students and staff in } \\
\text { schools with very high and very low ventilation rates. }\end{array}$ & $2 b$ & $\mathbf{X}$ & & $\mathbf{X}$ & & $\mathbf{X}$ \\
\hline$(5)$ & $\begin{array}{l}\text { Relate ventilation rates in residences to health } \\
\text { symptoms and to satisfaction with IAQ. }\end{array}$ & $2 f$ & & & $\mathbf{X}$ & & \\
\hline$(6)$ & $\begin{array}{l}\text { Quantify the influence of outside ventilation rates on } \\
\text { prevalences of communicable respiratory diseases. }\end{array}$ & $2 \mathrm{~h}$ & & & $\mathbf{X}$ & & \\
\hline (7) & $\begin{array}{l}\text { Investigate the influence of ventilation (natural and } \\
\text { mechanical) on concentrations of contaminants from a } \\
\text { diverse range of contaminant sources. }\end{array}$ & $2 \mathrm{i}$ & & & $\mathbf{X}$ & & $\mathbf{X}$ \\
\hline$(8)$ & $\begin{array}{l}\text { Quantify the relationships between indoor chemical } \\
\text { and biologic contaminants of greatest current concern } \\
\text { and health effects on occupants. }\end{array}$ & $3 d$ & $\mathbf{X}$ & & & & $\mathbf{X}$ \\
\hline
\end{tabular}


Table 1. Priority R\&D Areas (continued).

Clicking on the project number will take you to a project description. (to be implemented)

\section{Research Goals:}

1. Identifying IEQ problems and opportunities.

2. Developing and evaluating energy-efficient technologies for improving IEQ, health, comfort and productivity.

3. Developing and evaluating energy-efficient practices for improving IEQ, health, comfort and productivity.

4. Stimulating or assisting implementation of energy efficient technologies or practices for improving IEQ.

\begin{tabular}{|c|c|c|c|c|c|c|c|}
\hline & \multirow[b]{2}{*}{ Priority R\&D Area } & \multirow{2}{*}{$\begin{array}{l}\text { (Appx.4) } \\
\text { Original } \\
\text { project \# }\end{array}$} & \multicolumn{4}{|c|}{ Research Goals } & \multirow[b]{2}{*}{ Top 22} \\
\hline & & & 1 & 2 & 3 & 4 & \\
\hline$\underline{(9)}$ & $\begin{array}{l}\text { Identify and quantify the health, energy, comfort, and } \\
\text { productivity impacts of access to fixed and operable } \\
\text { windows. }\end{array}$ & $3 f$ & & $\mathbf{X}$ & $\mathbf{X}$ & & $\mathbf{X}$ \\
\hline$\underline{(10)}$ & $\begin{array}{l}\text { Evaluate the effects of thermal comfort parameters on } \\
\text { health and comfort in commercial and institutional } \\
\text { buildings, including comparisons between air- } \\
\text { conditioned and naturally ventilated buildings. }\end{array}$ & $3 \mathrm{k}$ & & $\mathbf{X}$ & $\mathbf{X}$ & & $\mathbf{X}$ \\
\hline (11) & $\begin{array}{l}\text { Based on health and comfort effects, determine, as a } \\
\text { function of climate, if the use of economizer cycles } \\
\text { can enable a reduction of minimum ventilation rates. }\end{array}$ & $4 \mathrm{c}$ & & $\mathbf{X}$ & $\mathbf{X}$ & & \\
\hline (12) & $\begin{array}{l}\text { Quantify the IEQ and energy impacts of } \\
\text { building/HVAC maintenance and space cleaning. }\end{array}$ & $4 \mathrm{f}$ & & & $\mathbf{X}$ & & \\
\hline (13) & $\begin{array}{l}\text { Quantify the impact of air flows, pressure } \\
\text { differentials, ventilation rates, and HVAC system } \\
\text { performance on indoor humidity levels and moisture } \\
\text { problems in small commercial buildings located in } \\
\text { humid climates, and develop associated remediation } \\
\text { measures. }\end{array}$ & $4 g$ & & & $\mathbf{X}$ & & $\mathbf{X}$ \\
\hline (14) & $\begin{array}{l}\text { For various climates, develop best ventilation and } \\
\text { insulation technologies and practices for crawl spaces } \\
\text { and attics to minimize moisture problems and energy } \\
\text { waste. }\end{array}$ & $5 \mathrm{a}$ & & $\mathbf{X}$ & $\mathbf{X}$ & & $\mathbf{X}$ \\
\hline
\end{tabular}


Table 1. Priority R\&D Areas (continued).

Clicking on the project number will take you to a project description. (to be implemented)

\section{Research Goals:}

1. Identifying IEQ problems and opportunities.

2. Developing and evaluating energy-efficient technologies for improving IEQ, health, comfort and productivity.

3. Developing and evaluating energy-efficient practices for improving IEQ, health, comfort and productivity.

4. Stimulating or assisting implementation of energy efficient technologies or practices for improving IEQ.

\begin{tabular}{|c|c|c|c|c|c|c|c|}
\hline & \multirow[b]{2}{*}{ Priority R\&D Area } & \multirow{2}{*}{$\begin{array}{l}\text { (Appx.4) } \\
\text { Original } \\
\text { project \# }\end{array}$} & \multicolumn{4}{|c|}{ Research Goals } & \multirow[b]{2}{*}{ Top 22} \\
\hline & & & 1 & 2 & 3 & 4 & \\
\hline$\underline{(15)}$ & $\begin{array}{l}\text { Identify the pollutants emitted from common energy } \\
\text { consuming office equipment such as copiers, printers, } \\
\text { computers, and quantify the pollutant emission rates. }\end{array}$ & $5 b$ & $\mathbf{X}$ & & & & \\
\hline$\underline{(16)}$ & $\begin{array}{l}\text { Quantify the VOC emissions and sorption of building } \\
\text { material/furnishing systems and their impact on IEQ } \\
\text { and required ventilation rate. }\end{array}$ & $5 c$ & $\mathbf{X}$ & & & & \\
\hline$\underline{(17)}$ & $\begin{array}{l}\text { Identify the dependence of microbiologic growth on } \\
\text { building envelopes upon the materials used, airflows, } \\
\text { humidity, moisture contents, condensation, and } \\
\text { soiling; and develop strategies that minimize risk of } \\
\text { microbiologic contamination, while maintaining } \\
\text { energy efficiency. }\end{array}$ & $5 \mathrm{j}$ & & $\mathbf{X}$ & $\mathbf{X}$ & & $\mathbf{X}$ \\
\hline$\underline{(18)}$ & $\begin{array}{l}\text { Develop new and innovative HVAC system designs } \\
\text { that provide improved IEQ at minimum life cycle } \\
\text { cost. }\end{array}$ & $6 a$ & & $\mathbf{X}$ & & & $\mathbf{X}$ \\
\hline$\underline{(19)}$ & $\begin{array}{l}\text { Identify the components and features of current } \\
\text { HVAC technologies posing risks, in actual use, of } \\
\text { microbiologic contamination and dissemination. }\end{array}$ & $6 \mathrm{~d}$ & $\mathbf{X}$ & & & & $\mathbf{X}$ \\
\hline
\end{tabular}


Table 1. Priority R\&D Areas (continued).

Clicking on the project number will take you to a project description. (to be implemented)

\section{Research Goals:}

1. Identifying IEQ problems and opportunities.

2. Developing and evaluating energy-efficient technologies for improving IEQ, health, comfort and productivity.

3. Developing and evaluating energy-efficient practices for improving IEQ, health, comfort and productivity.

4. Stimulating or assisting implementation of energy efficient technologies or practices for improving IEQ.

\begin{tabular}{|c|c|c|c|c|c|c|c|}
\hline & \multirow[b]{2}{*}{ Priority R\&D Area } & \multirow{2}{*}{$\begin{array}{l}\text { (Appx.4) } \\
\text { Original } \\
\text { project \# }\end{array}$} & \multicolumn{4}{|c|}{ Research Goals } & \multirow[b]{2}{*}{ Top 22} \\
\hline & & & 1 & 2 & 3 & 4 & \\
\hline$(20)$ & $\begin{array}{l}\text { Develop and evaluate strategies for micro-zoning } \\
\text { while providing individual control, with a focus on } \\
\text { spatial and temporal variability in IEQ conditions, on } \\
\text { occupant interactions with the building [including its } \\
\text { systems and environment] and on the resulting effects } \\
\text { on health, comfort, productivity, and building energy } \\
\text { use. }\end{array}$ & $6 \mathrm{i}$ & & $\mathbf{X}$ & $\mathbf{X}$ & & \\
\hline$\underline{(21)}$ & $\begin{array}{l}\text { Develop inexpensive instruments for rapid and } \\
\text { sensitive identification and measurement of indoor } \\
\text { pollutants of concern. }\end{array}$ & $7 e$ & & $\mathbf{X}$ & & & $\mathbf{X}$ \\
\hline$\underline{(22)}$ & $\begin{array}{l}\text { Develop diagnostic protocols and tools for failures of } \\
\text { HVAC that deteriorate IEQ and energy efficiency. }\end{array}$ & $7 \mathrm{~g}$ & & & $\mathbf{X}$ & $\mathbf{X}$ & $\mathbf{X}$ \\
\hline$\underline{(23)}$ & $\begin{array}{l}\text { Based on a cost/benefit analysis, determine the } \\
\text { appropriate minimum ventilation rates in building } \\
\text { codes. }\end{array}$ & $8 \mathrm{a}$ & & & $\mathbf{X}$ & & $\mathbf{X}$ \\
\hline$\underline{(24)}$ & $\begin{array}{l}\text { Combine current scientific and practical information } \\
\text { on health effects of building design operations and } \\
\text { maintenance, including ventilation, into guidelines for } \\
\text { best building practices. }\end{array}$ & $8 \mathrm{~d}$ & & & & $\mathbf{X}$ & $\mathbf{X}$ \\
\hline$\underline{(25)}$ & $\begin{array}{l}\text { Integrate scientific information on IEQ and materials, } \\
\text { with appropriate weighting factors, into the LEED } \\
\text { Rating System for Green Buildings. }\end{array}$ & $8 f$ & & & & $\mathbf{X}$ & $\mathbf{X}$ \\
\hline
\end{tabular}


Table 1. Priority R\&D Areas (continued).

Clicking on the project number will take you to a project description. (to be implemented)

\section{Research Goals:}

1. Identifying IEQ problems and opportunities.

2. Developing and evaluating energy-efficient technologies for improving IEQ, health, comfort and productivity.

3. Developing and evaluating energy-efficient practices for improving IEQ, health, comfort and productivity.

4. Stimulating or assisting implementation of energy efficient technologies or practices for improving IEQ.

\begin{tabular}{|c|c|c|c|c|c|c|c|}
\hline & \multirow[b]{2}{*}{ Priority R\&D Area } & \multirow{2}{*}{$\begin{array}{l}\text { (Appx.4) } \\
\text { Original } \\
\text { project \# }\end{array}$} & \multicolumn{4}{|c|}{ Research Goals } & \multirow[b]{2}{*}{ Top 22} \\
\hline & & & 1 & 2 & 3 & 4 & \\
\hline$(26)$ & $\begin{array}{l}\text { Use existing information to recommend maximum } \\
\text { pollutant concentrations for pollutants and pollutant } \\
\text { mixtures of particular concern. }\end{array}$ & $8 g$ & & & & $\mathbf{X}$ & $\mathbf{X}$ \\
\hline$(27)$ & $\begin{array}{l}\text { For design professionals, facility managers, and code } \\
\text { officials, develop and deliver education programs in } \\
\text { HVAC and building science related to best practice } \\
\text { for IEQ. }\end{array}$ & $9 b$ & & & & $\mathbf{X}$ & \\
\hline$(28)$ & $\begin{array}{l}\text { Identify key decision makers for IEQ and energy } \\
\text { efficiency in buildings through the building life cycle, } \\
\text { and develop effective information dissemination and } \\
\text { decision-making tools for IEQ and energy efficiency } \\
\text { specifically targeted to these individuals. }\end{array}$ & $9 d$ & & & & $\mathbf{X}$ & \\
\hline$\underline{(29)}$ & $\begin{array}{l}\text { Create a consumer-report style document that ranks } \\
\text { the performance IEQ related building products in use. }\end{array}$ & $9 f$ & & & & $\mathbf{X}$ & \\
\hline$(30)$ & $\begin{array}{l}\text { Develop a database of costs and economic benefits of } \\
\text { energy efficient practices and technologies for } \\
\text { improving IEQ. }\end{array}$ & $9 g$ & & $\mathbf{X}$ & & $\mathbf{X}$ & \\
\hline (31) & $\begin{array}{l}\text { Develop and demonstrate life cycle cost analyses } \\
\text { methods that include human and energy effects of } \\
\text { IEQ. }\end{array}$ & $10 \mathrm{~b}$ & & & $\mathbf{X}$ & $\mathbf{X}$ & $\mathbf{X}$ \\
\hline
\end{tabular}


Table 1. Priority R\&D Areas (continued).

Clicking on the project number will take you to a project description. (to be implemented)

\section{Research Goals:}

1. Identifying IEQ problems and opportunities.

2. Developing and evaluating energy-efficient technologies for improving IEQ, health, comfort and productivity.

3. Developing and evaluating energy-efficient practices for improving IEQ, health, comfort and productivity.

4. Stimulating or assisting implementation of energy efficient technologies or practices for improving IEQ.

\begin{tabular}{|c|c|c|c|c|c|c|c|}
\hline & \multirow[b]{2}{*}{ Priority R\&D Area } & \multirow{2}{*}{$\begin{array}{l}\text { (Appx.4) } \\
\text { Original } \\
\text { project \# }\end{array}$} & \multicolumn{4}{|c|}{ Research Goals } & \multirow[b]{2}{*}{ Top 22} \\
\hline & & & 1 & 2 & 3 & 4 & \\
\hline$(32)$ & $\begin{array}{l}\text { Develop financial incentive tools to stimulate energy- } \\
\text { efficient or energy-neutral improvements in IEQ in } \\
\text { commercial and institutional buildings, such as model } \\
\text { lease language; marketing strategies such as the LEED } \\
\text { rating system; model IEQ insurance policies; and } \\
\text { model IEQ/energy efficiency disclosure requirements } \\
\text { linked to sales. }\end{array}$ & $10 \mathrm{c}$ & & & & $\mathbf{X}$ & $\mathbf{X}$ \\
\hline$(33)$ & $\begin{array}{l}\text { Document the full human and environmental cost of } \\
\text { least-cost decision-making including health cost, } \\
\text { energy consequences, productivity losses, and waste } \\
\text { produced. }\end{array}$ & $10 \mathrm{~d}$ & $\mathbf{X}$ & & & & $\mathbf{X}$ \\
\hline$(34)$ & $\begin{array}{l}\text { Better quantify the productivity costs and } \\
\text { investigation and remediation costs of SBS problems. }\end{array}$ & $10 \mathrm{e}$ & $\mathbf{X}$ & & & & \\
\hline$\underline{(35)}$ & $\begin{array}{l}\text { Develop financial incentives for the design and } \\
\text { construction team that reward high IEQ and energy } \\
\text { performance. }\end{array}$ & $10 \mathrm{f}$ & & & & $\mathbf{X}$ & \\
\hline
\end{tabular}


Table 2 identifies the priority $R \& D$ areas linked to selected application categories or interest areas. Organizations with specific IEQ-related interests can use this table to identify the R\&D needs most related to their interests. For most application categories or interest areas, the links to priority R\&D areas are obvious. Priority R\&D areas that would facilitate the U.S. Department of Energy's Zero Energy Buildings Program, which requires a very high level of building energy efficiency, are those that develop or evaluate energy efficient technologies and practices for maintaining acceptable IEQ or help to define minimum requirements for acceptable IEQ. Priority R\&D areas that support the Homeland Defense program by reducing the vulnerability of buildings to chemical and biological attacks are those that: a) develop data needed to better quantify the vulnerability of buildings (e.g., ventilation rates, building envelope leakage areas, efficiencies of filters actually used in buildings), b) develop or evaluate technologies that could reduce exposures to chemical and biological agents; or c) provide related guidance and training to building professionals.

Table 2. Priority R\&D project areas associated with selected application categories and interest areas.

\begin{tabular}{|l|l|}
\hline \multicolumn{1}{|c|}{$\begin{array}{c}\text { Application Category or } \\
\text { Interest Area }\end{array}$} & \multicolumn{1}{|c|}{ Priority R\&D Areas } \\
\hline Schools & $\begin{array}{l}3,4,6,7,8,9,10,11,12,15,17,18,19,21,22,23,24,25, \\
26,27,28,29,30,31,32,34,35\end{array}$ \\
\hline Residences & $\begin{array}{l}2,3,5,6,7,8,9,12,14,17,18,19,6 \mathrm{I}, 21,22,23,8 \mathrm{~b}, 25, \\
26,27,28,29,30,31,32,33,34,35\end{array}$ \\
\hline Commercial buildings & $\begin{array}{l}1,3,6,7,8,9,10,11,12,13,15,17,18,19,20,21,22,23, \\
24,25,27,28,29,30,31,32,33,34,35\end{array}$ \\
\hline Codes and standards & $4,5,6,7,8,9,10,11,14,16,23,25,26,27,28,30,31,33$ \\
\hline Children's health & $4,5,6,8,9$ \\
\hline $\begin{array}{l}\text { Moisture and microbiological } \\
\text { problems }\end{array}$ & $\begin{array}{l}1,2,3,7,8,9,12,13,14,17,18,19,21,22,23,24,25,26, \\
27,28,29,30,31,32,34,35\end{array}$ \\
\hline $\begin{array}{l}\text { DOE's Zero Energy Buildings } \\
\text { Program }\end{array}$ & $2,3,5,6,7,9,10,11,14,15,17,18,23,24,30,35$ \\
\hline $\begin{array}{l}\text { Homeland Defense - assessing } \\
\text { or reducing the vulnerability of } \\
\text { buildings to chemical or } \\
\text { biological attacks }\end{array}$ & $1,2,3,18,22,24,27$ \\
\hline
\end{tabular}

Appendix 3 provides the one- to three-page summaries for each of the top 35 priority project areas.

The full list of 80 projects identified, which includes many meritorious projects that are not among the top 35, is provided in Appendix 4, organized within a set of ten research-oriented goals. 


\section{DISCUSSION}

\section{$\underline{\text { Research Agenda }}$}

As noted earlier, the research agenda describes priority research needed to identify IEQ problems and opportunities, to develop and evaluate technologies and practices for improving IEQ, health, comfort, and productivity, and to stimulate increased implementation of energyefficient technologies and practices for improving IEQ.

The identified R\&D priorities reflect the strong need to collect and analyze benchmark data on IEQ conditions and ventilation in small commercial buildings, schools, and residences. In these types of buildings, existing benchmark data were considered far from adequate. Large surveys are needed to collect baseline data in these classes of buildings.

The R\&D priorities convey the need, often expressed by architects, engineers, and facility managers, to better understand how peoples' comfort, health, and productivity are affected by IEQ conditions and by the related building characteristics and operation and maintenance practices. The associated research will provide a clearer definition of acceptable IEQ that is required to guide the development of technologies and practices and to set defensible targets or limit values for codes, standards, and guidelines.

Quantifying the effects of building characteristics and practices on IEQ conditions was also considered a priority. The associated research findings are needed to provide the underpinning for the development of energy efficient and effective IEQ control measures.

The research priorities include advancements in a broad range of IEQ tools, technologies, and practices, primarily those related to indoor pollutant sources and to HVAC. The research products include hardware, software, and recommended operation and maintenance practices for buildings.

Consistent with the focus on "energy-related" research priorities, building ventilation and HVAC are prominent in the agenda. Research related to moisture and microbiological problems, particularly within hot and humid climates, is also prominent within the agenda. The portfolio covers the range of building types; however, the agenda tends to emphasize research on residences, small commercial buildings, and schools because these types of buildings have been underrepresented in prior research. Most of the research areas apply to both new construction and existing buildings.

The portfolio of priority research areas is balanced among the four broad R\&D goals, with some of the priority areas supporting multiple goals. Ten project areas support the goal of identifying IEQ problems and opportunities. The goals of developing and evaluating energyefficient technologies, and energy efficient practices, for improving IEQ are supported by nine and fifteen project areas, respectively. Finally, eleven project areas support the goal of stimulating or assisting implementation of energy efficient technologies or practices.

The priority project areas, described in Appendix 3, range from moderate-sized single studies to broader and larger areas of research that would require multiple studies over several years. In many project areas, multiple phases of research have been identified, including a short-term first phase of work that would produce its own deliverable. There is a considerable overlap among the research project areas, reflecting the complex and interrelated set of issues that 
influence IEQ. The intent was to define research project areas that can stand alone, so that a failure to support research in one project area would not restrict research in another area.

Many of the project areas include analyses or synthesis of existing information. Given the high cost of collecting new measured data, further analyses of existing data sets should often be considered as a first step to achieve project-area objectives. The extensive EPA-BASE data set from 100 large office buildings has not been fully analyzed. In California, the Air Resources Board has a new set of data from a survey of relocatable classrooms. The data base from EPA's National Human Exposure Assessment Survey (NHEXAS) may also contain information data relevant to some of the project objectives. Many research organizations also have smaller sets of data that have not been fully analyzed.

The project area descriptions within Appendix 3 identify one or more possible research approaches. No attempt was made to provide comprehensive or detailed study designs. Other research approaches that achieve the same goals may be identified by those proposing research. Consequently, potential sponsors should not rule out proposed research projects simply because the proposed approach does not match the approach within Appendix 3.

Nearly all of the 35 recommended priority R\&D project areas incorporate tasks (Table 3 ) intended to facilitate the implementation of the research results. Examples of these tasks include: work with ASHRAE and other professional organizations to incorporate R\&D findings in handbooks and standards; communication of findings to decision makers via publications, presentations, and training materials; development of labeling or rating systems, web sites, software tools that make it easy to use research results; and demonstration programs. Some projects, such as Project 18 on new HVAC technologies, call for an explicit partnership with industry. In addition, the priority agenda includes numerous projects, especially those identified with R\&D goal \#4, specifically designed to communicate existing information and to stimulate increased use of energy-efficient technologies and practices for improving IEQ. For example, these projects would develop and deliver education programs, create a consumer-reports style document on IEQ-related products, and develop financial incentive tools that stimulate use of energy efficient technologies and practices for improving IEQ.

Table 3. Methods used to communicate R\&D results or facilitate implementation

\begin{tabular}{|l|l|}
\hline \multicolumn{1}{|c|}{ Methods } & \multicolumn{1}{c|}{ Project Areas } \\
\hline Publications & All projects \\
\hline Technical presentations & Nearly all projects \\
\hline Handbook chapters & $1,3,7,9,19,24,26,33,34$ \\
\hline Best practice guides & $12,13,14,19,24,27$ \\
\hline Web sites & $1,2,5,7,24$ \\
\hline Training programs, educational curricula & $1,13,27$ \\
\hline Labeling or rating systems & $15,25,29,32$ \\
\hline Suitable for incorporation in codes or standards & $\begin{array}{l}4,5,6,7,8,9,10,11,14,16,23,25,26, \\
27,28,30,31,33\end{array}$ \\
\hline Incorporation in, of development of, software tools & $16,22,28,31,32,33,34$ \\
\hline $\begin{array}{l}\text { Collaboration with industry during project } \\
\text { implementation }\end{array}$ & $18,21,28,32,33,34,35$ \\
\hline Financial information and incentives & $30,31,32,33,34,35$ \\
\hline
\end{tabular}


The total support required to implement the full priority research agenda is several tens of millions of dollars. While this is a large expenditure, the potential financial benefits of improved IEQ have been estimated as tens of billions of dollars per year (Fisk 2000; Mendell et al 2002).

It is very important to recognize that this agenda has been tailored to match the missions and R\&D capabilities of ASERTTI members and DOE; hence, many important research needs have been omitted from the agenda, e.g., studies of the mechanisms underlying IEQ-related health effects. Additionally, very important areas of research currently being addressed by sponsors (see Appendix 2) may not have ended up within the list of highest priorities, solely because our goal was to identify R\&D needs that are not being adequately addressed in existing R\&D programs.

We believe that many valuable research efforts proposed to sponsors will be consistent with the priorities in this agenda. Specific research efforts may contribute to multiple goals and research project areas, or be more narrowly focused. Due to the multidisciplinary nature of the IEQ field, multidisciplinary research approaches are strongly encouraged. Because it is likely that the core team has overlooked some critical research needs, we caution that sponsors should not exclude projects simply because they do not align with the priorities in this agenda.

\section{$\underline{\text { Recommendations for Implementation of this Agenda }}$}

The keys to success of this program of research include an adequate and sustained commitment by sponsors to support the research, coordination among sponsors, oversight to assure high quality of work, and support for the program by stakeholders.

We believe that research in this field has not been adequately supported, considering the very large potential benefits to the health, comfort, and productivity of tens of millions of people in the U.S., and considering the potential associated financial benefits of tens of billions of dollars annually. Organizations responsible for research in the buildings and energy field should support this research for two reasons. First, IEQ and energy are tightly linked and only an integrated program of research can assure that improvements in energy efficiency do not degrade IEQ and that improvements in IEQ do not reduce energy efficiency. Second, improving IEQ depends upon changes in building design, operation, and maintenance and only the sponsors and implementers of building research have the requisite capabilities in buildings' research to identify the most effective and energy-efficient changes to buildings.

To maintain the support of stakeholders for the program of research, they must be engaged in the program and the program must be designed and periodically updated to meet their needs. The involvement of stakeholders in shaping this agenda is an important first step. To facilitate continued stakeholder participation, we propose an annual meeting attended by sponsors, a balanced group of stakeholders, and a selection of researchers implementing the agenda. At these meetings, researchers would report on R\&D progress, providing a means of rapid communication of $\mathrm{R} \& \mathrm{D}$ findings to interested stakeholders. These meetings would also enable stakeholders to communicate their needs and priorities directly to researchers and 
sponsors, providing a process for selecting among the many priorities and for updating of priorities.

The annual meeting should include a session dedicated to the coordination of the research programs of different sponsors. We also recommend development of a single web site that maintains up-to-date one-page summaries of all energy-related IEQ research efforts supported by the sponsors. This web site would provide sponsors a convenient summary of ongoing research to aid their design of solicitations and selection of projects. The web site would also enable researchers who are proposing research to avoid proposing a project that duplicates ongoing work and to facilitate the development of collaborations among researchers at different institutions.

Finally, the core team recommends a formal reevaluation of priority research needs every five years, leading to an update of the agenda in this report.

\section{ACKNOWLEDGMENTS}

Preparation of this report was supported by the California Institute for Energy Efficiency (CIEE) using support from the California Energy Commission. Publication of these research results does not imply CIEE endorsement of or agreement with these findings, nor that of any of its sponsors.

This report was prepared as a result of work sponsored by the California Energy Commission (Commission) and the University of California (UC). It does not necessarily represent the views of the Commission, its employees, or the State of California. The Commission, the State of California, its employees, and UC make no warranty, express or implied, and assume no legal liability for the information in this report; nor does any party represent that the use of this information will not infringe upon privately owned rights. This report has not been approved or disapproved by the Commission nor has the Commission passed upon the accuracy or adequacy of the information in this report.

This work was also supported by the Assistant Secretary for Energy Efficiency and Renewable Energy, Office of Technology Development, Building Technologies Program of the U.S. Department of Energy under Contract ACO3- -76SF00098.

Participation by some core team members was supported by one or more of the following organizations: New York State Energy Research and Development Authority; Florida Solar Energy Center; North Carolina Advanced Energy Center; Iowa Energy Center; Energy Center of Wisconsin.

The authors thank the following individuals for their service on the industry/stakeholder advisory committee: Darryl Alexander; Charles Claar; Dan IntHout; Bert Kessler; Douglas Kosar; John Tiffany; Michael Jayjock; Tom Kenney; David Mudarri. 


\section{REFERENCES}

DOE 2000. High performance commercial buildings: a technology roadmap. U.S.

Department of Energy www.eren.doe.gov/buildings/commercial_roadmap

EPA 2000. Healthy buildings, healthy people: a vision for the $21^{\text {st }}$ century. U.S. EPA Office of Air and Radiation, EPA 402-K-00-002. U.S. Environmental Protection Agency http://www.epa.gov/iaq

Fisk, W.J. 2000. Health and productivity gains from better indoor environments and their implications for the U.S. Department of Energy. Proceedings of the E-Vision 2000 Conference, October 11-13, 2000, Washington, D.C. Available from RAND Corporation, Arlington, VA.

Fisk, WJ ,Brager, G, Brook, M, Burge, H, Cole J, Cummings, J, Levin, H, Loftness, V, Logee, T, Mendell, MJ, Persily, A, Taylor, S, Zhang, J (2002) A priority agenda for energy-related indoor environmental quality research. Proceedings of Indoor Air 2002, in Press.

Mendell MJ, Fisk WJ, Kreiss K, et al. 2002. Improving the health of workers in indoor environments: research needs for a national occupational research agenda, In press, American Journal of Public Health.

Wyon DP 2000. Enhancing productivity while reducing energy use in buildings. Proceedings of the E-Vision 2000 Conference, October 11-13, 2000, Washington, D.C. Available from RAND Corporation, Arlington, VA 


\section{APPENDIX 1. Tables of links between building energy use and IEQ}

Table 1.1. Processes that link IEQ and building energy use

\begin{tabular}{|c|c|c|}
\hline Process & Link to Energy & Link to IAQ- Health \\
\hline $\begin{array}{l}\text { Outside air } \\
\text { ventilation }\end{array}$ & $\begin{array}{l}\text { Energy used to transport and } \\
\text { thermally condition air }\end{array}$ & $\begin{array}{l}\text { Dilutes indoor-generated pollutants } \\
\text { Associated with symptoms, respiratory illness, perceived air } \\
\text { quality, and work performance } \\
\text { Brings outdoor pollutants and moisture into building } \\
\text { In some climates: inadequate ventilation leads to increased } \\
\text { humidity, condensation, and mold in houses }\end{array}$ \\
\hline Heating & $\begin{array}{l}\text { Energy used to heat and } \\
\text { transport air }\end{array}$ & $\begin{array}{l}\text { Affects thermal comfort } \\
\text { Risk of combustion product entry to indoor air }\end{array}$ \\
\hline $\begin{array}{l}\text { Air } \\
\text { conditioning }\end{array}$ & Energy to cool dehumidify air & $\begin{array}{l}\text { Affects thermal comfort } \\
\text { Risk of microbiological contamination of wetted surfaces. } \\
\text { Risk of condensation on occupied space surfaces when warm } \\
\text { air enters cooled interior. } \\
\text { Associated dehumidification may help prevent moisture } \\
\text { problems and microbiological contamination } \\
\text { Associated with increased health symptoms }\end{array}$ \\
\hline Humidification & Energy to evaporate water & $\begin{array}{l}\text { Affects comfort } \\
\text { Potential source of microbiological and chemical pollutants } \\
\text { May lead to condensation and microbiological growth on } \\
\text { occupied space surfaces. } \\
\text { Linked to respiratory illnesses from humidifier contaminants } \\
\text { Possible link to person-to-person respiratory illnesses } \\
\text { transmission }\end{array}$ \\
\hline $\begin{array}{l}\text { Particle } \\
\text { filtration }\end{array}$ & $\begin{array}{l}\text { Energy used to overcome } \\
\text { airflow resistance } \\
\text { May save energy by preventing } \\
\text { fouling and obstruction of } \\
\text { heating and cooling coils }\end{array}$ & $\begin{array}{l}\text { Reduces indoor particle concentrations with indoor or outdoor } \\
\text { origin } \\
\text { Reduces soiling of surfaces } \\
\text { Filters can be odor sources } \\
\text { Filters, if wet, can be contaminated microbiologically }\end{array}$ \\
\hline $\begin{array}{l}\text { Air } \\
\text { recirculation }\end{array}$ & Energy used to transport air & $\begin{array}{l}\text { Enables filtration of recirculated air } \\
\text { Causes dispersion of indoor pollutants } \\
\text { Reduces concentrations of indoor pollutants near sources } \\
\text { Potential source of noise in occupied space }\end{array}$ \\
\hline $\begin{array}{l}\text { Building } \\
\text { pressure } \\
\text { control }\end{array}$ & Energy used to transport air & $\begin{array}{l}\text { Affects pollutant and moisture transport through building } \\
\text { envelope and among rooms } \\
\text { May prevent or cause moisture problems in building envelope } \\
\text { Prevents or causes infiltration-related drafts and comfort } \\
\text { problems }\end{array}$ \\
\hline $\begin{array}{l}\text { HVAC } \\
\text { maintenance }\end{array}$ & $\begin{array}{l}\text { Improves HVAC system } \\
\text { operation, expected to normally } \\
\text { save energy }\end{array}$ & $\begin{array}{l}\text { May improve ventilation, air distribution, thermal comfort, } \\
\text { humidity control, and pressure control } \\
\text { Lack of maintenance may lead to microbial contamination }\end{array}$ \\
\hline $\begin{array}{l}\text { HVAC } \\
\text { Cleaning }\end{array}$ & $\begin{array}{l}\text { Cleaning of coils reduces airflow } \\
\text { pressure drops and improves } \\
\text { heat transfer, potentially } \\
\text { reducing HVAC energy use }\end{array}$ & $\begin{array}{l}\text { May reduce, or temporarily increase, pollutant emissions from } \\
\text { HVAC systems } \\
\text { Debris, microbiological contamination, and poor draining } \\
\text { from cooling coil drain pans are associated with increased } \\
\text { respiratory symptoms }\end{array}$ \\
\hline
\end{tabular}


Table 1.1 (continued) Processes that link IEQ and building energy

\begin{tabular}{|l|l|l|}
\hline Process & Link to Energy & Link to IAQ- Health \\
\hline Space cleaning & Minor energy use for cleaning & $\begin{array}{l}\text { May reduce indoor odors and resuspended particles } \\
\text { Cleaning compounds can be indoor pollutant sources } \\
\text { Workstation cleanliness has been associated with reduced } \\
\text { symptom reports and with lower dust fungal loads. }\end{array}$ \\
\hline Water leaks & $\begin{array}{l}\text { Degrades thermal performance } \\
\text { of building envelopes } \\
\text { May increase dehumidification } \\
\text { energy }\end{array}$ & $\begin{array}{l}\text { Increases indoor microbiological contamination } \\
\text { Linked to increase in respiratory symptoms and asthma }\end{array}$ \\
\hline $\begin{array}{l}\text { Indoor } \\
\text { pollutant } \\
\text { source } \\
\text { exclusion or } \\
\text { isolation }\end{array}$ & $\begin{array}{l}\text { Often energy neutral; except } \\
\text { when the source or its } \\
\text { replacement consumes energy or } \\
\text { affects heat transfer from } \\
\text { indoors to outdoors. } \\
\text { May reduce ventilation } \\
\text { requirements }\end{array}$ & Reduces indoor pollutant concentrations \\
\hline
\end{tabular}

Table 1.2. IEQ conditions linked to building energy performance.

\begin{tabular}{|c|c|c|}
\hline IEQ condition & $\begin{array}{l}\text { Associated energy-related } \\
\text { processes or conditions }\end{array}$ & Link to Comfort or Health \\
\hline $\begin{array}{l}\text { Airborne pollutant } \\
\text { concentrations }\end{array}$ & $\begin{array}{l}\text { Ventilation, filtration, } \\
\text { pressurization, humidity water } \\
\text { leaks, etc }\end{array}$ & $\begin{array}{l}\text { Increases risk of health effects } \\
\text { Diminishes perceived air quality }\end{array}$ \\
\hline $\begin{array}{l}\text { Pollutant } \\
\text { concentrations on } \\
\text { surfaces }\end{array}$ & $\begin{array}{l}\text { Affected by energy-related } \\
\text { processes that influence airborne } \\
\text { pollutant concentrations and by } \\
\text { humidity, water leaks, building } \\
\text { cleaning }\end{array}$ & Increases risk of health effects \\
\hline Air temperatures & $\begin{array}{l}\text { Heating and air conditioning } \\
\text { Thermal characteristics of } \\
\text { building envelopes }\end{array}$ & $\begin{array}{l}\text { Affects thermal comfort } \\
\text { Modifies perceived air quality } \\
\text { Affects prevalences of health symptoms } \\
\text { Affects pollutant emissions from indoor sources } \\
\text { Affects indoor pollutant phase changes and chemical } \\
\text { reactions }\end{array}$ \\
\hline Air movement, drafts & $\begin{array}{l}\text { Air supply rates, supply air } \\
\text { temperatures, locations and types } \\
\text { of air supply terminals, space } \\
\text { pressure control, building } \\
\text { envelope tightness }\end{array}$ & $\begin{array}{l}\text { Affects thermal comfort } \\
\text { Disperses indoor-generated air pollutants }\end{array}$ \\
\hline Thermal radiation & $\begin{array}{l}\text { Linked to level of thermal } \\
\text { insulation in envelope and to } \\
\text { window energy performance }\end{array}$ & Affects thermal comfort \\
\hline Indoor humidity & $\begin{array}{l}\text { Affected by ventilation rates, } \\
\text { humidification and } \\
\text { dehumidification; space pressure } \\
\text { control, envelope tightness, use of } \\
\text { air and vapor barriers in building } \\
\text { envelopes }\end{array}$ & $\begin{array}{l}\text { High and low humidity affect comfort } \\
\text { Affects risk of microbiological contamination } \\
\text { Affects rate of formaldehyde emission from } \\
\text { manufactured wood products }\end{array}$ \\
\hline Sound levels & $\begin{array}{l}\text { Heating and air conditioning are } \\
\text { sources of noise } \\
\text { Window design affects sound } \\
\text { transmission from outdoors, } \\
\text { especially openability of windows } \\
\text { Envelope tightness affects sound } \\
\text { transmission from outdoors }\end{array}$ & $\begin{array}{l}\text { Source of distraction and complaints } \\
\text { Poor speech privacy with low sound levels } \\
\text { Potential health effects of high sound levels }\end{array}$ \\
\hline
\end{tabular}




\section{APPENDIX 2. Summary of Ongoing IAQ Research Efforts Supported by Various Organizations and Agencies}

This appendix briefly summarizes the current IAQ research efforts undertaken with support from the primary US sponsors of energy-related IAQ research. These summaries provide a context for the identification of new priority research goals and projects. The information for these summaries was obtained from discussions with the sponsors and from web sites or printed documents. Because the information available from the sponsors varies considerably, the format and content of the summaries also vary. There is a substantial degree of co-funding of IAQ research; consequently some research activities are listed by multiple sponsors. To the degree possible, the summaries indicate when projects are co-funded and identify the co-sponsors.

\section{Air-Conditioning and Refrigeration Technology Institute (ARTI)}

The Air Conditioning and Refrigeration Technology Institute (ARTI) manages a program of research using funding from U.S. Department of Energy (DOE); Air-Conditioning and Refrigeration Institute (ARI); Copper Development Association (CDA); New York State Energy Research and Development Authority (NYSERDA); and the California Energy Commission (CEC). A portion of ARTI's research is on Indoor environmental quality. Based on information from ARTI, "The ARTI's IEQ Subcommittee fosters investigations that support industry's ability to provide high quality indoor environments for comfort, health, and productivity. This encompasses air quality, and other physiopsychological factors (i.e., noise, lighting, etc.). The primary concern is in recommending research that will position manufacturers to offer equipment that recognizes, measures, and controls defined indoor environmental concerns. Emphasis areas would include indoor air quality control strategies, identification of anti-microbial materials, improved concepts for particulate or gas-phase filtration, and enhanced control of temperature, moisture and humidity, ventilation, sound, and air velocity."

Titles and costs of five ongoing research projects plus one for which the contractor was not yet selected are provided in Table 2.1. The total cost of these projects is approximately 1.4 million. Most of these projects are multiyear efforts.

Table 2.1. Ongoing or to be Awarded IAQ Research by ARTI

\begin{tabular}{|l|l|}
\hline \multicolumn{1}{|c|}{ Project Title } & \multicolumn{1}{c|}{ Cost } \\
\hline Investigation of the Causes of "Black Soot Phenomena & 204,500 \\
\hline Health, Energy, And Productivity In Schools & 225,000 \\
\hline $\begin{array}{l}\text { Defining the Effectiveness of UV Lamps Installed in Circulating Air } \\
\text { Ductwork }\end{array}$ & 289,602 \\
\hline $\begin{array}{l}\text { Investigation of Building Exhaust Air Re-Entrainment into Outdoor Air } \\
\text { Intakes of Packaged Outdoor HVAC Equipment }\end{array}$ & 273,000 \\
\hline Development of a Residential Indoor Air Quality Evaluation Protocol & 245,000 \\
\hline The Role Of Filtration in Maintaining Clean Heat Exchange Coils & $\begin{array}{l}190,000 \\
\text { (budgeted) }\end{array}$ \\
\hline
\end{tabular}

\section{$\underline{\text { ASHRAE }}$}

ASHRAE Sponsors IAQ-related research projects. Project scopes are developed by ASHRAE's Technical Committee's and competitive bids are sought for high priority approved projects. Project monitoring committees oversee the work performed by successful bidders. The cost of ASHRAE research projects rarely exceeds $\$ 150 \mathrm{~K}$, which limits on the types of research efforts supported. 
Table 2.2 lists the titles, costs, and performance periods for ASHRAE IAQ research efforts completed within the last few years or currently active. The projects listed have been classified by ASHRAE as IAQ projects, although some projects have one or more additional classifications.

Based on a review of Table 2.2, ASHRAE spent approximately $\$ 822,000$ for the identified IAQ research projects between 1999 and the end of 2001, for a spending rate of approximately $\$ 275 \mathrm{~K}$ per year. A few of these projects are not within the scope of the current IAQ planning effort because they relate to industrial environments, animal shelters, or facilities housing locomotives. Design guides, field test methods, and studies of IAQ control methods have received the largest emphasis. A few research projects assess the relationship of indoor environmental conditions with comfort. No projects appear to assess how IAQ affects human health or productivity.

Table 2.2 ASHRAE IAQ research.

\begin{tabular}{|c|c|c|c|}
\hline Project Tile & Cost & $\begin{array}{l}\text { Start } \\
\text { Date }\end{array}$ & $\begin{array}{c}\text { Actual or } \\
\text { Expected End } \\
\text { Date } \\
\end{array}$ \\
\hline $\begin{array}{l}\text { Human response to air movement; part 1: preference and draft } \\
\text { discomfort }\end{array}$ & 104,760 & 98.01 & 99.04 \\
\hline $\begin{array}{l}\text { Determination of the relationship between low frequency noise } \\
\text { and comfort in occupied spaces (psycho-acoustic phase) }\end{array}$ & 124,320 & 96.04 & 98.07 \\
\hline $\begin{array}{l}\text { Laboratory observations of biocide efficiency against } \\
\text { Legionella in model cooling tower systems }\end{array}$ & 78,080 & 96.09 & 99.04 \\
\hline $\begin{array}{l}\text { Identification of contaminants, exposures, effect and control } \\
\text { options for construction/renovation activities, phase II }\end{array}$ & 106,375 & 98.04 & 00.04 \\
\hline $\begin{array}{l}\text { Design approaches to industrial ventilation (previously; } \\
\text { industrial ventilation design guide book) }\end{array}$ & 57,300 & 00.09 & 01.09 \\
\hline $\begin{array}{l}\text { Updating heat and moisture production of poultry and poultry } \\
\text { housing systems }\end{array}$ & 124,572 & 99.04 & 01.04 \\
\hline $\begin{array}{l}\text { Verifying mixed air damper temperature control and air mixing } \\
\text { characteristics }\end{array}$ & 81,139 & 99.01 & 00.07 \\
\hline Development of a design guide for humidity control & 50,000 & 99.06 & 01.01 \\
\hline Fuel cell cogeneration technology assessment guide & 71,485 & 99.06 & 01.01 \\
\hline $\begin{array}{l}\text { Coordinate and analyze inter-laboratory testing of filters under } \\
\text { std. Test } 52.2 \text { to determine adequacy of apparatus qualification } \\
\text { tests }\end{array}$ & 125,128 & 01.09 & 03.03 \\
\hline $\begin{array}{l}\text { Modeling VOC sorption of building materials and its impact on } \\
\text { indoor air quality }\end{array}$ & 98,115 & 99.04 & 01.06 \\
\hline $\begin{array}{l}\text { Field test methods to measure contaminant removal } \\
\text { effectiveness of gas phase air filtration equipment; phase II of } \\
\text { 791RP }\end{array}$ & 147,723 & 00.04 & 02.04 \\
\hline $\begin{array}{l}\text { Optimization of sampling tubes for in-duct fan sound } \\
\text { measurements }\end{array}$ & 19,221 & 99.09 & 00.01 \\
\hline Thermal comfort models and "call-out" (complaint) frequencies & 90,000 & 00.04 & 01.10 \\
\hline $\begin{array}{l}\text { Guidelines on the use of cfd for indoor environmental } \\
\text { modeling }\end{array}$ & 35,000 & 00.04 & 01.06 \\
\hline Evaluation of photocatalytic air cleaning capability & 0 & 99.12 & $00-03$ \\
\hline $\begin{array}{l}\text { Development of a draft method of test for determining grease } \\
\text { removal efficiencies }\end{array}$ & 89,172 & 00.04 & 01.04 \\
\hline Limiting criteria for human exposure to low humidity & 132,400 & 00.04 & 02.04 \\
\hline $\begin{array}{l}\text { The effect of personal control and thermal variability on } \\
\text { comfort and acceptability }\end{array}$ & 141,717 & 00.09 & 02.09 \\
\hline Exhaust contamination of hidden vs. visible air intakes & 79,205 & 00.09 & 02.03 \\
\hline $\begin{array}{l}\text { Control of diesel exhaust fumes in enclosed locomotive } \\
\text { facilities }\end{array}$ & 69,721 & 01.06 & 03.06 \\
\hline
\end{tabular}


The California Air Resources Board (ARB) supports a broad program of research which includes research on personal and indoor exposures to air pollutants. ARB has developed a 10-year Strategic Plan for Research, 2001 - 2010 (July 2001). In this document, the ongoing research projects are briefly described and important questions for future research are defined. The basic questions related to personal and indoor exposures are: 1) what is the impact of air pollution on children's exposures; 2) how do indoor and outdoor sources of air pollution affect indoor and personal exposures; 3) how effective are improvements and new formulations of consumer and building products on reducing indoor exposures; 4) how do short but elevated exposures to smoke impact indoor air quality and exposures; and 5) are people at the lower end of the socioeconomic scale exposed to higher levels of pollutants? Future research projects will be designed to address aspects of these questions. ARB seeks to coordinate new research projects with projects sponsored by other State and Federal agencies. The ARB web site contains descriptions of current and one planned ARB project with indoor exposure components. Summaries of these projects are provided below.

\section{California Portable Classrooms Study}

California Assembly Bill (AB) 2878 mandated the (ARB) and the California Department of Health Services (DHS) to jointly conduct a comprehensive study and review of environmental health conditions in relocatable (portable or modular) classrooms. The main budget is approximately $\$ 1 \mathrm{M}$, with an additional $\$ 125,000$ contributed by ARB for collection and analysis of floor dust samples for persistent compounds. Work began in December 2000, and a final report, including recommendations to remedy any problems identified in the study, is due to the Legislature in June 30, 2002.

\section{F.A.C.E.S. (Fresno Asthmatic Children's Environment Study)}

The five-year FACES study is the first study sponsored by the ARB's new Vulnerable Populations Research Program. The study began in November 2000. The total funding is $\$ 4.5 \mathrm{M}$. The overall objective of the study is to learn how natural and man-made air pollutants influence the way a child's asthma progresses over time. The major focus is on different components of particulate matter (PM), including PM10 and PM2.5 mass, and PM chemical constituents (metals, nitrogen species and polyaromatic hydrocarbons). The influence of ozone, nitrogen oxides, sulfur dioxide, carbon monoxide and bioaerosols also is being considered. The program includes assessment of outdoor, indoor and personal exposures to pollutants, evaluations of children's respiratory health, and walkthrough surveys of the subjects' homes by technicians to include observations of mold growth, moisture content of indoor surfaces, and combustion sources. The information obtained will be used in the development and evaluation of ambient air quality standards and public health policies that are intended to protect against the harmful effects of pollutants.

Characterization of the Composition of Personal, Indoor, and Outdoor Particulate Matter Exposures Individuals with chronic obstructive pulmonary disease (COPD) have been identified by previous studies as one of the subpopulations most susceptible to the acute health effects of particulate matter (PM) exposure. This study focuses on the identification and analyses of the contribution of outdoor air pollutant sources to indoor PM2.5 and personal PM2.5 exposures for a group of COPD patients in Los Angeles. The primary objectives of this study are to: 1) obtain detailed chemical speciation of personal, indoor, and outdoor PM2.5 samples; 2) examine the relationships among personal, indoor, and outdoor levels of the components of PM2.5; and 3) identify the relative contributions of different indoor and outdoor sources to personal PM2.5 exposures. The ARB will use the data from this study to improve the accuracy of its estimates of Californians' exposures to PM2.5, metals, and related toxic air contaminants. The ARB and U.S. EPA co-funded this project.

\section{Detailed Characterization of Indoor and Personal Particulate Matter Concentrations}

The goal of this study is to further investigate the contribution of outdoor particulate matter (PM) to indoor and personal exposures to PM. This study focuses on the PM exposures of a population of healthy individuals in Los Angeles. The study is co-funded by the U.S. EPA, and is similar in design 
to the study mentioned above on the particulate exposures of patients with COPD. However, this study will provide additional information on indoor and personal exposure to PM through the use of a number of real-time or near real-time monitors. The funding provided by U.S. EPA is being used to investigate the deposition and resuspension of PM in the subjects' houses.

\section{Refinement and Demonstration of a New Indoor Continuous Nitrogen Dioxide Monitor} Under ARB funding, a real-time, portable indoor nitrogen dioxide $\left(\mathrm{NO}_{2}\right)$ monitor was developed based on an electrochemical sensor. The monitor can accurately measure both $\mathrm{NO}_{2}$ and nitrous acid. In this project, investigators will improve the monitor with a refined amplification circuit to reduce noise and improve accuracy at low concentrations, and train ARB staff on monitor use, calibration, and data reduction. Monitor performance will be documented during use in 2002 in independent ARB-funded field studies. Use of these monitors in large field studies will help improve estimates of $\mathrm{NO}_{2}$ exposure and the relationship of those exposures to health impacts.

\section{Children's Microenvironmental and Personal Pollutant Exposures for SB 25 with NAP Health Status} Survey

This study will provide data on pollutant concentrations in microenvironments where children spend a significant portion of their time. Since the school sites in each community have been selected based on proximity to major industrial sources or freeways, the results will be representative of locations with potentially elevated exposures. The study includes measurements of pollutant concentrations in schools, residences, and outdoors plus a limited amount of personal exposure monitoring of VOC exposures using badges. The budget for the study is approximately $\$ 400,000$ with an additional $\$ 80,000$ of support requested from EPA for public outreach, metals analysis, and some determinations for moisture and mold. This study will increase our understanding of children's exposures to air pollutants in areas with potentially elevated pollution.

Indoor Air Chemistry: Cleaning Agents, Ozone, and Toxic Air Contaminants

Volatile components of cleaning agents used in residential settings and ozone are ubiquitous constituents of indoor air. The primary emissions from cleaning agents are of potential concern as contributors to Toxic Air Contaminant (TAC) exposures. Additionally, secondary emissions that result from the interactions of volatile components of cleaning products (for example, terpene compounds) with ozone are also of potential concern with regard to TAC exposures. The overall objectives of this project will be to: 1) generate new data on the composition and primary emissions of TACs from common cleaning agents; 2) generate new data on the secondary emissions from cleaning agent constituents upon exposure to ozone; and 3) generate new data on the production of the hydroxyl radical from reactions of ozone with terpenes in cleaning products. The projected funding level is $\$ 450 \mathrm{~K}$.

\section{Department of Energy (DOE)}

The U.S DOE has sponsored research on ventilation and indoor air quality (VIAQ) for approximately 20 years with annual funding for this research on the order of $\$ 1$ million during recent years. One major goal of the DOE's program is to develop information, metrics, tools, and technologies that enable building energy efficiency programs to be implemented without adverse IAQ-related discomfort or health effects. Secondary goals of DOE's R\&D program are to improve comfort, health, and productivity.

DOE's VIAQ R\&D emphasizes addresses indoor environments in residences, commercial buildings, and schools. The scope of DOE's activities is relatively broad, ranging from assisting professional organizations in the development of new standards to investigations of the relationship of IAQ with occupant health or productivity. Because this research is supported by DOE's Assistant Secretary for Energy Efficiency and Renewable Energy, the program of research has a substantial emphasis on VIAQ issues that are clearly related to energy. 
A brief summary of DOE's current R\&D activities follows. Most of the tasks identified are performed over a period of several years.

Ventilation, Infiltration, and Indoor Air and Pollutant Transport

DOE supports several research tasks in the ventilation and infiltration area including:

- Participation in the development of ASHRAE's commercial and residential standards for minimum ventilation rates

- Evaluations of technologies integrated into HVAC systems for continuous monitoring of outdoor air intake rates

- Evaluation of the effects of changing ventilation rates on indoor volatile organic compound concentrations

- Assessment of air leakage characteristics of building envelopes and duct systems, which influence air infiltration rates

- An evaluation of the energy recovery that occurs during air infiltration

- Evaluations of methods of supplying ventilation air near occupants to preferentially ventilate the breathing zone, i.e., to increase ventilation efficiencies

- Assessment of the energy use due to infiltration and ventilation in U.S. office buildings and development of technologies and guidance for reducing this energy liability

- Develop new natural and hybrid ventilation system design tools for commercial buildings

- Simulations of the performance of natural and hybrid ventilation systems

- Development of a design procedure in which contaminant loads, target concentrations, contaminant sources and indoor air quality control technologies, including minimum ventilation requirements, are specified

\section{Pollutant Sources}

DOE supports studies of the emission rates of volatile organic compounds (VOCs) from building materials and assessments of technologies and protocols for reducing emission rates in buildings. DOE also supports the development of models that can be used to predict the time history of VOC emission rates.

\section{Air Cleaning}

DOE has supported experiments and modeling to evaluate the performance of particle air filtration systems. In 2002, research will study the potential of ozone air cleaning systems with lower airstream pressure drops than commercially available granular carbon beds.

\section{Healthy Buildings and Productivity Research}

DOE has supported experimental field studies to determine the risk factors for sick building syndrome symptoms in offices and to test promising interventions for reducing these symptoms and increasing productivity. DOE is also co-funding with ARTI the development of a protocol for quantifying the effects of indoor environmental control on the health and performance of students and staff in elementary schools. DOE is providing co-funding, with EPA, for the multivariate statistical analyses of EPA's BASE data collected from 100 office buildings. These analyses are assessing the relationship of sick building syndrome symptoms with several IAQ factors including carbon dioxide, VOC, and particle concentrations, filter efficiencies, and metrics of HVAC system maintenance and contamination.

\section{$\underline{\text { U.S Environmental Protection Agency Indoor Environment Management Branch (IEMB) }}$}

The IEMB conducts research that is specifically related to indoor air quality. Only IEMB research projects are summarized here, although other branches of ORD conduct research on topics that may have components related to indoor air quality issues. Most of the IEMB research is performed in house. However, some projects are jointly conducted with other organizations such as Research 
Triangle Institute (RTI). IEMB has extensive laboratory capabilities and facilities including a test house, large-scale environmental chambers, and small-scale chambers. IEMB is moving into a new laboratory in spring 2002. The new laboratory includes a static and dynamic chamber facility for the study of microbial contamination issues. IEMB anticipates that this facility will provide many opportunities for new research projects.

An IEMB project is developing analytical and modeling tools and conducting experiments to characterize the impact of ozone on indoor air chemistry with the goal of improving the understanding of the relationship between ozone and risk indoors. As one activity, they are investigating the impact of operating an ozone generator air cleaner on VOC concentrations in a room-sized chamber. A series of tests in a research house has investigated the ability to predict indoor ozone concentrations based on the chamber-derived generation rates. The ozone deposition velocity in the house and a penetration factor for outdoor ozone were determined. The IAQ model RISK is being used to predict the time history of ozone in houses. Other experiments are being conducted to investigate the reaction of ozone with the emissions of VOCs from consumer products, such as cleaning agents. Analytical methods are being developed to detect and quantify organic species that are intermediate products of ozone-mediated reactions with VOCs.

The Bi-Clean project is developing predictive exposure models for emissions of VOCs from waterbased cleaning products that contain high levels of surfactants. The work is in support of the "Tools for Schools" program. Experimental work to characterize the VOC emissions from cleaning products is being conducted in small-scale chambers. The models will predict exposures for both people using the products and general building occupants. It is anticipated that the end users of the models will be manufacturers of cleaning products and schools. IEMB plans to add integrated pest management to this project in the future.

In another project, indoor combustion sources including candles and incense are being investigated. The issues are exposures to lead from some imported candles with lead-cored wicks, exposures to elevated concentrations of fine particulate matter, and soiling of indoor surfaces. New test methods have been developed to obtain representative emissions data, and models are being developed. Much of the experimental work is complete.

The penetration of contaminants from outdoor air and from soil into buildings is being investigated. In the research house, the influence of building construction characteristics, crack morphology, and building operating parameters on the penetration of ambient fine particulate matter is being studied. A model is being developed to predict the entry into buildings of VOCs originating from ground water. This model is being applied at a Super Fund site in EPA Region 1.

There are continuing IEMB projects to characterize emissions of VOCs from diffusion sources, to study the effectiveness of air cleaners and to develop modeling tools. The VOC emissions work is producing an ASTM standard practice for paints. The VOC source and sink behavior of a variety of indoor materials is being studied and incorporated into models. The long-term effectiveness of particle air cleaners is being investigated in large chambers and in the test house. The potential for air cleaners to reduce total human exposures including dermal and oral pathways is being investigated. A protocol for testing electronic air cleaners is being produced under the Environmental Technology Verification program. The indoor air quality models are being updated to include new mass transfer equations and sink effects.

There are several projects related to microbial contamination and allergens. In one project, the effectiveness of anti-microbial control agents and measures is being investigated using RTI's microbial chamber facilities. The ability of anti-microbial agents applied to certain materials to inhibit microbial colonization and growth is being studied. The effectiveness of UV irradiation sources in duct systems to inhibit microbial growth on surfaces is being studied. Under the Children's Health Initiative, the environmental conditions and the material properties that lead to colonization of 
buildings by the mold Stachybotrys chartarum are being defined. Under the Asthma Research Initiative, methods are being developed and validated for the collection of particulate matter of biological origin including molds, endotoxins, animal dander, dust mites and other allergens. Rapid analytical techniques for these materials using PCR technologies are also being developed.

\section{$\underline{\text { U.S Environmental Protection Agency EPA - Indoor Environments Division }}$}

The Indoor Environments Division in EPA's Office of Radiation and Indoor Air performs a number of research, education, and policy analysis efforts related to IEQ. The information provided by this Division, and summarized below, describes both prior and current research activities. The education and information-related activities of this Division are described briefly at http://www.epa.gov/iaq/largebldgs/index.html

\section{IAQ Building Education and Assessment Model (I-BEAM) Computer Software}

I-BEAM is computer software for use by building professionals and others interested in indoor air quality in commercial buildings. I-BEAM updates and expands EPA's existing Building Air Quality guidance and is designed to be comprehensive state-of-the-art guidance for managing IAQ in commercial buildings. I-BEAM contains text, animation/visual, and interactive/calculation components that can be used to perform a number of diverse tasks.

\section{Energy Cost and IAQ Performance of Ventilation Systems and Controls Modeling Study}

In 1999, EPA completed an extensive modeling study to assess the compatibilities and trade-offs between energy, indoor air quality, and thermal comfort objectives for HVAC systems, and to help formulate strategies to simultaneously achieve superior performance on each objective. Variations of Constant Volume (CV) and Variable Air Volume (VAV) HVAC systems were modeled in three different climates-hot and humid (Miami), temperate (Washington D.C.), and cold (Minneapolis). Buildings included several variations of an office building, plus a school, and an auditorium.

\section{Building Assessment, Survey and Evaluation Study (BASE)}

In order to gain a better understanding of IAQ, the EPA conducted two major studies of indoor air quality in public and commercial buildings. EPA's Office of Radiation and Indoor Air conducted the Building Assessment, Survey and Evaluation (BASE) study which was a cross-sectional study of 100 buildings. EPA's Office of Research and Development concurrently conducted the complimentary longitudinal Temporal Indoor Monitoring and Evaluation study (TIME) in federal buildings. Information relating to BASE is currently being updated including basic summary results from the 100 buildings studied. EPA is supporting some of the analyses of BASE data, while other analyses are supported by other organizations.

\section{Department of Housing and Urban Development (HUD)}

HUD launched the Healthy Homes Initiative (HHI, now called Technical Studies) in 1998 in response to an executive order on "Protection of Children from Environmental and Safety Risks." HUD has identified a number of housing-associated health and injury hazards considered key targets for interventions. Emphasis has been placed on those interventions and demonstrations that address multiple hazards. HUD also focuses on public education and outreach. Much of the HHI work is accomplished through competitive grants in which organizations (not-for-profit institutions, for-profit firms, state and local governments, Indian tribes are eligible) make proposals addressing HUD's general needs. For FY 2001, 14 grantees were awarded a total of $\$ 8$ million. Some of these projects are directed toward moisture and mold control. Some studies evaluate the effectiveness of interventions by performing before and after intervention monitoring. HUD has additionally developed a Healthy Homes model for affordable comfort, which attempts to integrate health and 
energy efficiency. HUD funds targeted research through its Policy Development and Research (PDR) branch. These are non-competitive projects, some of which are conducted by NIST.

\section{National Institute for Occupational Safety and Health/CDC (NIOSH)}

In 1999, after about ten years of a low-level internal research effort (about \$200K year) on health effects and related risk factors for workers in indoor environments, NIOSH began a more ambitious research effort, still ongoing, on respiratory health effects (e.g., asthma) of indoor work environments. Costs of this effort, including personnel, are approximately $\$ 1.5 \mathrm{M}$ annually. Other smaller internal research projects at NIOSH include characterizing IEQ in aircraft cabins and modeling airflow in aircraft cabins.

Since 1999, NIOSH has also funded extramural research on IEQ in work environments, at a level of approximately $\$ 1 \mathrm{M}$ annually. Current project titles, with end dates ranging from FY2002-2004, include:

"Micro-analytical system for indoor VOC monitoring,"

"Prevention of IEQ-related absence: an intervention study,"

"Ultraviolet lights in HVAC systems - effect on health and well being,"

(2000-2002)

"Health effects of VOCs, ozone, and stress,"

(2000-2003)

"Floor-supply displacement ventilation system,"

(2001-2004)

"Health and socioeconomic consequences of nonspecific building-related illness," (2001-2004)

"An indoor environment design tool for entire buildings"

(2001-2004).

\section{$\underline{\text { National Institutes of Health (NIH) }}$}

The National Institute of Environmental Health Sciences (NIEHS) funds extramural IEQ-related research on measurement or prevention of residential exposures posing health risks, including ETS and risk factors for asthma such as dust mites, cockroach antigen, and molds. NIEHS-funded projects include:

- "A Wipe Test for [Indoor] Antigen Collection"

- "Seattle-King County Healthy Homes: a project to improve home environmental quality"

- "Reducing indoor allergen exposures in Northern Manhattan and South Bronx"

- "Rural childhood asthma study - Louisa environmental intervention project"

- "Increased levels of markers of microbial exposure in homes with indoor storage of organic household waste"

Also, NIEHS and the National Institute for Allergic and Infectious Disease (NIAID) jointly conduct the National Cooperative Inner-City Asthma Study, which has identified factors involved in asthma among inner city children (including cockroach antigens, environmental tobacco smoke, and nitrogen dioxide). The study is also identifying cost-effective strategies to improve indoor environments in order to reduce asthma morbidity and mortality among inner-city children.

NIH also conducts a broad range of more basic health research, with implications for IEQ. An example is research on the immunologic mechanisms that underlie asthma. This research generally does not address building science or energy issues and is very different from the types of research likely to be supported by ASERTTI members or DOE. 
National Institute for Standards and Technology (NIST)

The National Institute for Standards and Technology supports IAQ research performed by NIST staff, with additional work funded by DOE or other federal agencies. A brief summary of the four projects supported in 2002 follows.

\section{Contaminant-Based IAQ Design Procedures}

This project is developing design tools and guidance to support building and ventilation system design based on contaminant loads, much the way thermal control systems are currently designed based on thermal loads and thermal comfort limits. The ability to implement contaminant-based design, as opposed to the current prescriptive procedures, will enable industry to quantify the advantages of innovative indoor air quality control technologies and to provide tools to assist designers. This multiyear effort was initiated in 2000. During 2002, work will focus on integrating a VOC emissions database into a design tool and developing new tools for designing natural ventilation systems in commercial buildings

\section{Indoor Environment Performance of Air Cleaning Systems}

This project is providing a method to demonstrate and evaluate the performance of innovative air cleaning technologies. During 2001, the ability to predict the performance of particulate air filters and gaseous air cleaning devices was studied via a series of tests conducted at a test house. During 2002, the measurement data will be compared with model predictions and experiments will be initiated in a multizone test facility to study the performance of three types of air cleaners (portable photocatalytic oxidation air cleaner, portable adsorption air cleaner, and an in-duct adsorption/chemisorption filter) for gaseous pollutants.

\section{Performance Metrics for Indoor Environments}

The objective of this project is to establish building performance based metrics for evaluating the quality of the indoor environment. The first phase, to be conducted in FY2002, includes a review of existing research related to indoor environmental quality metrics and holding an associated workshop. The second phase of the project, also to be performed in FY2002, will focus on the development of candidate metrics of IEQ performance based on the results of the literature review and workshop. Subsequent work would evaluate the candidate metrics in a field study with the eventual goal being a standard guide for building environment professionals.

\section{Ventilation of Single-Family Residential Buildings}

This project is investigating approaches intended to meet single-family residential ventilation requirements and their implications for standards compliance and indoor air quality, particularly indoor moisture levels. The basic approach is to conduct experimental studies in an IAQ test facility equipped with multiple mechanical ventilation options; as well as with natural ventilation and infiltration options. Multizone airflow modeling will also be performed to confirm the field results and extend them to other climates and scenarios.

\section{National Science Foundation (NSF)}

The National Science Foundation (NSF) awards proposals under the Partnership for Advanced Technologies for Housing (PATH) initiative. This NSF-PATH grant program is for fundamental engineering research related to the development of new generation housing. It is open to eligible U.S. academic institutions and encourages collaboration with industry or government laboratories. PATH's Technology Roadmap defines the research areas. The stated objectives are to develop new technologies, increase the use of advanced technologies, strengthen the U.S. building industry, and institute mechanisms to support the next generation of U.S. housing. Far-reaching exploratory research that could lead to breakthrough technologies such as whole systems analysis, advanced panels, and information technology are encouraged. The funding level is about $\$ 150 \mathrm{~K}$ for a two-year project. Ongoing projects funded in 2000 are not addressing any IAQ issues. However, two of the 11 
newly funded projects have an IAQ-related component. One at Pennsylvania State University is entitled, "Moisture control-convective drying in residential wall systems." The other at Virginia Tech is entitled, "Designing panelized systems to minimize impact on indoor air quality in tightly-sealed buildings." 


\title{
Appendix 3. Descriptions of Project Areas
}

\author{
Project Area 1. \\ Collect benchmark data on ventilation rates and IEQ in small $\left(<5,000 \mathrm{~m}^{2}\right)$ commercial \\ buildings.
}

\section{Description}

Most published IEQ field studies in commercial buildings have been performed in buildings with a floor area $>5,000 \mathrm{~m}^{2}$. Research in this project area should include surveys of: a) ventilation system types, features, conditions, and performance; b) operation and maintenance practices; c) pollutant sources; d) IEQ conditions (e.g., temperatures, pollutant concentrations); and, when possible, energy use (e.g., energy bill data) in commercial buildings with a floor area $<5,000 \mathrm{~m}^{2}$. The projects should cover a range of building designs, occupancy types, use patterns, and climate zones and the highest priority measurements will vary with the building use. For example, measurements of pollutants from combustion and cooking would be a priority in restaurants, but less important for small offices. When possible, protocols and measurements similar to those of the U.S. EPA BASE Study of large commercial buildings may be adapted for this research. Modifications to the BASE protocol may be needed so that these surveys can answer specific, pre-defined, research questions. To the degree possible, measurement and reporting methods should be similar to those employed in the BASE study to facilitate comparisons and to take advantage of existing approaches to data analysis. The data should be analyzed as needed to define the distributions of parameters or conditions within the building stock, with results compared to available guidelines or standards. For example, the distributions of measured ventilation rates would compared to minimum ventilation requirements specified in standards. Other analyses, primarily multivariate statistical analyses, should assess the interrelationships among parameters in order provide information about possible causal factors. For example, one set of analyses would examine whether maintenance practices are related to indoor IEQ conditions. Other analyses would examine whether climatecorrected energy use is related to IEQ conditions.

\section{Explanation of Priority Status}

The majority of non-industrial, non-agricultural workers in the United States work in small commercial buildings; however, very little is known about IEQ in small commercial buildings. (Energy efficiency field studies have also concentrated on large commercial buildings.) The prior focus on large buildings in IEQ studies is due in large part to the researchers' desire to obtain health symptom data from large numbers of people and to the additional administrative burdens of gaining access to multiple buildings for research purposes. It is believed by many researchers and building professionals that the quality of building systems and the qualifications of building operational personnel are far lower in the smaller commercial building stock resulting in a higher frequency of indoor environmental and energy efficiency problems.

\section{How the Research Results Would Be Used}

The data obtained from this research will be communicated in technical papers, handbooks, conference presentations, and training programs and made available on a web site. The data from this research will identify design features, technologies, and practices that help to maintain acceptable IEQ without degrading building energy performance. Some of the data, such as ventilation rates and air filter types, can be used in assessments of the vulnerability of small commercial buildings to potential chemical and biological attacks or to accidental releases during industrial accidents. The findings should help researchers, building professionals, and policy makers identify the extent and nature of ventilation and IEQ problems in small commercial buildings and also better and will elucidate where corrective measures should be focused.

\section{Expected Research Products}

- Data base of building characteristics, ventilation rates, pollutant sources, and IEQ conditions

- Documents, presentations, and web site pages that describe benchmark conditions, identify risk-causing and risk-reduction characteristics of buildings

- Documents and presentations that encourage building professionals to address identified problem areas

\section{Related R\&D goals}

- Identifying IEQ problems and opportunities 
Related R\&D Application Categories

Residential, Commercial, Schools, New Construction, Existing buildings

Term of R\&D Projects

Mid term to long term

\section{Co-funding or leverage opportunities}

The U.S. EPA may be interested in these surveys with are a logical follow-up to the BASE survey.

Return to page 6 


\section{Project Area 2. \\ Collect benchmark data on IEQ conditions, ventilation rates, and energy use in energy efficient and conventional new housing.}

\section{Description}

The purpose of research in this project area is to collect baseline data on ventilation rates, and indoor environmental quality (IEQ) for an array of contaminants of concern in energy efficient and conventional new housing and to analyze these data to identify ventilation and IEQ problems and opportunities, and to relate IEQ with building energy use. Data would be collected in phases, by region of the U.S. Each region would include a diverse population of residences within a limited range of climatic zones, and each survey would provide building design related energy and IEQ information for that region. Using a standardized survey method will enable comparison across regions as they are studied. Eventually surveys would collect representative data from all regions with significant amounts of new housing.

Phase 1: The first phase of the study will focus on development of a statistical sampling design and a survey protocol. Sources of data for selecting the sample of homes include the Census Bureau's American Housing Survey, the Department of Energy's Residential Energy Consumption Survey, state and local housing authorities, and the housing industry. A single high-energy demand region, possibly defined by state (e.g., California or New York), would be chosen for initial study. A building population-based random sampling strategy would be developed in order to select a building study population representative of the new housing stock within the region. Each region is likely to have a number of distinctly defined housing designs that will need independent study. For example, standard and energy efficient housing construction in a temperate coastal climate zone will differ from that in a mountainous area within the same region. Sample size calculations will be made to determine the minimum number of homes to in each study group. It can be expected that each study group will have a sample size between 30 and 100 homes. Simultaneously with the survey design, a ventilation and IEQ monitoring plan will be developed, including a cost effective, unobtrusive environmental monitoring package appropriate for the study design. Ventilation rates, and envelope and duct system leakage areas will be measured in all homes while IEQ variables may be more appropriately selected by region. IEQ variables to be studied include as many of the following as possible: selected volatile organic compounds (VOCs) and aldehydes; carbon monoxide and nitrogen dioxide; humidity, temperatures, respirable suspended particles preferably with source speciation for environmental tobacco smoke and ambient sources, and radon. In some sets of houses, pollutants from cooking processes should be measured, as cooking can be a strong source of pollutants. Indoor dust samples will be collected and analyzed to provide information on microbiological agents in indoor environment that can cause allergic and toxic responses. Monitoring periods must be selected to provide representative annual or seasonal estimates of ventilation and IEQ conditions. A building characteristic survey will be employed to provide detailed information on the building design and construction details, building shell and lighting energy efficiency parameters, presence of vented and unvented combustion appliances and readily obtainable information on faulty (e.g., disconnected) combustion vents, internal building and furnishing materials, and HVAC system details. A building occupancy and usage survey will be employed to collect data on the occupants, building usage patterns, and HVAC usage patterns. Total energy usage during study periods will be collected from gas and electric meters, and annual energy billing data will also be collected.

Phase 2: A pilot study will be conducted in a second phase to test and improve the study protocol. This study will not have a large enough sample size to provide a statistically valid sample, but it will be large enough to identify problems with data collection and processing systems. It will provide an opportunity to fine-tune the IEQ monitoring package.

Phase 3: The third phase of work will be conduct of the regional surveys using the protocol finalized at the end of the second phase of work, and to analyze the data. Simplified DOE-2 modeling will be conducted for each building design and location in order to compare design against actual building energy performance. This analysis may be of use in assessing the cost-benefit of different energy efficiency measures relative to their impact (positive or negative) on IEQ. Regression analyses will be conducted using models constructed to study the association between building design/usage/ventilation data and measured IEQ parameters. IEQ parameters will be compared against available information on health risk to identify the building design and usage factors that present the greatest potential for health risk reduction while optimizing energy efficiency. We anticipate that results of this benchmark survey would be help to identify the need for more focused studies or related education programs. For example, particularly high levels of combustion pollutants, even within a small fraction of houses, could point to the need for better combustion appliance safety programs. 
The results of each phase of work would be summarized in technical papers, conference presentations, and on web sites

\section{Explanation of priority status}

The IEQ literature suggests that there is a substantial prevalence of sources of toxic, irritating, allergenic, and odorous agents in residential indoor environments, and that building ventilation is the primary mechanism for their removal. The sources are a function of building design and construction, location, occupant-introduced materials, and building usage and maintenance. Indoor air contaminants are implicated in numerous chronic, acute, and fatal health effects, and also with odor complaints, but little consistent information exists on the distribution of these agents across indoor environments, or the relative amounts within different residential building designs. The EPA BASE Study has recently surveyed IEQ in large offices; however, no comparable survey data are available from residences. The most closely related data are from surveys performed in the 1980s of homes located in the Pacific Northwest (PNW). These data are representative only of the PNW and are dated. There have been many changes in home design, materials, and air tightness, and furnishings since the 1980s. In addition, current survey designs and methodologies will differ research substantially from those in the 1980s surveys to reflect subsequent research findings and new more convenient measurement methods that reduce survey costs. New housing starts in the U.S. continue to increase with population growth.

Simultaneously, energy demands from the residential sector are at all-time high, and the need for energy efficient housing increases. New housing today will dominate the housing stock tomorrow. The design of this housing has a long-term impact on both energy consumption in the residential sector and IEQ related health impacts and costs to the population. An urgent need exists to identify those building practices that provide the highest benefit for both energy saving and IEQ at the lowest cost. Implementation of such practices will save energy an improve health of Americans in the next generation.

\section{How the research results would be used}

The data collected in the regional surveys would be used to determine how much residential ventilation rates have decreased, whether they meet current standards, the extent to which pollutants in residences are at levels of concern, and the relationship of IEQ conditions with building features and building energy performance. Analyses of study data should identify the relative benefits of various new residential building designs in terms of both energy efficiency and the quality of the indoor environment. Some of the data, such as the resulting distribution of ventilation rates, can be used in assessments of the vulnerability of homes to possible chemical and biological attacks. These results will be communicated to builders, homeowners, public health agencies, and organizations responsible for building codes and will lead to improved guidelines, codes, and practices. We anticipate that these surveys will demonstrate that energy efficient buildings can have good IEQ.

\section{Expected Research Products}

- New protocols and survey tools for collecting benchmark data in residences

- Data bases of building characteristics, ventilation rates, pollutant sources, IEQ conditions, and building energy use for each region

- Documents, presentations, and web site pages that describe baseline conditions, identify risk and risk reduction characteristics of buildings, relate IEQ with building energy use

- Documents and presentations that encourage building professionals to address identified problem areas

\section{Related R\&D goals}

- Identifying IEQ problems and opportunities

\section{Related R\&D application categories}

- Residences, new construction, existing buildings

\section{Term of R\&D Project(s)}

Short term (phase 1) to mid term (phases 2 and 3)

\section{Co-funding or leverage opportunities}

EPA. Return to page 6 
Project Area 3.

Collect benchmark data on ventilation and air flow performance in existing buildings as a function of region, building type, and HVAC system type.

\section{Description}

Forced air distribution and ventilation is the method of choice in most commercial buildings and many residences in the U.S. Building ventilation rates and the rates, balances, and directions of other airflows in buildings influence IEQ, thermal comfort, and building energy use. The degree to which ventilation rates and airflows match the design intent or code requirements is not adequately understood, although the available data clearly suggest that deficiencies are common. Consequently, research in this project area would involve surveys to collect benchmark data on : a) ventilation rates (in buildings and rooms); b) duct leakage rates; c) balances between supply and return flows in rooms; and d) directions of airflow through building envelopes, between building zones, or between the building and buffer zones. The surveys need to be performed for a range of climates, building types, and HVAC system types, with the number of required buildings per survey likely to be between 20 and 40. The parameters measured and measurement periods will vary among studies depending on the specific objectives. For example, one study might seek to quantify the nature and causes of airflows through building envelopes of small offices located in hot humid climates, and consequently focus on indoor-outdoor pressure differences, duct leakage, and balances between supply and return and between outdoor and exhaust airflows during the summer.

\section{Explanation of Priority Status}

Airflows and ventilation rates are strongly linked to both IEQ and building energy performance. In addition, airflow rates and directions of airflow through the building envelope and between building zones affect the vulnerability of buildings to potential chemical and biological attacks, for example, by substantially affecting the spread of pollutants within buildings and the extent to which incoming outside air bypasses filters. Existing data suggest that airflow and ventilation rates are often poorly controlled. The existing data on airflows and ventilation rates, except possibly for duct leakage data from studies in residences, are inadequate for characterizing the extent of problems or of associated opportunities. For example, residential energy efficiency efforts have clearly led to reduced leakage in building envelopes and duct systems; however, we do not currently know if ventilation rates in new energy efficient houses are consistent with guidelines. Uncontrolled airflows through envelopes of building envelopes located in hot and humid or very cold climates deserve special attention because these airflows can cause moisture problems that degrade IEQ and building energy performance.

Surveys of ventilation rates in newer energy-efficient buildings, especially residences and small commercial buildings, also deserve special attention because of the paucity of existing data and the associated potential for widespread IEQ problems.

\section{How the Research Results Would Be Used}

This research will provide a database that identifies the extent to which energy efficiency and IEQ programs, in specific climates and building types, should emphasize improvements in design, construction, and commissioning practices related to building airflow and ventilation rates. The database will also aid assessments of the vulnerability of buildings to potential chemical and biological attacks. Research results will be incorporated into handbooks and communicated to building professionals in conferences. Research results should lead to changes in future codes and guidelines pertaining to energy efficiency and ventilation. We anticipate that this research will identify deficiencies in current test and balance tools and practices and help to stimulate improvements.

\section{Expected Research Products}

- Data bases on ventilation and airflow rates, rates of leakage in duct systems, and directions of airflow through building envelopes (which influence moisture problems)

- Documents based on analyses of data collected that describe benchmark data and identify problems and opportunities related to building airflows

\section{Related R\&D goals}

- Identifying IEQ problems and opportunities

\section{Related R\&D Application Categories}

Residential, Commercial, Schools, Existing buildings 
R\&D Term

Short term to long term projects are anticipated

Co-funding or leverage opportunities

ASHRAE should be interested in the same projects, particularly in studies of ventilation rates because of ASHRAE's leadership role in minimum ventilation rate standards. Return to page 6 


\section{Project Area 4.}

Compare health outcomes among students and staff in schools with very high and very low ventilation rates.

\section{Description}

In this research project area, the most likely research approaches are as follows:

1) An initial broad screening survey of schools, including facilities with a variety of ventilation types, would be undertaken to estimate ventilation rates. This initial survey would be used both to determine the levels of ventilation rates in US schools, and to select schools for a more targeted study of schools with very high or very low [or average] ventilation rates. Design of the screening survey would allow some generalization of findings from the targeted study back to the population of US schools.

2) The targeted study would collect more detailed cross-sectional data at least twice, at the beginning and end of a school year, allowing prospective data analyses. Data collection would include measurements of ventilation rates and other key IEQ parameters including airborne concentrations of pollutants; descriptive characterization of school facility buildings and ventilation systems; and health data from students including symptoms, respiratory illnesses, and absenteeism. Student data collected simultaneously with environmental measurements and including retrospective periods coinciding with the period of the study would allow analyses with the environmental data.

Data analyses would

1) describe ventilation levels in US schools

2) assess associations between ventilation rates and concurrent symptoms and other outcomes, and between ventilation rates averaged over the year and respiratory illness, illness absence, doctor visits, etc., controlling for other potential personal and environmental confounding factors.

3) also describe other building characteristics in schools relevant to environmental health of occupants, including the ventilation type

\section{Explanation of priority status}

There is widespread concern about health effects on students of poor IEQ in schools. Although available information suggests that IEQ in schools, due to limited resources for maintenance of school facilities, is often inadequate, the health risks for students have received little scientific study in the US.

One of the most consistently identified risks for adverse health effects in buildings is low ventilation rates. Most of these findings come from studies of adult workers in offices. Little research is available on students in schools, although children may be more sensitive to some environmental pollutants increased in buildings with low ventilation levels. Also, no representative data on ventilation rates in US schools are available, but the limited available data suggests that ventilation rates below current standards are very common. Adverse health effects on students nationwide may be common, and may include allergic sensitization leading to chronic health problems. Furthermore, these health effects may, in turn, reduce student attendance and performance (learning).

Ventilation rates affect energy use in all buildings; however, ventilation is a larger factor in spaces with a high occupant density such as classrooms. Thus, scientifically based minimum ventilation rate requirements are particularly important for schools.

\section{How the research results would be used}

Results would demonstrate whether lower ventilation rates posed risks for adverse health outcomes among students, and also define the proportion of US schools with ventilation rates below desirable levels due to health risks. Estimation of the scale of health risks from study data could be weighed against estimated costs increases from increased ventilation rates. The results would provide badly needed data for minimum ventilation standards in classrooms.

\section{Expected Research Products}

- Database from screening survey that defines the distribution of ventilation rates in schools

- Documents, presentations, and web pages that compare measured and prescribed minimum classroom ventilation rates

- Documents and presentations that describe the risk factors associated with low ventilation rates in classrooms

- Information for scientifically defensible minimum ventilation standards and codes for classrooms 


\section{Related R\&D goals}

- Identifying IEQ problems and opportunities

- Developing and evaluating energy-efficient practices for improving IEQ, health, comfort and productivity

Related R\&D application categories

Schools, Existing buildings

\section{Term of R\&D Projects}

Mid-term

\section{Co-funding or leverage opportunities}

NIOSH, EPA, ASHRAE. ASHRAE has an approved work statement for a study of the extent to which IEQ interventions in schools improve student performance.

$\underline{\text { Return to page } 6}$ 
Project Area 5.

Relate ventilation rates in residences to health symptoms and to satisfaction with IAQ

\section{Description}

This observational study will begin with a broad initial survey of homes, from different climatic regions, of a variety of ages, envelope air tightness levels, ventilation strategies, occupant densities, and indoor pollutant sources. Limited data will be collected, including on building envelope air tightness, ventilation rates, size, number of occupants. Sub-samples of surveyed homes will be selected from different climatic regions for more detailed study, with very high, average, or very low ventilation rates, and also having a variety of occupant densities. Data will be collected on ventilation rates, indoor pollutant sources including potential chemical and microbiologic sources, and other house factors potentially related to occupant symptoms and satisfaction with IEQ. Data will also be collected from occupants on symptoms, IE satisfaction, demographic variables, and health status. Analyses will assess relations between ventilation rates and occupant symptoms and satisfaction, adjusted for occupant density and presence of specific indoor pollutant sources. Analyses will also assess the influence of specific indoor sources (e.g., moisture, mold, new paint, carpets, or other materials) on ventilation required for low levels of symptoms or dissatisfaction.

Study results will be summarized in technical papers, conference presentations, and on web sites and communicated directly to the organizations responsible for ventilation standards.

\section{Explanation of priority status}

In many studies among office workers, lower ventilation rates have been associated with increased symptoms and with increased environmental dissatisfaction. These studies have recently provided an initial scientific basis for health and comfort-protective minimum ventilation standards in offices and similar indoor settings.

However, very little information on the relationship of ventilation rates with health or environmental satisfaction is available from residential settings, where people spend the largest amount of their time. In residences, relative to offices, the pollutant source types and source strengths of indoor contaminants and other factors may be substantially different. For example, factors which may differ substantially between residences and offices include: occupant density, building materials, equipment, contents, chemical use, and types of ventilation systems. Consequently, ventilation rate standards must set appropriately for specific indoor settings. With the current absence of scientific data for selecting ventilation rates in residences, there is a strong risk that current standards will fail to strike a proper balance between the health and energy concerns associated with residential ventilation.

\section{How the research results would be used}

Results of this study would describe the distribution of ventilation rates in existing U.S. homes, provide data for making benefit/cost decisions on acceptable levels of residential ventilation, and thus contribute to more scientifically-based residential ventilation standards.

\section{Expected Research Products}

- Database from residences with the following measured data: ventilation rates; envelope air tightness; pollutant sources; and occupant symptoms

- Documents, presentations, and web pages that describe distributions of collected data

- Documents and presentations relating ventilation rates in homes with occupants health symptoms and satisfaction with air quality

- Information for scientifically defensible minimum ventilation standards and codes for residences

\section{Related R\&D goals}

- Developing and evaluating energy-efficient practices for improving IEQ, health, comfort and productivity

\section{Related R\&D application categories}

Residential, New construction, Existing buildings

Term of R\&D Projects

Mid-term to long term

\section{Co-funding or leverage opportunities}

HUD, EPA, ASHRAE Return to page 6 
Project Area 6.

Quantify the influence of outside air ventilation rates on prevalences of communicable respiratory diseases.

\section{Description}

Ten prior studies have found that prevelances of common respiratory illnesses (e.g., common colds, influenza) or of short-term absence (considered a surrogate for respiratory illness) are associated with characteristics of buildings or of building operation, such as ventilation rates, occupant density, type of ventilation system (possibly a surrogate for ventilation rate), and mold contamination. The risks of illness or absence are $17 \%$ to $100 \%$ higher in buildings with hypothesized risks (e.g., lower ventilation rate) and the findings are statistically significant. However, five of ten studies were performed in rather unusual types of buildings (military barracks, Antarctic Station, jail) and ventilation rates can only be quantified in four studies, with two of these studies performed in unusual building types. Hence, the available data suggest that ventilation rates substantially affect prevalences of respiratory illnesses in typical buildings, but these data are inadequate for firm conclusions. Research in this project area would address this issue for various types of buildings, such as schools, day care centers, offices, and possibly homes. Two types of studies could be performed: a) cross sectional surveys in sets of buildings with a wide range in ventilation rates; and b) experiments with ventilation rates manipulated in smaller numbers of buildings. To the degree possible, studies should control, either experimentally or via the data analyses, for other factors suspected of affecting prevalences of respiratory illness (e.g., humidification, influenza vaccinations). Studies should be long term (e.g., multi-year) to average over episodes of respiratory illness, or investigate how epidemics develop in populations with high and low ventilation rate. Ventilation rates must be measured, not inferred from design data. The strongest studies will use tests (such as polymerase chain reaction analyses of nasal lavage or swab samples) to confirm reported illnesses; however, lower cost opportunities to study the relationships of ventilation rates with reported sick leave or self reported illness data are also warranted.

\section{Explanation of priority status}

The annual cost of common respiratory illnesses in the U.S. is approximately $\$ 70$ billion. These illnesses affect nearly all people and reduce people's quality of life. These illnesses, especially influenza, contribute to thousands of deaths each year, primarily within the elderly. Despite the enormous costs, extensive morbidity, and substantial mortality associated with common respiratory illnesses, society has treated these illnesses primarily as an unchangeable fact of life. However, the available data suggest a potentially very large opportunity to reduce illness and save money through practical changes in ventilation rates. Consequently, the research in this project area is needed to inform decision making about ventilation rates in buildings and should be reflected in future building codes.

Unfortunately, increases in ventilation rate will generally increase building energy use. Consequently, if this research confirms that increased ventilation rates will diminish respiratory illness, follow-up studies should investigate energy-efficient means of increasing ventilation rates and alternatives to increased ventilation, such as better filtration or UV disinfection technologies. Although ventilation rate is the logical starting point for this research, if increased ventilation is found effective, there is a high probability of identifying alternative, less energy intensive, measures for reducing respiratory illness.

\section{How the research results would be used}

The results of this research would be communicated to employers, facility managers, and those responsible for building codes and standards and would be expected to lead to changes in both practices and code requirements. As discussed above, if increased ventilation is found effective, this research will point out the need to search for alternative, less energy intensive, measures for reducing respiratory illness

\section{Expected Research Products}

- Documents and presentations that relate ventilation rates with absence rates and prevalences of respiratory illnesses

- Information needed for scientifically defensible minimum ventilation standards and codes

\section{Related R\&D goals}

- Developing and evaluating energy-efficient practices for improving IEQ, health, comfort and productivity

Related R\&D application categories

Residential, Commercial, Schools, New construction, Existing buildings 
Term of R\&D Project

Short term to mid term

Co-funding or leverage opportunities

NIH, NIOSH Return to page 6 
Project Area 7.

Investigate the influence of ventilation (natural and mechanical) on concentrations of contaminants from a diverse range of contaminant sources.

\section{Description}

Outside air ventilation consumes energy and reduces indoor concentrations of indoor generated air pollutants. Indoor concentrations of outdoor pollutants may be increase with ventilation rate or be unaffected by ventilation rate. In general, increased ventilation rate is viewed as an IAQ control measure; however, the influence of ventilation rates methods on indoor pollutant concentrations is not adequately understood or documented. We do know that that pollutant sorption and desorption, pollutant deposition on surfaces, and chemical reactions complicate the relationships of ventilation rate with indoor concentrations. Additionally, the rate of pollutant emission from some indoor sources increases with ventilation rate.

Research in this project area will investigate how mechanical and natural ventilation affects the indoor concentrations of pollutants (including water vapor) from various indoor sources and from outdoor air. In general, this research will require simultaneous measurements of ventilation rate and indoor and outdoor pollutant concentrations, with a simultaneous characterization of indoor pollutant sources and of indoor materials that may affect rates of pollutant sorption and desorption. Measurements should be repeated with a range of ventilation rates in each study setting (e.g., building), restricting study buildings to those for which ventilation rates can be modified using practical measures. For pollutants that may be filtered, the characteristics of the filtration systems must also be documented. For pollutants that may be chemically reactive, the concentrations of multiple reactive species may need to be measured simultaneously. The timing and duration of measurements must account for the expected dynamics of ventilation rates, pollutant concentrations, emission rates, sorption and desorption processes, and chemical reactions. Some studies may be performed in controlled laboratory mockups of sections of real building, while other studies should be performed in actual residential and commercial buildings. The data should be analyzed using mass balance models. The results will indicate the extent to which ventilation rate is effective in controlling indoor pollutant concentrations and the risks associated with reductions in ventilation rates. The data should also be used to calculate indoor source strengths for various contaminants of interest.

These studies should be undertaken for a variety of indoor pollutant types and associated pollutant sources known or strongly suspected to affect occupant health, satisfaction, or work performance.

\section{Explanation of Priority Status}

This project area is a priority because: a) ventilation is strongly linked to both IEQ and building energy use; b) increased ventilation rate is one of the most common measures used in attempts to prevent or diminish IAQ problems; and c) the related data available today are inadequate to guide practice. The widespread adoption of building codes with minimum ventilation rates exemplifies the importance of ventilation. However, the degree to which ventilation rate affects indoor concentrations of pollutants varies widely among pollutants and pollutant sources and for some pollutants increased ventilation is relatively ineffective in controlling indoor concentrations. The number of prior studies of the influence of ventilation rates on indoor pollutant concentrations is surprisingly small. Consequently, decisions about using ventilation to solve IAQ problems and the specification of minimum ventilation rates in codes are based on general impressions about the effects of ventilation, without the benefit of substantial quantitative data. Additionally, typical values of indoor pollutant source strengths are largely unknown, making it very difficult to predict the amount of ventilation needed to maintain indoor concentrations below guidelines.

\section{How research results will be used}

The results of this research should be communicated in technical papers, handbook articles, and via web pages to architects, engineers, and building operators. The results will help building operators to make better decisions about the use of ventilation, or alternative methods, to control indoor air quality or solve IAQ problems.

Because ventilation will be shown to be relatively ineffective for some pollutants/pollutant sources, the research will help to stimulate increased implementation of pollutant source control measures, which are often the most effective and energy efficient measures for controlling IEQ. The pollutant source strength data obtained will aid building professionals in designing buildings for acceptable IAQ, for example, using the IAQ procedure in ASHRAE Standard 62-2001. The research results will also be an important source of information for future revisions of minimum ventilation rate standards. 


\section{Expected Research Products}

- Data and associated documents, web pages, and presentations quantifying the effects of natural and mechanical ventilation rate on indoor pollutant concentrations

- Data on strengths of pollutant sources in buildings, enabling building professionals to better design buildings for acceptable IAQ

- Information that can be used in best practice guidelines for buildings

\section{Related R\&D goals}

- Developing and evaluating energy-efficient practices for improving IEQ, health, comfort and productivity

Related R\&D Application Categories

Residential, Commercial, Schools, New Construction, Existing buildings

\section{Terms of R\&D Projects}

Short term to mid-term

Co-funding or leverage opportunities:

ASHRAE Return to page 6 


\section{Project Area 8.}

Quantify the relationships between indoor chemical and biologic pollutants of greatest current concern and health effects on occupants.

\section{Description}

The first phase of research in this project area would identify an initial list of specific indoor biological and chemical pollutants of greatest current concern, based on at least some plausible evidence of adverse health effects, and evidence of occurrence in either residential, educational, or occupational indoor environments. The initial list would be developed through consultation with experts in the range of relevant fields. A second phase of work would formally review available research findings on exposure-response relations for these pollutants, and define key information gaps. Based on these two phases of work, a shorter list of approximately ten pollutants for which additional research is most critical, would be developed. The next phase of research would likely involve multiple studies, with each study focusing on elucidating exposure-response relations one or a few pollutants. Some observational field studies may be informative here, given adequate measurement methods for exposures and response. Some of these studies, such as for low-level chemical exposures, might also include controlled human exposure studies in research chambers. Others, however, such as for microbiologic exposures, might need to be in vitro or animal studies in laboratories. At each step in this process, current information would be summarized and reported in a form useful for regulators, scientists, and consumers.

\section{Explanation of priority status}

Despite increasing public, scientific, and governmental concern about health effects of IEQ, this concern has not effectively focused on specific indoor exposures, and little information has been produced on the health effects of specific pollutant exposures. To protect human health indoors most effectively and in the most energy efficient manner will require scientific evidence on effects of specific exposures. A systematic scientific synthesis and prioritization based on current information is necessary to produce focused progress in this key area. This will facilitate setting of standards, prevention of harmful exposures, mitigation of existing exposures.

Generic preventive measures such as minimum ventilation rates have served this purpose to date, but ventilation rates are likely to rise based on available scientific evidence of indoor environmental health effects. To conserve energy under these circumstances, we need to identify exposure/response relations for adverse indoor exposures so that sources can be reduced, standards for acceptable exposures can be set, and amounts of generic ventilation required to dilute unknown pollutants can be reduced.

There is little impetus for private sector investment in this research, so funding will need to be governmental. Research findings can then be used competitively in the marketplace.

\section{How the research results would be used}

These results would, in an efficient way, contribute to reduction and elimination of indoor sources of the currently most likely harmful indoor exposures, by providing input to the processes of regulation and to the marketplace.

\section{Expected Research Products}

- List of most important indoor contaminants based on consensus of experts

- Documents, presentations and web sites that provide best possible current estimates of the linkage of contaminant concentrations with health risks, providing the basis for concentration guidelines or standards

- Information that will help building professionals to design buildings to maintain acceptable air quality, analogous to the current design of buildings to maintain acceptable temperatures

\section{Related R\&D goals}

- Identifying IEQ problems and opportunities

Related R\&D application categories

Residential, Commercial, Schools, New construction, Existing buildings

\section{Term of R\&D Projects}

Mid term to long term

\section{Co-funding or leverage opportunities}

NIH, HUD, EPA, NIOSH Return to page 6 
Project Area 9.

Identify and quantify the IEQ, health, energy, comfort, and productivity impact of access to fixed and operable windows

\section{Description}

This project is intended to capture the benefits and liabilities of individual access to windows in commercial buildings and schools in relation the building energy used and IEQ conditions and the related health, comfort and productivity of building occupants. The impacts of both fixed and operable windows should be assessed in buildings of different ages, in different climates, and of different floor plate sizes (articulated and large floor plate buildings with $20-100 \%$ of occupants within seven meters of windows). The studies should include buildings with all-mechanical ventilation, all-natural ventilation, and with mixed mode systems. The relationship of these variables to building energy use, to IEQ conditions, and to occupant health, comfort and productivity are to be studied. In a series of coordinated or phased efforts, this project could undertake literature studies, simulation studies, cross-sectional field studies, and experimental studies. To the degree possible, research efforts should address all of the environmental influences of windows and of the systems accompanying windows. With individual access to either fixed or operable windows, the influence of windows on the following IEQ conditions should be studied: light; view/content; solar heat; thermal comfort; mean radiant conditions; noise from outdoor sources; ventilation rate, infiltration rate, moisture condensation; and type of HVAC service (e.g., local HVAC with local versus central HVAC, natural ventilation versus mechanical ventilation). With individual access to operable windows, the influence of windows on the following IEQ conditions should also be studied: rain penetration; exposure to outdoor pollution (including allergens); and entry of pests. Human outcomes studied whenever possible should include comfort, environmental satisfaction, health, and work performance.

\section{Explanation of priority status}

Several factors or trends emphasize the importance of this research, especially for the State of California and other states with comparatively benign climates: the energy savings opportunities associated with openable windows; the observed lower prevalences of sick building syndrome symptoms among occupants of naturallyventilated buildings; the relatively rapid sealing up of buildings that pre-date central air conditioning; the pervasive reliance on $7 \times 24$ air conditioned buildings in all new construction in all regions of the U.S.; the unchallenged acceptance of deep section buildings for commercial and institutional functions in the U.S. which conflicts with European requirements for access to windows; and the need to develop new window and HVAC technologies that support "mixed mode" futures while addressing the performance concerns of building professionals.

The potential impact of this study to influence new and retrofit building projects is significant. The benefits of windows might include: measurable energy savings (e.g., through daylight, natural ventilation, passive cooling); measurable health benefits (e.g., through dilution, full spectrum light, circadian cycles); measurable comfort/user satisfaction benefits, reduced SBS symptoms, or reduced health costs; and measurable productivity gains such as reduced absenteeism, greater attraction/retention, improved collective output/ collaboration, or improved individual output. The liabilities of windows might include: measurable energy costs (e.g., through solar overheating, heat loss/gain, uncontrolled air exchange); measurable health concerns (e.g., through rain penetration, condensation, poor mean radiant conditions, outdoor pollutants); and measurable productivity costs (e.g., distraction from outdoor noise, time spent in modifying window conditions).

\section{How research results would be used}

The results of this research would be communicated to architects, engineers, and businesses via technical publications, articles in trade journals, handbook articles, and conference presentations. In the longer term, findings would be incorporated in the educational curricula for architects, and some buildings standards or codes may be changed to reflect research findings. Based on current information, we would expect the research to stimulate increased access to windows and increased provision of openable windows, at lease in mild climates.

\section{Expected Research Products}

- Data base of building energy use, IEQ conditions, and occupant comfort and health in buildings with sealed and openable windows

- Documents, presentation, and web pages that quantify the benefits and liabilities of openable windows

- Information for use by building designers to improve designs of energy efficient and healthy buildings 


\section{Related R\&D goals}

- Developing and evaluating energy-efficient technologies for improving IEQ, health, comfort and productivity

- Developing and evaluating energy-efficient practices for improving IEQ, health, comfort and productivity

\section{Related R\&D application categories}

Commercial, Schools, New Construction, Existing buildings

\section{Terms of R\&D Projects}

Short term to mid-term

\section{Co-funding or leverage opportunities}

NIMH, glass/window industry

Return to page 7 


\section{Project Area 10.}

Evaluate the effects of thermal comfort parameters on health and comfort in commercial and institutional buildings, including comparisons between air-conditioned and naturally ventilated buildings.

\section{Description}

Research in this project area would focus on the thermal aspects of IEQ conditions in existing buildings (i.e., using field studies, as opposed to laboratory studies), and how they affect occupant health and comfort. All research will necessarily involve both physical measurements and subjective surveys. The focus is on commercial and institutional buildings, especially of small-to-medium size because these have been underrepresented in prior research. In particular, studies should purposely seek out both air-conditioned and naturally ventilated buildings, and the experimental and analysis plans should be designed so that the performance of these two building types can be compared and causal relations determined.

At a minimum, research projects would measure the six parameters that are traditionally investigated in thermal comfort studies because they directly affect the body's heat balance (air temperature, humidity, air velocity, mean radiant temperature, clothing insulation, and activity or metabolic rate). In addition, research projects should investigate other contextual factors that can either affect these six heat balance parameters, or are known to affect people's behavior, expectations and subjective response. As examples, these might include:

1) outdoor context (i.e., climate, noise, pollution, view, relevant site characteristics, etc.);

2) factors directly related to the building, such as characterizing opportunities for behavioral adaptation (i.e., flexibility in dress codes, rigid vs. variable workstation locations, availability and use patterns of personal control of environmental conditions through HVAC micro-zoning, blinds or operable windows, etc.); and

3) demographics and other factors related to the subjects used in the study (i.e., age, gender, health history, environmental sensitivities, availability and use of air-conditioning in the home and car, etc.).

Regarding subjective response, research projects should also build on, but move beyond, traditional survey methods so that we can contribute new information to the field. Traditional thermal comfort questions address thermal sensation and preference. Additional questions might investigate issues of personal control, behavioral patterns, and preferences for uniformity versus variability, and how all of these affect people's expectations, preferences, and comfort responses. In the area of health, a first step of the research should be to identify what building-influenced or building-related health effects are most likely to be related to thermal aspects of IEQ, and surveys should be developed to focus on these relationships. The research should also take an integrative approach, where measurements and survey questions are designed to assess the connection between thermal environmental parameters, thermal comfort, and building-related health symptoms. Examples might include validating relationships found in the laboratory between temperature and perception of IAQ. Other examples might include investigating relationships between temperature, air movement, and perceptions of "stuffiness". In addition to perceptions of IAQ, the research projects should also identify and quantify the most relevant health symptoms that may be influenced by the thermal conditions.

The project would begin with a phase to develop new physical and subjective experimental methods to assess these issues in the field. The purpose would be to develop and describe a package of measurement methods that could easily be replicated by others.

\section{Explanation of priority status}

Existing standards for thermal comfort have been developed based exclusively on laboratory studies, which ignore many contextual factors that influence the thermal response of people in real buildings. These standards are being universally applied regardless of climate, culture, or building type, often leading to the exaggerated need for air-conditioning with significant consequences for energy use. There is also a significant lack of studies that simultaneously investigate both thermal conditions/comfort and health outcomes in buildings, and the relationships between them. As a result guidelines and standards that address thermal comfort are completely independent of those that address health concerns. Prior research shows clear evidence that both thermal comfort and health responses are different in air-conditioned and naturally ventilated buildings, but there is still a lot of unanswered questions. An improved understanding of the relationship between thermal comfort and health in real buildings can lead to changes in building practice and standards which result in reduced energy consumption and improved environmental quality. 
How research results will be used

The results of this research will be communicated to architects, building operators, and those responsible for thermal comfort standards. The research results would be expected to influence future building designs (e.g., selection of air conditioning), operating conditions (temperature setpoints), and related standards.

\section{Related R\&D goals}

- Developing and evaluating energy-efficient technologies for improving IEQ, health, comfort and productivity

- Developing and evaluating energy-efficient practices for improving IEQ, health, comfort and productivity

\section{Expected Research Products}

- Database from buildings with and without air conditioning of measured thermal comfort conditions and comfort perceptions

- Documents, presentations, and web sites pages that indicate how comfort perceptions in actual buildings (as opposed to laboratories) with and without air conditioning relate to thermal conditions

- Improved models of thermal comfort

- Information for improved thermal comfort guidelines and standards

\section{Related R\&D application category or categories}

Commercial, Institutional, New construction

\section{Term of R\&D Project}

Short to mid-term (phase 1-measurement methods) to long term (field studies)

\section{Co-funding or leverage opportunities}

ASHRAE Return to page 7 


\section{Project Area 11.}

Based on health and comfort effects, determine, as a function of climate, if the use of economizer cycles can enable a reduction of minimum ventilation rates.

\section{Description}

Air economizers are systems designed to use outdoor air in cool and cold weather to reduce or eliminate the need for mechanical cooling. They are primarily designed to reduce energy usage, but they simultaneously result in an increase in ventilation rates (approximately six times greater than code-minimum rates for offices) for many hours per year, particularly in mild climates. This project is intended to determine if the increased ventilation during cool/cold weather conditions can result in a reduced need for ventilation during extreme weather when the economizer is disabled. The premise is that the health and comfort impacts of short-term exposures to increased pollutant concentration may not be significant enough to warrant the equipment and energy costs provided long-term average exposures are below acceptable levels. In addition, periods of economizer operation with high ventilation rates help to deplete indoor pollutant sources, bringing benefits during the periods of low ventilation rate. Thus, the average ventilation rate over some period of time, rather than the lowest rate, may be the appropriate parameter in codes. Other forms of ventilation codes may also be preferable to those in current practice and evaluated in this study. For example, a ventilation code might specify a yearly average ventilation rate, a range of ventilation rates below the required annual average that is permitted up to a few hundred hours per year, and an absolute minimum ventilation rate during occupancy. These concepts have not yet been evaluated.

The following three phases of work are anticipated:

Phase 1: The duration of periods of extreme weather in various climates would be compiled. Computer modeling would then be used to identify the potential savings in equipment and energy costs from using averaging periods, ranging from hours to months, for the minimum ventilation rates in codes. Simultaneously, the available data on the health, productivity, and odor-related effects of ventilation would be reviewed and risk and economic assessments performed to assess, to the degree possible, the annual average levels of health, productivity, and complaints with different averaging periods for minimum ventilation rates. It is anticipated that time-average risks of chronic health effects and infectious disease transmission will depend primarily on long-term-average ventilation rates and, therefore, not be a barrier to short-term reductions in ventilation. However, SBS symptoms and odor complaints are likely to vary with the average ventilation rate during the past few hours. Thus, compensating for brief periods of reduced ventilation during extreme weather by increasing the annual average ventilation rate could provide overall health benefits and reduce equipment and energy costs. The results of this phase of work would be documented in a technical report. While this phase of work is not likely to provide conclusive answers about the optimal averaging time, this phase should provide a foundation for future work, and may provide a basis for interim changes in minimum ventilation standards and associated codes.

Phase 2: Field and/or chamber studies would be performed to evaluate whether ventilation control strategies based on different ventilation rate averaging periods actually influence health, complaints, and, if possible, productivity as predicted in Phase 1. Experiments would control minimum ventilation rates per current practice and also using longer averaging times for minimum ventilation rates, while health, odor, and productivity are measured. The experimental studies would assess how these outcomes change within buildings, as the minimum ventilation control strategy is varied to reflect different averaging times. Other factors that may affect these outcomes and change during the studies would be monitored and statistical models used to analyze the resulting data and control for confounding. Experiments would be performed in roughly five to ten buildings. Multi- year studies, with the minimum ventilation control strategy, changed on a yearly basis, may be necessary to evaluate effects on some outcomes.

Phase 3: The Phase 1 predictions would be revised to reflect the new information obtained from the phase-2 research. Specific proposals would be developed incorporating different minimum ventilation rate averaging periods in major ventilation codes and standards. Researchers would participate in the committees revising these standards to best facilitate adoption of the research findings.

\section{Explanation of priority status:}

The higher the minimum ventilation rate, the larger the size, cost, and energy use of the HVAC systems required to heat, cool, dehumidify, and (in some cases) distribute ventilation air. Since the energy use is highest in warm weather, the impact of high ventilation rates on peak energy demand can be significant. Because of the large diurnal temperature swings characteristic of many climates (e.g., most California climates), there are many hours 
when economizers are operational and hence there is a significant opportunity for this strategy to reduce minimum rates and correspondingly reduced on-peak energy demand.

\section{How the Research Results Would Be Used}

As described in the description of Phase 3, the research results would be incorporated into future versions of minimum ventilation codes and standards. If the Phase 1 results are sufficiently conclusive, some changes to standards may occur before completion of the multi-year Phase 2 research. In addition, study results will be communicated in technical papers and meetings and are likely to lead to changes in ventilation control practices before codes are modified.

\section{Expected Research Products}

- Datasets quantifying human responses as a function of several minimum ventilation rate metrics and control strategies

- Documents, presentations, and web pages that define new metrics for the minimum ventilation rates in standards and codes and that discuss the merits of these new metrics, considering both energy use and human responses.

- Information for and contributions to professional committees developing revised ventilation standards

\section{Related R\&D goals}

- Developing and evaluating energy-efficient technologies for improving IEQ, health, comfort and productivity

- Developing and evaluating energy-efficient practices for improving IEQ, health, comfort and productivity

\section{Related R\&D application categories}

Residential, Commercial, Schools, New construction, Existing buildings

\section{Term of R\&D Projects}

Short term (Phase 1) to long term

\section{Co-funding or leverage opportunities}

ASHRAE

$\underline{\text { Return to page } 7}$ 
Project Area 12.

Quantify the IEQ and energy impacts of building/HVAC maintenance and space cleaning.

\section{Description}

The purpose of this project is to develop a quantitative understanding of the IEQ and energy benefits of high quality space and HVAC system maintenance in commercial buildings. The project is intended to cover the full spectrum of maintenance and cleaning practices addressing the maintenance of HVAC system components (e.g. changing filters, inspecting and cleaning coils, inspecting and repairing dampers and actuators, calibration of temperature and humidity sensors) and the cleaning of occupied spaces (e.g., vacuuming, floor cleaning, dusting, restroom cleaning). This project would begin with the identification of maintenance and cleaning practices that have the potential for improving IEQ and energy efficiency. Previous studies of the impacts of these practices would also be identified in this initial phase of the project. The results of previous studies would be reviewed and, when appropriate and possible, additional data analyses should be performed. The potential benefits of further analyses of the EPA BASE dataset should be specifically examined. Based on the results of the initial effort, a plan for field studies to quantify the IEQ and energy impacts of selected maintenance practices will be developed for implementation in a second project phase. This experimental phase would necessarily be limited in number of buildings studied, but would include a range of maintenance and cleaning practices in several different types of commercial buildings. The final phase of the project would take the results of the field testing and the findings from previous efforts identified in the first phase to perform analyses of the benefits of different maintenance and cleaning practices for a range of buildings types and climates. These analyses would focus on economic impacts of improved IEQ based on productivity impacts as well as reductions in energy consumption.

\section{Explanation of priority status}

Poor maintenance of buildings and systems has long been cited as a cause of many IEQ complaints in buildings, but there has been insufficient demonstration of the connection and therefore an inability to justify the increased expense of quality maintenance practices. The "common wisdom" within the IEQ community is that increased resources (e.g. higher paid and well-trained staff, and higher quality equipment and cleaning products) should be devoted to maintenance and cleaning, but the economic argument has been difficult due to a lack of data. In addition, poor system maintenance also impacts energy efficiency through dirty heat transfer surfaces, sensors that are out of calibration and other problems. Therefore, there are also energy-based arguments to be made for improved maintenance practices, but again the data are inadequate to support economic arguments for these increased costs.

\section{How the research results would be used}

The results of this research would be communicated to building owners, engineers, and facility managers in technical and handbook articles, articles in trade journals, best practice guides, and conference presentations. It is possible that the results would also result in design recommendations to make buildings and systems easier to maintain and clean. The research results would provide needed information to these building professionals about the energy and IEQ benefits of improved maintenance and cleaning practices, and would be expected to lead to changes in actual practice. Depending on the strength of the findings, some changes in codes and standards may be implemented. For example, a current California OSHA Regulation requires an annual inspection of HVAC systems, and correction of problems identified during the inspection. This research project could lead to a specific set of inspection and maintenance requirements in future versions of this code.

\section{Expected Research Products}

- New measured data, plus associated documents, presentations, and web pages, quantifying the energy and IEQ benefits of HVAC maintenance and of HVAC and space cleaning practices.

- Recommended changes in standards and codes

\section{Related R\&D goals}

- Developing and evaluating energy-efficient practices for improving IEQ, health, comfort and productivity

Related R\&D application categories

Commercial, Existing buildings, New construction

\section{Terms of R\&D Project}

Short term to mid term 
Co-funding or leverage opportunities

ASHRAE, ARTI, BOMA, EPA Return to page 7 


\section{Project Area 13.}

Quantify the impact of air flows, pressure differentials, ventilation rates, and HVAC system performance on indoor humidity levels and moisture problems in small commercial buildings located in humid climates, and develop associated remediation measures.

\section{Description}

Research in this project area will identify and quantify uncontrolled air flows and HVAC dehumidification performance, identify the impacts on indoor humidity levels and moisture problems, and develop and demonstrate remediation measures. The research will focus on hot and humid climates where uncontrolled airflows and dehumidification problems often lead to microbiological contamination in buildings. Various forms of uncontrolled air flow will be measured in a sample (10 to 40) of small commercial buildings located in humid portions (average dew point temperatures $>70{ }^{\circ} \mathrm{F}$ for at least three months) of the United States. This study will include measurements of relevant building characteristics, potentially including envelope and air distribution system air tightness, pressure differentials, air distribution to spaces, and ventilation rates under a variety of HVAC operational configurations. HVAC system dehumidification performance will be evaluated sufficiently in these buildings in order to determine whether the HVAC system contributes to elevated humidity and associated IEQ problems. Temperature, humidity, and other IEQ conditions will be measured at various indoor and building cavity locations. To assess how HVAC operation, duct system air tightness, and other factors contribute to humidity and moisture problems, remediation plans will be developed and implemented in a portion of the tested buildings, and post-remediation measurements will assess how the remediation measures affected indoor humidity, indoor-to-outdoor pressure differences, etc. An end product of the research will be guidelines on indoor airflows and pressure control.

\section{Explanation of Priority Status}

Uncontrolled air flows and cooling system design/control deficiencies may create indoor environmental quality problems, especially in hot and humid climates. Uncontrolled air flows can create humidity problems (and related fungal growth) by increasing rates of moisture entry and transporting humid air into walls and other building cavities. Moisture problems in building envelopes can also degrade the thermal performance of buildings. The dehumidification performance of cooling systems is interrelated with uncontrolled airflows and moisture problems. Some cooling systems dehumidify poorly under part-load conditions, particularly when cooling output is modulated by changing the coil temperature, because cool but not cold coil temperatures produce little or no dehumidification. The dehumidification performance of cooling systems is linked to cooling system energy use. Understanding the relationships between HVAC system design and operation problems and IEQ can be the basis of guidelines for improved best practice design and construction. The effective remediation measures identified in this research to correct uncontrolled air flows or cooling system performance problems should improve both IEQ and building energy performance.

\section{How the Research Results Would Be Used}

The information gained from this project should be communicated in technical papers and conference presentations and incorporated into continuing education curricula and into the curriculum of architecture and mechanical engineering degree programs. The findings of this research can be used to improve diagnosis of building problems. The results should alter the way buildings are designed, constructed, and commissioned (including Test and Balance), and lead to improvements in building codes.

\section{Expected Research Products}

- Data, documents, and presentations on uncontrolled airflows, HVAC operation, and humidity and moisture problems in buildings located in hot and humid climates

- Guidelines on controlling indoor airflow and pressure differences to limit moisture problems

\section{Related R\&D goals}

- Developing and evaluating energy-efficient practices for improving IEQ, health, comfort and productivity

Related R\&D Application Categories

Commercial, Schools, Existing buildings

\section{R\&D Terms}

Short term to mid term 


\section{Co-funding leverage opportunities}

The U.S. EPA, the CDC, and HUD have a considerable interest in the related moisture problems in buildings.

Return to page 7 


\section{Project Area 14.}

For various climates, develop best ventilation and insulation technologies and practices for crawl spaces and attics to minimize moisture problems and energy waste.

\section{Description}

This project will assess the interrelationships between venting practices, use of thermal insulation and vapor barriers and moisture problems in attics and crawlspaces. The project will start with an assessment of existing building codes to determine code elements that currently control crawl space and attic venting requirements. Surveys in representative samples of homes located in various climates will assess humidity, soil moisture levels, ventilation rates, and extent of microbiological contamination as a function of venting, thermal insulation, and use of vapor barriers. Experiments will be performed in sub-samples of the buildings to evaluate measures that are thought to be beneficial, including membrane and other types of vapor barriers, different crawlspace venting arrangements (including unvented), and construction of the crawlspace "ceilings" for improved air tightness. Studies of venting of crawlspaces must also assess the potential for elevated radon concentrations in houses with unvented crawlspaces. Similarly, studies of attic ventilation strategies will be performed to assess their effectiveness and impact on energy, airflow and moisture problems. The research will provide a basis for guidelines on venting, insulation, and use of vapor barriers in attics and crawlspaces as a function of climate. Recommendations will be developed for changes in building codes.

\section{Explanation of Priority Status}

The venting, insulation, and use of vapor barriers in attics and crawlspaces affects building energy use and the potential for moisture and indoor radon problems. Crawl spaces and attics in North America are commonly vented. In some climates and circumstances, venting these buffer spaces tends to reduce moisture problems. In other climates, particularly in hot and humid climates and especially when portions of cooling system are located in those spaces, evidence suggests that venting tends to increase moisture problems. Excessive moisture in these spaces can create fungal growth, produce building materials damage, and worsen indoor air quality. Some building practitioners are recommending that crawl spaces and attics should not be vented in certain climates in order to resolve or avoid moisture related IEQ problems. It is important to determine under what conditions, if any, that venting of crawl spaces and attics can be eliminated and. Associated guidelines and sections of building codes, that are scientifically supportable, are needed by house builders, but the available scientific data are inadequate for defining the best guidelines. These guidelines for crawlspace venting must account for the potential effects on indoor radon concentrations, an issue not adequately considered in recent papers.

\section{How the Research Results Would Be Used}

The design guidelines developed in this project for attics and crawl spaces will be important information to insert into continuing education and degree-oriented education programs. Elements of the guidelines should be incorporated into future versions of building codes.

\section{Expected Research Products}

- Data, documents, presentations, and web site pages on crawlspace and attic venting and insulation practices and on the associated humidity and moisture levels and extent of microbiological contamination

- $\quad$ Recommended changes to building standards and codes

\section{Related R\&D goals}

- Developing and evaluating energy-efficient technologies for improving IEQ, health, comfort and productivity

\section{Related R\&D Application Categories}

Residential and small commercial, Existing buildings, New buildings

\section{Term of R\&D Project \\ Mid term}

\section{Co-funding leverage opportunities}

EPA, HUD Return to page 7 
Project Area 15.

Identify the pollutants emitted from common energy consuming office equipment such as copiers, printers, and computers, and quantify the pollutant emission rates.

\section{Description}

The objectives of the project are to: 1) identify the type and nature of pollutants emitted from common energy consuming office equipment such as copiers, printers, computers, etc.; 2) determine the pollutants emission rates of this equipment; 3 ) develop a standard test method for testing this equipment and providing a rating (e.g., a labeling program) based on their pollutant emissions and energy consumption; and 4) identify measures to reduce the emissions and energy consumption. The following three phases would be conducted to achieve the above project objectives.

Phase 1: Develop methods to measure the pollutant emissions and establish a baseline data set by testing the commonly used energy consuming equipments. A "standard room" condition would be established for the testing. A common test procedure would be developed and used for the same type of equipments. Various gaseous (organic and inorganic) and particulate pollutants would be measured. Specific compounds of the gaseous pollutants emitted should be identified. For particulate contaminants, the size distribution in terms of both mass concentration and particle counts should be determined, and the composition of the particles of different sizes be analyzed. The emission rates of the various pollutants as a function of time should be determined using a dynamic chamber testing method that simulates real environmental condition under which the equipments are to be used. Tests should be conducted for the various equipment operating modes and conditions. In addition, the energy consumption of the equipment should also be measured during the tests. Based on the test results, the pollutants that can cause potential IAQ concerns would be identified, and a comparison between different types of equipment would be made in terms of pollutant emission rates and energy consumption. This information would be useful for selecting equipment, and for designing energy-efficient ventilation or air cleaning systems that would prevent or remediate IAQ problems due to emissions from the office equipment.

Phase 2: For types of office equipment that emit pollutants at a rate sufficient to contribute to odor or health problems, standard methods for testing and rating the office equipment would be developed. The results and experience learned from Phase I would be used to develop a standard test method in collaboration with equipment manufacturers. Inter-lab comparison tests will be conducted to verify the standard test method. The method would be submitted to ASTM or ASHRAE for adoption. A formal standardization of the test method will help industries to evaluate their product's performance uniformly, and speed up the development of new products. A voluntary labeling program would be established to encourage technology innovation for reductions of pollutant emissions and energy consumptions.

Phase 3: Develop methods to reduce pollutant emissions in an energy-efficient manner. The results from Phase I would also be used to identify measures for emission reductions. Researchers would work with equipment manufacturers to develop innovative approach to reducing pollutant emissions and energy consumptions.

\section{Explanation of priority status}

Office equipment such computers, copiers, printers and fax machines, etc. generate various types of gaseous (e.g., volatile organic compounds) and particulate pollutants in buildings. At the same time, they also consume significant amount of energy in buildings, including those for powering the equipments and those used by HVAC system to remove the heat and pollutants generated by the equipment. At present, the data available on pollutant emissions from office equipment is quite limited. In order to control and minimize the pollutant emissions from office equipment in an energy efficient manner, it is essential to understand the their emission characteristics, including the type of pollutants emitted and the rate of emissions as function of time and operating conditions. This information is also needed to develop ventilation and air cleaning technologies that are effective and energy-efficient for removing the pollutants generated from office equipments. Emission and energy consumption data for office equipment are also needed for building owners and managers for selecting products that are energy efficient and have little or no emissions of pollutants of health concerns. In order to encourage the equipment manufacturers to reduce the pollutant emissions and energy consumption of office equipment, it is also necessary to have a uniform testing standard and the testing data on which they can benchmark their products. The proposed project is intended to meet these needs, and improve the understanding of indoor pollutant sources. 
How the research results would be used

The results of this research would include a standard test method for characterizing the pollutant emissions from various types of office equipment, baseline data on pollutants emission and energy consumption, and recommendations for reductions of emissions and energy consumptions. The standard test method would be used as the basis for developing a voluntary labeling program for the office equipments to encourage manufacturers to reduce pollutant emissions and improve energy efficiency of their products. The test results would be used by manufacturers to benchmark their products, by building designers to design adequate ventilation or air cleaning systems or devices for IAQ control, and by building owners or managers to select office equipments. Further more, the results will help the equipment manufactures to develop more energyefficient equipment with less or no pollutant emissions.

\section{Expected Research Products}

- Database, documents, presentations, and web site pages on pollutant emission rates for common energyconsuming office equipment

- Standard method for measuring emissions from office equipment

- Proposed labeling program for office equipment

- Proposed technology design changes or usage changes to reduce pollutant emissions from office equipment

\section{Related R\&D goals}

- Identifying IEQ problems and opportunities

Related R\&D application categories

Commercial, Residential (home offices)

\section{Term of R\&D Projects}

Short to mid-term

\section{Co-funding or leverage opportunities}

ASHRAE, ARTI, Equipment manufacturers

Return to page 7 
Project Area 16

Quantify the VOC emissions and sorption of building material/furnishing systems and their impact on IEQ and required ventilation rate.

\section{Description of project:}

The objectives of this project are:

- Develop models for predicting the time history of the rate of VOC emissions from building materials and furnishings;

- Develop models for predicting the VOC sorption on and desorption from of building materials and furnishings;

- Develop a database of VOC emission rates and sorption/desorption interactions with building materials and furnishings;

- Develop or advance methods and tools for building material selections and predicting the impact of the VOC emissions, sorption, and ventilation rate on indoor VOC concentrations.

The project will be focused on the emission characteristics of building material and furnishing systems (or assemblies) as well as individual component materials. Typical assemblies of walls, floors, and ceilings should be examined. Specific questions to be answered include: 1) What compounds are emitted from individual component materials? 2) What are the VOC emission/transport rates as functions of time and environmental conditions? 3) How can emission and sorption of VOCs be modeled? 4) How do the emission, sorption and ventilation rate/schedule together affect the indoor VOC concentrations.

Typical building design and material use would first be identified for different types of buildings including schools, commercial buildings and residential house. Emission test data for individual materials would be collected from existing sources (if available) or through coordinated testing programs to establish a benchmark database for typical materials. Fundamental mass transfer and kinetic models would then be developed to predict the emission, sorption and transport of VOCs in the buildings, and how they affect the VOC concentrations under given ventilation rates/schedules.

\section{Explanation of priority status:}

Source control is the most energy-efficient way for achieving optimal indoor environmental quality in buildings. VOCs emitted from building materials and furnishings are an important class of indoor pollutants. This project will help ensure that low-emitting materials and building assemblies be used in the development of high performance buildings, and as a result, less ventilation rate and air purification treatment (which are usually energy intensive) would be required. Currently, there are limited data on VOC emissions from building materials and furnishings. A suitable method for determining the rates of VOC emissions from material and furnishing assemblies or systems, and their impact on IAQ and building energy efficiency is especially lacking. The proposed project will fill the information gaps, and result in a practical and reliable tool for optimizing decisions on material selection, ventilation rate/schedule and air treatment strategies for buildings.

\section{How the research results would be used}

The results of this research would be baseline data on VOC emissions from typical building materials and furnishings, and emission and sorption models for predicting the emission/sorption rates for typical building material and furnishing systems. The database and prediction models will be incorporated in existing indoor air quality simulation and analysis tools for selecting low-emitting materials in building design and renovation, and for determining the combined impact of sources/sinks, ventilation and air cleaning measures for VOC controls. The database could be used by material manufacturers to benchmark their products' emissions. Building designers would use the simulation tools and database to select appropriate materials, determine adequate ventilation rate or select air cleaning systems/devices for IAQ control. Building owners or managers could also use the database to select low-emission materials. The emission data would also be useful for establishing proper material selection criteria in green building programs such as the LEED. The prediction models developed for material systems will also be used to refine and update the material emission test methods for individual materials so that the emission data for individual materials are more readily usable for predicting the emissions from material systems. 


\section{Expected Research Products}

- Data base and improved models of VOC emissions from building materials, and associated documents, presentations, and web pages

- $\quad$ Data base and improved models of VOC sorption on and desorption from building materials, and associated documents, presentations, and web site pages

- Improved models for predicting indoor VOC concentrations, and associated documents, presentations, and web site pages

\section{Related R\&D goals}

- Identifying IEQ problems and opportunities

Related R\&D application category or categories

- Commercial

- Residential

Term of R\&D Project

- Short term to long term

Co-funding or leverage opportunities

EPA, HUD, ASHRAE Return to page 7 
Project Area 17.

Identify the dependence of microbiologic growth on buildings envelopes upon the materials used, airflows, humidity, moisture contents, condensation, and soiling; and develop strategies that minimize risk of microbiologic contamination, while maintaining energy efficiency.

\section{Description of project}

Research in this broad project area would require a combination of approaches, including:

- A contractor (or panel of experts) should define, based on published literature and interviews with field investigators, the indoor surfaces, and associated environmental conditions, most prone microbiological contamination and dissemination of contaminants into indoor air.

- Limited field studies should be performed to verify the information obtained from the literature review and interviews.

- Laboratory studies should evaluate the susceptibility/resistance to microbiological growth of existing materials identified in the prior research.

- New cost-effective materials, products, assemblies, or treatments practices for building envelopes should be developed to minimize microbiological growth. Examples may include interior wall covering materials that are less prone to fungal contamination than current gypsum boards, and roof and wall systems that are less prone to water leaks or water vapor condensation. Costs must be considered explicitly in this work. Implications for building energy performance should be a key consideration, with opportunities for simultaneous improvements in resistance to microbiological contamination and energy efficiency deserving special priority.

- In conjunction with industry, the resistance to microbiological contamination of the new materials or products should be tested in the laboratory and in field studies.

- Handbook articles and continuing education curricula should be revised to reflect research findings.

\section{Explanation of priority status}

Airborne microbiologic exposures are one of the key components of poor IEQ. Airborne microbiologic exposures (other than those from outdoor air or infectious organisms from people) result from dissemination from indoor microbiologic growth on indoor and HVAC surfaces with adequate moisture and nutrients. Prevention is currently the most feasible solution to this problem, and prevention measures must not require excessive maintenance. Although it is obvious that microorganisms can grow on most materials, the conditions under which such growth occurs vary among materials and are not adequately understood. In order to prevent growth, it is essential to match materials to achievable ambient moisture conditions. Such a match requires an understanding of moisture-growth relationships for materials and information on the moisture conditions encountered in different uses. New materials and products can help to reduce growth where high moisture levels are unavoidable.

Many of the moisture and mold problems in buildings stem from features or processes in buildings with relevance to energy efficiency, including vapor barriers, fibrous insulation in walls, moisture permeability of envelope materials in general, infiltration of outdoor air and moisture through building envelopes.

Despite the widespread recognition that moisture and microbiological problems are very common within buildings, technologies and practices that prevent these problems have not advanced rapidly.

\section{How the research results would be used}

Results would be used to provide for the marketplace materials and designs documented to resist microbial growth in building envelopes.

\section{Expected Research Products}

- Data, documents, presentations, and web pages documenting the risks of microbiologic contamination for a range of indoor materials

- New materials, assemblies, or treatments for building envelopes that minimize risks of microbiologic growth, while maintaining or improving building energy performance

\section{Related R\&D goals}

- Identifying IEQ problems and opportunities

- Developing and evaluating energy-efficient technologies for improving IEQ, health, comfort and productivity

- Developing and evaluating energy-efficient practices for improving IEQ, health, comfort and productivity 
Related R\&D application categories

Residential, Commercial, Schools, New construction, Existing buildings

Term of R\&D Projects

Mid-term to long-term

Co-funding or leverage opportunities

EPA, NIOSH, ASHRAE, ARTI, Industry Return to page 7 


\section{Project Area 18.}

\section{Develop new and innovative HVAC system designs that provide improved IEQ at minimum life cycle cost.}

\section{Description of project:}

Research in this project area would develop new HVAC system designs, starting from "scratch" (as opposed to modifying or enhancing existing HVAC concepts), that provide better IEQ than systems commonly used in standard practice in the US, while minimizing life cycle costs, including first costs, maintenance costs, and energy costs. Some of the elements of the new HVAC designs, such as better filters and features that reduce interzonal airflows, could also help to protect occupants in the event of chemical and biological attacks. The initial focus should be on large office buildings because they represent a large market sector and one where IEQ benefits can have a large return on investment due to improvements in worker productivity. They also are commonly conditioned by large, complex, energy intensive HVAC systems that are far from optimum with respect to IEQ and energy efficiency.

The research team would be balanced among: HVAC system engineers and HVAC contractors practicing in the US and Canada; HVAC system designers from other parts of the world where HVAC concepts are very different from those used in the US; maintenance and facility engineers; IAQ/IEQ experts; and experts in building energy systems, analysis, and conservation.

The project would start with a conceptual design phase that would include identifying desirable features of HVAC systems, such as reduced fan energy, better control of ventilation rates, better filtration, improved thermal control, increased dehumidification capacity in hot climates, individual control, increased maintainability, reduced microbiological contamination, and more convenient fault detection and maintenance. The next step would be to develop several conceptual HVAC system designs that include and maximize as many of these features as possible; analyzing and optimizing the designs with respect to IEQ, energy costs, maintenance costs, and first costs in various US locations; and finally ranking the applicability of the designs as a function of building characteristics, climate, and local labor factors.

Examples of possible features incorporated into new conceptual designs include: separate outside air ventilation and thermal conditioning; use of water in place of air to transport energy; air supply systems, including displacement ventilation and task ventilation, that improve ventilation at the breathing zone; controls for each occupant; evaporative or desiccant cooling; use of waste heat from distributed generation; advanced sensors and fault detection algorithms; thermal storage, and removable components for ease of cleaning and maintenance.

Possible future phases of work could include development and testing of prototypes (prototype phase) and demonstrations of prototypes in either laboratories or real-buildings depending on the specifics of the design (demonstration phase). These phases should have industry participation co-funding. Ideally, industry would undertake these phases without public support, but prior experience suggests that public co-funding will be necessary.

\section{Explanation of priority status}

HVAC systems used in the United States are most commonly designed to provide minimally acceptable thermal conditioning performance, energy costs, and maintenance costs at the lowest possible first costs. The most common system types used for large offices are variations of the central variable air volume (VAV) system, such as VAV with zone reheat. These systems have inherent energy inefficiencies, such as the use of simultaneous heating and cooling, they commonly have high fan energy, and they must rely on complex design techniques and controls to ensure that minimum ventilation rates are maintained in all spaces served by the system. Often, these systems control outside air ventilation rates poorly, fail to maintain a high level of satisfaction with thermal comfort, and use low efficiency particle filters with considerable air bypass around filters. Some of these systems become contaminated microbiologically. System designs and installation practices often complicate maintenance, for example, by making access difficult. A large number performance problems that may degrade energy and IEQ performance are reported anecdotally. In addition, the current system designs have not considered the potential to reduce occupant's exposures to chemical and biological agents that may be released by terrorists. To maximize performance with respect to comfort, energy efficiency, and IAQ new system concepts must be developed. Because standard practice is so engrained, developing new concepts must include professionals outside the current HVAC design/construction practice who can bring fresh ideas and varying perspectives to this complex issue. 
How the research results would be used

The results of this research would be new conceptual HVAC designs that are communicated widely to the HVAC industry by distributing copies of the project report(s), publishing articles in professional and trade magazines, and via presentations at professional meetings. In addition, leading members of the HVAC industry would participate in the project and, consequently, communicate results to their employers. Assuming that highly promising conceptual designs are developed, we anticipate that HVAC manufacturers will invest their resources to develop some of the conceptual designs into real products. Partial public support of follow up prototype-phase and demonstration-phase projects would facilitate adoption of the conceptual designs by industry.

\section{Expected Research Products}

- New HVAC system designs that improve IEQ while minimizing life cycle and energy costs, and associated documents, presentations, and web pages

- Increased collaborations between IEQ researchers and the HVAC industry

\section{Related R\&D goals}

- Developing and evaluating energy-efficient technologies for improving IEQ, health, comfort and productivity

\section{Related R\&D application categories}

Commercial, New construction

\section{Term of R\&D Project}

Short to mid-term (phase 1) to long term (Phases 2 and 3)

\section{Co-funding or leverage opportunities}

Conceptual Design Phase: ASHRAE, ARTI, SMACNA

Prototype and Demonstration Phases: HVAC Companies

Return to page 7 
Project Area 19.

Identify the components and features of current HVAC technologies posing risks, in actual use, of microbiologic contamination and dissemination.

\section{Description}

This project is designed to evaluate HVAC systems for materials and conditions that promote microbial growth, to evaluate exposures to building occupants as a result of such growth and to evaluate the role of UVC irradiation on prevention of such growth. Specifically, objectives are to 1) survey and critically evaluate the literature on microbial growth in ventilation systems; 2) design and perform a field survey to supplement existing data; 3) perform laboratory evaluations to further enhance data quality; and 4) develop climate-specific guidelines for ventilation system design, materials, and operational/maintenance parameters.

Phase 1: Form a team that includes at least a ventilation engineer with field experience, a materials specialist, and a microbiologist/mycologist experienced in evaluation of indoor air quality literature. Critically review the peer-reviewed, proceedings, web-based, and other literature on microbial colonization of ventilation systems and the materials commonly used in their construction. Produce a critical review that assesses the quality of the data, validity of conclusions, and generalizability of the data. Include a discussion of the types of data that are needed before useful design and maintenance guidelines can be developed.

Phase 2: Using the same or a similar team, conduct a field study as prescribed in Phase 1 that includes a survey of ventilation system components including sampling and analysis for growth (including types of organisms), measurements of water retention characteristics of materials, and tracking of release of materials from growth through the system and into occupied spaces. This field study should cover a variety of climatic conditions, include systems with UV radiation systems, and provide sufficient data to allow statistical analysis.

Phase 3: Based on literature and field survey, develop protocols for testing HVAC components under a range of realistic environmental conditions, and using microorganisms appropriate to materials, conditions in the HVAC system, and the regional air spora. In addition, document the range of conditions under which UVC disinfection of ventilation systems is effective.

Phase 4: Using all available data, develop climate-specific practical guidelines for design and materials, operational conditions, maintenance schedules for ventilation systems and recommendations for the use of UVC that will minimize the probability that microbial growth will occur and lead to occupant exposure to microbial effluents.

Results of all phases of research will be summarized in technical papers and conference presentations, incorporated in handbook chapters, and best practice guidelines.

\section{Explanation of priority status}

Microbial growth has been observed on filters, ductwork, fans, cooling coils, drip pans, and on ventilation system filters. These observations have led to conclusions regarding reasons for the growth that primarily focus on duct lining materials in the absence of adequate data to support such conclusions. Linings that are important for energy conservation and for sound control have been arbitrarily removed and recommendations made that such materials should not be used. In addition, exposure to microbial components has been assumed, and, in many cases, exposure/disease associations been made in the absence of adequate data. Considering the importance of HVAC design and operation for energy consumption control, the apparent frequency of microbial growth problems especially in warm humid climates, and the lack of data-based guidelines all make this a high priority area for DOD research.

\section{How the research results would be used}

Results of these studies will be extremely valuable to the HVAC industry as guidance for improvement in design, materials, and operational guidelines for HVAC systems. Building supervisors will benefit from specific directions on operation and maintenance of HVAC systems, and inspectors and remediators will more easily identify problems and make practical, cost-effective, energy efficient recommendations. 


\section{Expected Research Products}

- Data, documents, presentations, and web site pages on risks of microbial growth in HVAC systems as a function of system design, operation, and maintenance

- Data quantifying the benefits of using specific technologies or practices to prevent microbial growth in HVAC systems

- Guidelines for limiting microbial growth in HVAC systems

\section{Related R\&D goals}

- Identifying IEQ problems and opportunities

\section{Related R\&D application categories}

- Commercial, residential, schools, both new construction and existing buildings.

\section{Term of R\&D Project(s)}

Short term (Phase 1) to mid term (Phases 2-4).

\section{Co-funding or leverage opportunities}

EPA, ASHRAE, equipment and materials manufacturers, NIH, CDC. Return to page 7 


\section{Project Area 20.}

Develop and evaluate strategies for micro-zoning while providing individual control, with a focus on spatial and temporal variability in IEQ conditions, on occupant interactions with the building [including its systems and environment] and on the resulting effects on health, comfort, productivity, and building energy use.

\section{Description}

This project will develop, test and evaluate innovative environmental control strategies for commercial buildings that allow people to individually control various attributes of the IEQ conditions in their personal environment. Traditionally, such systems have focused on controlling aspects of the thermal environment such as temperature and air movement. This project should take both a broader and more integrative approach, examining other IEQ conditions that could be easily and economically controlled by individuals. Research projects should be phased, so that simple prototypes could be quickly developed and tested for their feasibility before embarking on longerterm more detailed studies. Evaluation should include both physical and subjective measurements to understand the effects of the micro-zoning strategies both on the IEQ conditions, and also on occupant response. Physical measurements should consider both local and ambient conditions, and point-in-time versus transient measurements, allowing the determination of spatial and temporal variability in IEQ conditions. In addition, evaluation methods should include an assessment of the frequency and effectiveness of relevant occupant interactions (e.g., with the building, systems, and environment). The impact of the strategies should be evaluated in terms of building energy use and occupant effects (such as health, comfort and productivity). Included in the development of innovative local control strategies should be suitable sensing devices for recording and communicating the IEQ data needed for operation. The project should evaluate the means and effectiveness of integrating environmental controls on a micro-zoning level with those of the building's system-wide level. The development of these systems should consider practical issues such as complexity, flexibility, and cost.

\section{Explanation of priority status}

It is difficult for centrally-controlled HVAC systems in commercial buildings to produce IEQ conditions which are acceptable to $100 \%$ of occupants, given the wide variety of inter- and intra-individual differences in people's environmental preferences and sensitivities. While it is generally accepted that providing individuals with control over their personal environment is the only way to achieve this $100 \%$ goal, there are few practical ways to do this and there is great debate as to whether this would lead to increased or reduced energy use. There are limited systems on the market which provide users with individual control of IEQ conditions in their personal environment, and there is not much known about their performance in terms of their impact on building energy use or occupant health, comfort and productivity. Given the perception that individual control inevitably increases both complexity and first cost, such performance information is essential to determine the benefits and life cycle paybacks of such investments. Building professionals need reliable information about the performance of such micro-zone systems, so they can make better informed design decisions. In the long run, information about system performance, combined with building professionals' accumulated experience, could eventually lead to guidelines about the design and operation of micro-zoning environmental control strategies.

\section{How research results would be used}

Architects and engineer would use the results of this research in decisions about the selection of indoor environmental control systems. Manufacturers of HVAC equipment would use research results to design improved technologies for micro-zoning.

\section{Expected Research Products}

- New technologies or control strategies that enable individual control of thermal and IEQ conditions, and data quantifying the effects of these technologies and strategies on IEQ conditions and occupant responses

- Documents, presentations and web site pages on the new technologies or control strategies

\section{Related R\&D goals}

- Developing and evaluating energy-efficient technologies for improving IEQ, health, comfort and productivity

- Developing and evaluating energy-efficient practices for improving IEQ, health, comfort and productivity

Related R\&D application categories

Commercial, New Construction, Existing Buildings 
Term(s) of R\&D Project Area

Short to mid term

\section{Co-funding or leverage opportunities}

ARTI, HVAC manufacturers Return to page 9 


\section{Project Area 21 \\ Develop inexpensive instruments for rapid and sensitive identification and measurement of indoor pollutants of concern.}

\section{Description}

The purpose of this project is to develop key measurement methods needed for large-scale IEQ surveys. Many measurement issues, such as sensitivity, selectivity, specificity, detection limits, cost per data point, analyte variability in time and space, etc., are shared across environmental monitoring disciplines. However, IEQ has a unique problem that does not exist for the disciplines for which available instrumentation can be found. In order to adequately assess the distribution of pollutant concentrations or human exposures in common indoor environments, it is necessary to sample in enough individual environments to achieve a statistically valid sample. For ambient sampling in a community this might be one representative instrument per millions of individuals. In industrial hygiene studies, measurements are focused on individuals, but often limited by tasks in extreme working conditions. For IEQ, the sheer number and diversity of indoor environments requires much greater numbers of observations to ensure adequate characterization. Consequently, industrial hygiene instruments are often not adequate or too costly for IEQ surveys. The instruments and protocols developed in this project area for large surveys will also enable building operators, employers, and investigators of IEQ complaints to more cost effectively evaluate IEQ and diagnose problems. Some instruments may enable real-time control of HVAC systems to maintain acceptable IAQ.

Phase 1 of this research will develop a consensus regarding the most critical identify gaps in available IEQ instrumentation and methods and a set of standard specifications for the related IEQ measurements. This phase would be implemented by conducting an extensive product and literature search, and through a facilitated workshop to be attended by invited leading experts in IEQ and members of industry. The workshop will develop a priority list of IEQ measurement methods needed to fill research gaps, and also develop a set of specifications related to the identified priority gaps. The workshop attendees will be encouraged to interact in designing collaborative efforts of priority IEQ studies that would be enabled by the new instrumentation. Through this process it is anticipated that new creative research programs will be developed. A major benefit of this collaborative approach will be standardization of methods across the leading research programs, which will lead to cross comparability of studies.

Phase 2 efforts will include multiple projects that develop new convenient cost-effective monitoring systems, or evaluate or upgrade existing systems, as needed to fill the gaps identified in Phase 1. The number of instruments developed will be a function of the selected analytes, the intrinsic difficulty in developing the devices, and the available funding. We anticipate the Phase 1 will identify a need for new more convenient instrumentation for microbiological agents (i.e., fungi, bacteria, virus, and allergens), non-biological particulate matter including respirable suspended particles and ultrafine particles, chemical speciation/characterization of particles, and environmental tobacco smoke constituents. More convenient or acceptable technologies for measuring building ventilation rates are likely to identified as a need, because the costs and labor requirements of existing technologies are high. In addition, the tracer gases used commonly to measure ventilation rates used are greenhouse gases, and permission is sometime denied for use of the current tracers because of concerns about health effect (e.g., in schools). Other gaps identified in Phase 1 may include standardized methods for assessing or monitoring occupant use of buildings (e.g., window opening) and improved questionnaires for assessing occupant characteristics and health status, particularly for studies of young children who can not complete the questionnaires developed for adults. For several other IEQ parameters, potentially suitable instruments or samplers already exist as validated designs, or even as commercialized products. These include passive samplers for carbon monoxide, nitrogen dioxide, formaldehyde, volatile organic compounds, nicotine, radon, and relative humidity. Acceptable temperature monitoring equipment also exists. Although these devices are designed for IEQ studies, they may need additional development work in order to meet the standards of IEQ research.

For instrumentation routinely used nationally in IEQ characterization studies, a centralized analytic facility, supported collaboratively could reduce costs and increase efficiency over decentralized, redundant facilities. A Phase 3 effort would develop this facility to serve the national IEQ research community.

\section{Explanation of priority status}

The costs associated with IEQ measurement instrumentation and associated labor for deployment, calibration, maintenance, and data handling: a) substantially limit our ability to perform large IEQ surveys; b) prevent building owners from performing periodic IEQ checkups; and c) inhibit investigations of IEQ complaints. With few exceptions, the available instrumentation has been developed for the specialized industrial hygiene and outdoor ambient air monitoring markets. IEQ researchers are often challenged to adapt commercially available 
instrumentation developed for outdoor air or industrial applications to meet the needs of IEQ studies, or to develop new instrumentation to suit their needs. Very often such methods development must be done with minimal funding on very short time schedules. Thus, in many instances the poor applicability of available research tools imposes significant barriers to advances in understanding IEQ issues or resolving IEQ problems. Technological advances in IEQ measurement methods are needed to overcome these barriers. These technological advances require funding for instrument development. While industry has contributed substantially to the development of such instrumentation, many obvious key gaps remain. Without adequate tools for characterization of indoor environments, progress in ensuring that standard and energy efficient buildings have adequate IEQ is hampered.

\section{How the research results would be used}

This research would develop a toolbox of cost effective IEQ measurement instruments and tools for key IEQ parameters. Researchers would use these tools to perform surveys and exposure assessment studies that are presently too costly. Building operators and facility managers would use these tools to perform periodic IEQ checkups. Finally, consultants who investigate IEQ problems, such as complaint buildings, would use these tools to diagnose problems. The results of this IEQ tools development effort would include a better understanding of the population's exposure to indoor pollutants, their sources, and the opportunities for exposure reduction, without excessive reliance on energy intensive ventilation. Thus, this research should ultimately lead to improved public health and reduced building energy consumption.

\section{Expected Research Products}

- Document describing most critical needs for improved IEQ instrumentation, and associated instrument specifications

- Designs for selected new IEQ instruments or for improvements to existing instruments

\section{Related R\&D goals}

- Developing and evaluating energy-efficient technologies for improving IEQ, health, comfort and productivity

\section{Related R\&D application categories}

Residential, Commercial, Schools, New construction, Existing buildings

\section{Term of R\&D Projects}

Short term (phase 1) to mid or long term (Phase 2 or 3 )

\section{Co-funding or leverage opportunities}

Instrumentation industry, EPA

\section{$\underline{\text { Return to page } 9}$}




\section{Project Area 22}

Develop diagnostic protocols and tools for failures of HVAC that deteriorate IEQ and energy efficiency.

\section{Description}

The project would provide diagnostic tools that would provide real-time alarms or other indications that HVAC systems were improperly functioning in a manner that resulted in deterioration of IEQ. Many of these failures will also increase energy usage. Some of these failures would increase people's exposures to chemical and biological agents that may be released by terrorists. Examples of failures that can be monitored and alarmed include: fan failure (via status contact if available or deduced from supply air temperature or other available sensors); failure of minimum ventilation outdoor air damper or economizer outdoor air damper (deduced from return air, supply air, and mixed air temperatures); valve failure (deduced from entering and leaving temperatures, excessive space temperatures, etc.); and cooling coil condensate drain failure (float switch in drain pan).

The initial focus would be on systems that have built-in alarming capability and that are programmable (e.g. DDC/energy management systems) since the first cost impact will be minimal. Later work can address how these tools might be inexpensively applied to smaller systems (e.g. packaged equipment).

The project should build upon existing research on HVAC fault detection which tends to focus exclusively on energy performance. This research would also consider IEQ-related faults.

A part of this project must include methods to disseminate the protocols and reduce the cost of their implementation in the field. For instance, software-based diagnostics could be prewritten in the software languages of several of the most common DDC manufacturers so that they could be incorporated into DDC system programming at very low cost. For packaged equipment, a detailed design of a diagnostic monitoring and alarm kit could be developed that could be freely used by equipment manufacturers to add to their standard control options.

\section{Explanation of priority status}

Failures of HVAC systems, even large, well maintained systems, are common and often go undetected because of the lack of tools that automatically notify operators or occupants that a failure has occurred. HVAC systems tend to be in remote, unattended locations, so failures can go undetected for hours, days, or even months. Typically, failure is only indicated by complaints from occupants, e.g. when space temperatures become extreme. Some failures that result in energy cost increases (e.g. economizer failures) may go undetected indefinitely because they do not result in space temperature excursions, and some IAQ-related failures (e.g. closed outdoor air dampers) may go undetected for some time until health effects are noticed and reported by occupants. Some undetected failures would increase people's exposures to chemical and biological agents released by terrorists.

Few diagnostic tools and protocols for monitoring HVAC system failures have been developed to date and most have focused on energy impacts (e.g. PNNL's IMDS), not on IEQ. Even those protocols that are in the public domain are seldom implemented into HVAC systems due to the cost. This project is intended to minimize the cost barrier and thus increase the number of systems with diagnostic/alarm capability.

\section{How research results would be used}

The results of this research would be incorporated into the software and hardware of HVAC control system vendors. The resulting diagnostic data would be used by facility managers to detect and diagnose IEQ problems.

\section{Expected Research Products}

- Diagnostic tools, consisting of instrumentation and software, for detecting and diagnosing HVAC system failures that deteriorate IEQ and system energy performance, and papers and presentations describing the tools

\section{Related R\&D goals}

- Developing and evaluating energy-efficient technologies for improving IEQ, health, comfort and productivity

- Developing and evaluating energy-efficient practices for improving IEQ, health, comfort and productivity

- Stimulating or assisting implementation of energy efficient technologies or practices for improving IEQ. 
Related R\&D application categories

Residential, Commercial, Schools, New construction, Existing buildings

Term of R\&D Projects

Short term to mid-term

\section{Co-funding or leverage opportunities}

ASHRAE, DDC/EMS manufacturers

Return to page 9 


\section{Project Area 23}

Based on a cost/benefit analysis, determine the appropriate minimum ventilation rates in building codes.

\section{Description}

The purpose of this project is to determine minimum ventilation rates appropriate for model building codes and IAQ standards, such as ASHRAE Standards 62.1 and 62.2, based on a cost-benefit analysis. Costs would include first costs for ventilation systems and related heating, cooling, and air distribution systems; energy costs to heat, cool, and distribute ventilation air (including the impacts on simultaneous heating and cooling when applied to variable air volume systems, and for dehumidification in humid climates); productivity impacts (including lost-time due to illness) associated with IAQ; and health care costs associated with IAQ.

Before this project can proceed, sufficient data must be collected on the health and productivity impacts of ventilation for the building occupancy category under consideration. At present, substantial health and productivity data are available only for large office buildings, allowing this cost-benefit approach to be used to develop office building rates in the short term. While health and productivity data for other occupancies are being collected, ventilation rates for these occupancies could be extrapolated from office rates using engineering judgment, which was the approach taken to develop ASHRAE's most recent proposed revisions to the rates required by ASHRAE Standard 62.1 (proposed Addendum 62n).

\section{Explanation of priority status}

Ventilation rates influence building energy use and IEQ. The rates in current standards and codes were developed based on quite limited research findings and on the judgment of engineers, IAQ experts, and other affected parties. Politics also has played a major part. Many feel current rates are excessive in some applications (resulting in an unnecessary increase in first costs and energy costs) while many others feel they are insufficient (resulting in poor IAQ). The lack of consensus is primarily due to the lack of a consistent rationale for and an objective means of determining appropriate code-minimum ventilation rates. The total life-cycle cost approach developed and implemented in this project will result in minimum rates that balance all costs associated with ventilation.

\section{How the research results would be used}

The results of this project would be used by those responsible for developing or revising ventilation standards and codes, such as ASHRAE Standards 62.1 and 62.2 and California Title 24. Additionally, in advance of the development of new codes and standards, some employers and facility owners or managers would be likely to utilize project results to select minimum ventilation rates.

\section{Expected Research Products}

- New values of recommended minimum ventilation rates that are based on cost-benefit analyses, documented in papers and presented to committees and organizations responsible for ventilation standards

\section{Related R\&D goals}

- Developing and evaluating energy-efficient practices for improving IEQ, health, comfort and productivity

\section{Related R\&D application categories}

Residential, Commercial, Schools, New construction, Existing buildings

\section{Term of R\&D Projects}

Medium term to long term

\section{Co-funding or leverage opportunities}

ASHRAE, ARTI Return to page 9 
Project Area 24.

Combine current scientific and practical information on health effects of building design, operations and maintenance including ventilation into guidelines for best building practices.

\section{Description}

The purpose of this project is to provide guidance to improve IEQ performance for designers and building owners and operators based on currently available scientific and practical information. Elements of this guidance would address means of reducing the vulnerability of buildings to possible chemical and biological releases by terrorists. This project would begin with an initial phase in which the research literature and industry/government guidance documents will be studied to identify available information on building design and operation to reduce health impacts of IEQ conditions. This information would be collected and converted into a collection of best practices for design and construction. A series of workshops would then be held to sort through these best practices and develop a consensus on which should be retained and put forward in the end product of the effort. Finally, based on the findings of these workshops and other considerations, a guidance document and web site on design, operation and maintenance for good IEQ will be developed, reviewed and published. Subsequent outreach efforts would include work with ASHRAE committees to incorporate the results in ASHRAE's handbook chapters and standards, with EPA to incorporate results on EPA's web sites and in the IBEAM Program, and presentations at meetings of architects and facility managers.

\section{Explanation of priority status}

The provision of quality indoor environments depends on building and system design, operation and maintenance. Failures in any or all three of these areas can lead to indoor environmental conditions that increase the potential for adverse health effects or discomfort. Many failures will also increase building energy use and some failures would increase people's exposures to the chemical and biological agents in the event of attacks by terrorists. While there is not an overwhelming amount evidence linking operation and maintenance practices to health and comfort, there is still some information that merits being transferred into the hands of practitioners. Practical information can also be provided on means of reducing building vulnerability to terrorist attacks. Some of the information on best practices is based on the practical experience of those who design, operate and maintain buildings, while some has come from research studies. Pending the outcome of future research into this area, it is important to develop guidance based on what we know today.

How the research results would be used

The results of this research would be immediately applied to building design, operation and maintenance and would be expected to result in immediate IEQ improvements where it is used. While further research will be needed to develop this guidance further, confirm the benefits and identify new opportunities for improving IEQ in buildings, the current information is deemed adequate to realize a beneficial impact almost immediately.

\section{Expected Research Products}

- Consensus best-practice guidelines for design, operation, and maintenance of buildings to assure a high level of IEQ while maintaining energy efficiency

- Handbook chapters, standards, and web sites that incorporate the best practice guidelines

\section{Related R\&D goals}

- $\quad$ Stimulating or assisting implementation of energy efficient technologies or practices for improving IEQ.

Related $R \& D$ application categories

Residential, Commercial, Schools, New construction, Existing buildings

\section{Term of R\&D Projects}

Short term

Co-funding or leverage opportunities

ASHRAE, ARTI, EPA's related support for the IBEAM Program

$\underline{\text { Return to page } 9}$ 
Project Area 25.

Integrate scientific information on IEQ and materials, with appropriate weighting factors, into the LEED Rating System for Green Buildings. Top22

\section{Description}

This research project is intended to bring the scientific information of the IEQ community into the next generation LEED rating system, or, if necessary, to devise an alternate rating system. The LEED (Leadership in Energy and Environmental Design) rating system has had a significant impact on moving building owners and developers to pursue more energy and environmentally effective buildings. The rating system covers a wide range of decisions from land-use and site to alternative energy to building materials, with a weighting system that is intended to reflect the importance to overall societal energy and environmental benefits. This project would support the scientific IAQ/IEQ community to contribute wording, weighting, and appropriate standards/methods to the next LEED release, towards improving the combined energy and IEQ of new US buildings. This is especially important since next LEED release will include certification for residential, commercial interiors, and operation and maintenance projects.

Due to limitations in the LEED Rating System and in the process to modify the LEED system, it is possible that an alternate "model" rating system should also be developed and promoted, e.g., as a future alternative to the LEED system.

\section{Explanation of priority status}

The pursuit of LEED certification, bronze, silver, gold, and platinum ratings has become a trademark for enlightened industries and federal agencies, including international governments. The development of the next release should go beyond voluntary, consensus input to include the scientific input of the research community including the results of literature searches, simulation, experimentation and scientific debate. The influence that LEED is having on the developers and owners of buildings has resulted in demands on design professionals and even building industry players to "retool" to meet the new client demands. Consequently, the LEED rating system is a very powerful vehicle to get the research results of the IEQ community to the decision makers in the built environment.

\section{How the research results would be used}

The results of this work would be improvements to the LEED rating system used to determine LEED certification. Consequently, this work would influence the design and furnishing of future buildings.

\section{Expected Research Products}

- Improved LEED rating system for green buildings that incorporates current scientific information, or a new alternate model rating system

\section{Related R\&D goals}

- Stimulating or assisting implementation of energy efficient technologies or practices for improving IEQ.

Related R\&D application categories

Commercial, Schools, New Construction, Existing buildings

\section{Terms of R\&D Projects}

Short term

\section{Co-funding or leverage opportunities}

EPA

Return to page 9 
Project Area 26.

Use existing information to recommend maximum pollutant concentrations for pollutants and pollutant mixtures of particular concern.

\section{Description}

Work in this project area would use experts to compile, review, and analyze existing information and perform risk assessments, to define a methodology for setting maximum acceptable pollutant concentrations, and finally to develop recommendations. The following three efforts are envisioned:

- Assembly of a panel of experts on indoor contaminant sources, indoor exposures, toxicology, and human health to identify the set of indoor pollutants and pollutant mixtures of primary current concern regarding health effects, based on available scientific information augmented as appropriate by empiric information, and to review and summarize the current information on the health effects of these pollutants.

- Assembly of a panel of experts on health effects of indoor exposures, quantitative risk assessment, and health risk management to develop a methodology for setting maximum acceptable pollutant concentrations and, finally, to develop recommend maximum pollutant concentrations for pollutants and pollutant mixtures of particular concern. This would involve application of risk management algorithms using the available information or reasonable estimates, and the use of reasonable assumptions such as of linear additivity, unless information to the contrary is available.

- Work with ASHRAE, AIHA, and other professional organizations to incorporate both the methodology and the recommended maximum pollutant concentrations in handbooks and standards (e.g., within the IAQ procedure of ASHRAE Standard 62.1).

\section{Explanation of priority status}

A variety of existing information on health effects of diverse indoor exposures, because it is very broad and incomplete, has not been synthesized for practical use. This project would target specific pollutants of greatest apparent concern, optimize current policies, and focus the priority research to fill key data gaps needed to improve these decisions. There has been little effort to date to synthesize this available but incomplete information, resulting in lack of use of available information and lack of coordination in related research.

\section{How the research results would be used}

The reported results could be incorporated into informal or consensus standards for good building practice, or into environmental regulations, and also could be reflected in the marketplace for products used indoors or in building construction.

\section{Expected Research Products}

- Recommended maximum concentrations for selected indoor pollutants

- Revised handbooks and professional standards that incorporate the new recommended maximum concentrations for selected indoor pollutants

\section{Related R\&D goals}

- Stimulating or assisting implementation of energy efficient technologies or practices for improving IEQ.

\section{Related R\&D application categories}

Residential, Commercial, Schools, New Construction, Existing buildings

\section{Term of R\&D Project}

Short-term to mid-term

\section{Co-funding or leverage opportunities}

EPA, HUD, NIOSH, NIH Return to page 10 
Project Area 27.

For design professionals, facility managers, and code officials, develop and deliver education programs in HVAC and building science related to best practice for IEQ.

\section{Description}

Both time and resource limitations often make it difficult for design professionals, facility managers, and code officials to get current information about how to improve the IEQ and energy performance of buildings. This research project will develop and deliver a variety of IEQ and related energy-efficiency educational programs aimed at architectural and engineering design professionals, facility managers, and related code officials. The education programs can include guidance on means of reducing the vulnerability of buildings to the possible chemical and biological attacks by terrorists. The programs should represent a range of objectives and formats to match the wide variation in participants' expertise, needs, and available time. At the simplest level, programs might include evening lectures that can be attended on a drop-in basis. These have the advantage of fitting in most easily to people's busy work days, but may be the least effective in terms of training because participants are simply passive observers. More effective, but requiring a greater time commitment, would be $1 / 2$-day or fullday classes or workshops. Ideally, these would include interactive exercises where participants learn by doing, rather than just listening. Workshops should be oriented towards giving participants real analysis and decisionmaking tools that they could use directly in their own work. Another type of program might involve creating asneeded resources, such as libraries or websites, or design advice services, which designers could use to apply directly to a current design problem. Another type of resource might be tool-lending libraries that give professionals access to easy-to-use measurement devices that allow them to essentially use existing buildings as laboratories to measure IEQ conditions in the field and evaluate the impact of various design decisions on environmental quality. Research projects might also consider going into existing A \&E firms to help them setup in-house resources and training programs that could be ongoing. Part of this research project should also include developing and implementing evaluation methods for assessing the effectiveness of these educational programs. An important part of research projects in this area would be to develop a phased plan, where quick and easy education programs would be developed and implemented in the short-run. The effectiveness of these initial programs could then be evaluated in parallel with developing more sophisticated programs.

\section{Explanation of priority status}

It is essential that existing information about how to design and operate buildings for improved IEQ and energy performance, and for reduced vulnerability to attacks by terrorists, get communicated to the professionals who can put it to practice. Too often, research results get disseminated only to other researchers. Common forums for distributing research information - such as conferences and journals - are not the most effective means for communicating to the end users. Designers are primarily interested in how to apply information to current problems, and it is critically important that educational programs be designed specifically for their needs in order to stimulate the incorporation of research findings into more intelligent design decisions.

\section{How research results will be used}

This project will develop educational curricula on best practices for IEQ that can be adopted in existing continuation education programs. The project will also provide information directly to the end users. The anticipated outcome is changes in building design, operation, and maintenance that improve IEQ using the most energy efficient measures available.

\section{Expected Research Products}

- Education programs that address both IEQ control and building energy efficiency, delivered to architects, engineers, facility managers, and code officials

\section{Related R\&D goals}

- Stimulating or assisting implementation of energy efficient technologies or practices for improving IEQ.

Related R\&D application categories

Residential, Commercial Schools, New construction, Existing buildings

\section{Term of R\&D Project}

Short

\section{Co-funding or leverage opportunities}

EPA

$\underline{\text { Return to page } 10}$ 


\section{Project Area 28.}

Identify key decision makers for IEQ and energy efficiency in buildings through the building life cycle, and develop effective information dissemination and decision making tools for IEQ and energy efficiency specifically targeted to these individuals.

\section{Description}

Research in this project area will require the following sequence of efforts:

- Assembly of a panel including representatives of the key groups of decision-makers for IEQ and energy efficiency in buildings, along with experts in economics, organizational behavior, behavioral research, and other relevant disciplines. The panel would work to define the full spectrum of groups and individuals making IEQ and energy-efficiency decisions through building life cycles, including decisions related to buildings, contents, and occupants.

- Conduct of focus groups, run by appropriate experts and containing representatives of all appropriate groups, to define the key decisions influencing IEQ and energy-efficiency in buildings, the inputs and influences on these decisions for the different groups, and ideas for new information, processes, or tools that would change these decisions in specified ways.

- Development of information produced by the panel and focus groups into prototype tools for information dissemination and improved decision-making related to IEQ and energy-efficiency in buildings; also, identification of key missing scientific information necessary to influence decisions in desired directions.

- Field testing of prototype tools as appropriate.

- Research to produce key missing scientific information needed to change decision patterns.

\section{Explanation of priority status}

While traditional scientific research is essential to document how to improve IEQ and energy-efficiency in buildings, even available information in these areas is not adequately implemented, due to social and economic barriers among building professionals, building owners, produce manufacturers, and others. The research in this project is also essential to achieve timely changes in building practices.

\section{How the research results would be used}

Research results would include a variety of tools, processes, and information with potential to change decisions made in buildings, in directions to improve IEQ and energy-efficiency. Tools might include meaningful and practical metrics for assessing IEQ or energy-efficiency, and improved products and services for measuring and controlling IEQ or energy-efficiency. Processes might include educational or informational activities.

Information might include guidelines on relations of IEQ to health, documentation of costs versus benefits of improvements in IEQ or energy-efficiency.

\section{Expected Research Products}

- New more effective tools for dissemination of information about IEQ and energy efficiency to the people who make the most important decisions affecting IEQ and building energy efficiency, and new decision making tools that incorporate IEQ and energy efficiency information

\section{Related R\&D goals}

- Stimulating or assisting implementation of energy efficient technologies or practices for improving IEQ.

\section{Related R\&D application categories}

Residential, Commercial, Schools, New Construction, Existing buildings

\section{Term of R\&D Projects}

Short-term to mid term

\section{Co-funding or leverage opportunities}

EPA, HUD, NIOSH Return to page 10 
Project Area 29.

Create a consumer reports that ranks the performance IEQ related building products in use.

\section{Description}

The purpose of this project is to assemble the collective findings of building managers in relation to the performance of major HVAC equipment/ components in non-residential buildings. These rankings will enable building managers to select the highest performance products affordable, building on the experience of their peers. These rankings will also help professionals to avoid products that raise consistent concerns, notifying manufacturers that improvements are needed. The range of products that could be evaluated for IAQ and energy performance, and published in a yearly/bi-yearly report, include: humidifiers; air handlers; filters; chillers; boilers; unitary heat pumps; distributed heat pumps; distributed fan coils; induction units; window/room air conditioners; split heat pumps; pumps; fans; task air diffusers; zone boxes; dampers; thermostats, sensors for $\mathrm{CO}_{2}$ daylight, and occupancy; EMCS/BAS systems. The performance criteria in this professional "consumers report" (with a five point or higher scale similar to black and red dots, empty, half full or full) could include: air quality; thermal quality/ control; acoustic quality/ noise; energy performance; cost/ frequency of repair; maintainability; life of product; first cost of product; life cycle cost of product including M\&R within life of product. Once the program is established, the "Consumer Union" which publishes "Consumer Reports" would be contacted regarding their interest in taking over the program and making it a self-supporting enterprise.

The identification of products, criteria and survey instruments would be the task for a phase-1 effort, as well as the identification of a major partner/partners with a resolution of the legal ramifications for publishing the collective professional evaluations. Phase 2 would be the implementation and publication of the results, annually or every other year. Phase 3 would pursue comparative laboratory testing of the IEQ/energy performance of critical building products for the commercial building market.

\section{Explanation of priority status}

Consumer Reports has given invaluable service to the American consumer by clearly identifying the quality differences of products with multi-dimensional scales. The use of questionnaires and laboratory testing to identify the performance differences in "commodity" products has supported manufacturers and consumers alike. For the manufacturer, these scales have helped to explain why better products cost more, and the importance of looking at multiple performance indices in the selection of products. The collecting rankings have helped to eliminate unsatisfactory products from the market and to promote the highest performance alternatives, raising the standards year by year. For the facility manager, project manager, or design professional, these collective rankings would help the decision maker avoid problematic products and select the highest performance product affordable. While most veteran engineers and managers have a "black list" of products that perform so poorly that they would not buy them again, and a "high quality" list for owner occupied projects, novice decision makers are left to repeat mistakes driven by least-cost decision making. The project is of critical importance to give widespread access to field experience, especially in relation to "hidden infrastructures" that have a major impact on IAQ and energy performance over time.

\section{How the research results would be used}

These rankings will enable novice and veteran building managers to select the highest performance products affordable, building on the experience of their peers. The rankings will also notify practitioners and the manufacturing community about the quality differences between products, and identify products where performance is unsatisfactory in an effort to "raise the bar". With a growing understanding of quality differences in the range of products that make up the "hidden infrastructures" in buildings, it may also be possible to revise the simplistic Class A, B, C designations for commercial buildings to reflect the performance of a broader range of subsystems and components (as done in automobiles) to effectively ensure IAQ and energy performance.

\section{Expected Research Products}

- A consumer reports style document that ranks IEQ-related building products based on the experiences of building managers

\section{Related R\&D goals}

- $\quad$ Stimulating or assisting implementation of energy efficient technologies or practices for improving IEQ.

\section{Related R\&D application categories}

Commercial office, schools and institutions, new and existing buildings 


\section{Terms of R\&D Project area}

Short term potential to affect practice and urge industry investments in higher performance products.

\section{Co-funding or leverage opportunities}

IFMA, BOMA, GSA, Consumer Reports, ARTI Return to page 10 


\section{Project Area 30.}

Develop a database of costs and economic benefits of energy efficient practices and technologies for improving IEQ.

\section{Description}

A variety of practices and technologies are currently employed in buildings to improve indoor environmental quality. Many of these practices and technologies also affect building energy use. Some are specifically put in place to address IEQ. Others are choices among various options for HVAC, building design, or building furnishing, often made without considering the implications for IEQ. Examples include: high efficiency air filtration, room air cleaners, UV treatment of air handlers and ductwork, ventilation rate measurement and control technologies; cooling system types, natural ventilation, dehumidifiers, heat and enthalpy recovery ventilators, contaminant isolation and capture ventilation, and low-emission building materials and furnishings. The implementation costs and economic benefits of many of these technologies and practices are poorly documented, and available information has not been compiled for easy use by building professionals. This research project area will compile data on the costs and benefits of these technologies and practices, to the degree possible without performing new studies of health and productivity benefits. Cost elements addressed must include initial capital costs, operation (e.g., energy) and maintenance costs. Economic benefits addressed should initial those associated with improved health and productivity, better employee recruitment or retention, and reduced need to investigate and respond to employee complaints. Results may be communicated in printed form and via computer-based tools. Modeling and existing cost analyses methods will be used as appropriate. As new cost and economic benefit data are developed, the database should be updated.

\section{Explanation of Priority Status}

Economic considerations dominate most decisions about building design, construction, operation, and maintenance. In order for individuals and institutions to make best decisions related to achieving high performance buildings and avoiding IEQ problems, the costs and benefits must be well documented. Consider, for example, the circumstance of so-called "value engineering" that often occurs during the design process. Those who argue for cost reductions can readily present the costs of high performance systems. Those who argue for the high performance systems often do not have clear data on economic and energy costs and the IEQ benefits by which to justify and guide the design decision. Therefore, the resulting database will bring greater parity to those arguing for and against practices and systems that will produce improved IEQ, and consequently should result in greater likelihood of high performance buildings that also avoid IEQ problems.

\section{How the Research Results Would Be Used}

The information developed in this project would be used by decision makers to select and justify the most cost and energy efficient systems and equipment options (considering first cost and life cycle cost) for producing high quality IEQ environments. The information should be integrated into software packages for decision making, such as EPA's IBEAM program.

\section{Expected Research Products}

- Data base of costs and economic benefits of energy efficient practices for improving IEQ, available in printed form and on the web

\section{Related R\&D goals}

- $\quad$ Stimulating or assisting implementation of energy efficient technologies or practices for improving IEQ.

\section{Related R\&D Application Categories}

Residential buildings, Commercial buildings, Existing buildings, New buildings, Schools

\section{R\&D Term Categories}

Short term

\section{Co-funding leverage opportunities}

The potential to integrate this project with the IBEAM effort of U.S. EPA should be investigated. $\underline{\text { Return to page } 10}$ 


\section{Project Area 31}

Develop and demonstrate life cycle cost analyses methods that include human and energy effects of IEQ.

\section{Description}

Building upon existing life cycle analyses tools focusing on energy, this research project will develop and demonstrate new life-cycle cost analyses methods or tools that take into account a wide range of operational costs related to the building, IEQ, and occupants. Life cycle benefits should be broadly interpreted, and can include energy and resource use, operational cost savings, asset value, productivity of tenant businesses, and sustainable community development. Analyses methods needs to translate these benefits into measurable, defensible, and reproducible financial returns so that designers and developers can make sound decisions about investing in improved IEQ and energy performance.

The analyses methods should be developed in a way that will allow the different players in the building industry to understand how improvements in IEQ conditions will affect their concerns. Developers need to know how improved occupant comfort and reduced energy consumption can lead to better asset value as a result of the building's stronger market appeal and adaptability. Analyses methods should also be designed to help financiers and insurers to put these benefits in economic terms, so that they can translate them to more favorable lending and underwriting practices, and will be in a better position to market such high-performance features as an option to their customers.

Corporate executives and A\&E firms should be consulted about most useable life-cycle analyses methods. Once methods are developed, their use should be demonstrated via collaborations with the most progressive corporations that serve as a model for other corporations.

\section{Explanation of Priority Status}

The driving force in commercial development is typically to control first costs, and little discussion and value is placed on the benefits of reducing life-cycle operational costs related to IEQ or other aspects of building performance. This is commonly acknowledged as a significant barrier to implementing innovations in building and HVAC design. Although issues of building energy use are occasionally considered, developers and building generally have no stake in either these or other longer-term operating costs related to the performance of the buildings. The exception seems to be the cases where the building owner and occupant are the same. Because of the emphasis in commercial development is on economics, it is essential that the benefits of reducing energy use and enhancing occupant comfort, health and productivity are communicated in monetary terms.

\section{How the research results would be used}

This project area would develop information and tools (e.g., software) that would be used by architects and employers in decision making about building design and operation.

\section{Expected Research Products}

- Modified tools (software and data) for life cycle analyses that account for IEQ-related costs

\section{Related R\&D goals}

- Developing and evaluating energy-efficient practices for improving IEQ, health, comfort and productivity

- Stimulating or assisting implementation of energy efficient technologies or practices for improving IEQ.

\section{Related R\&D Application Categories}

Commercial, New Construction

Term(s) of R\&D Project Area

Short to long term projects

\section{Co-funding or leverage opportunities}

EPA (This project has elements in common with EPA's IBEAM effort)

$\underline{\text { Return to page } 10}$ 


\section{Project Area 32}

Develop financial incentive tools to stimulate energy-efficient or energy-neutral improvements in IEQ in commercial and institutional buildings; such as model lease language, marketing strategies such as the LEED rating system, model IEQ insurance policies, and model IEQ/energy efficiency disclosure requirements linked to sales.

\section{Description}

- A sequence of activities would be required to complete this work in this project area, for example:

- Assembly of a panel including representatives of the key groups of decision-makers for IEQ and energy efficiency in commercial and institutional buildings, along with experts in economics, organizational dynamics, behavioral research, and other relevant disciplines. The panel would work together to define the full spectrum of groups and individuals making IEQ and energy-efficiency decisions through building life cycles, including decisions related to buildings, contents, and occupants. (This activity is also included in project 9d)

- Conduct of focus groups, run by appropriate experts and containing representatives of all appropriate groups, to define the key decisions influencing IEQ and energy-efficiency in buildings and to generate ideas for financial incentives that would change these decisions in specified ways.

- Development of concepts for new incentives, as suggested by focus groups, into prototypes for testing. Example strategies might include: model IEQ-related lease language, marketing strategies such as the LEED rating system, model IEQ insurance policies including IEQ loss-prevention, model IEQ/energy efficiency disclosure requirements linked to sales, model guideline or regulatory language, or other strategies used successfully in related fields.

- Focus group/simulation testing of prototype strategies.

- Reporting of successful strategies identified for key decision-making groups.

\section{Explanation of priority status}

While traditional scientific research is essential to document how to improve IEQ and energy-efficiency in buildings, such will not be sufficient to stimulate the necessary improvements. Even available information in these areas is not adequately implemented, due to social and economic barriers among building professionals, building owners, produce manufacturers, and others. The research in this project is one essential component in achieving more rapid improvements in IEQ and energy efficiency in buildings.

\section{How the research results would be used}

Results would be available for use by tenant groups, financial sector organizations, consensus organizations, and government agencies to use for proactive improvement of building practices related to IEQ and energyefficiency.

\section{Expected Research Products}

- Tools, such as model lease language; building rating systems, model insurance policies, and model disclosure requirements linked to sales, that provide financial incentives for utilization of energy-efficient or energy-neutral technologies and practices that improve IEQ

\section{Related R\&D goals}

- Stimulating or assisting implementation of energy efficient technologies or practices for improving IEQ.

\section{Related R\&D application categories}

Commercial, Schools, New construction, Existing buildings

\section{Term of R\&D Projects}

Short-term

\section{Co-funding or leverage opportunities}

EPA, HUD, NIOSH, GSA, insurance companies

$\underline{\text { Return to page } 11}$ 
Project Area 33.

Document the full human and environmental cost of least cost decision making including health cost, energy consequences, productivity losses, and waste produced.

\section{Description}

This purpose of this project is to document the full human and environmental costs of least cost decision making in relation to critical sets of materials, assemblies and systems for new and retrofit construction with known consequences for energy, waste, health, productivity or other human and environmental costs. This project would utilize information compiled in Project 9g. At least four efforts need to be undertaken:

- Identify critical sets of materials, assemblies and systems with known consequences for IEQ and energy.

- Identify high performance/ quality alternatives with poor market penetration due to least cost decision making.

- Identify human and environmental costs to be calculated and the method of calculation, to include energy, waste, health, productivity.

- Calculate the human and environmental costs and develop life cycle decision support materials for decision makers, including building owners, design professionals, Congress/GAO and state officials.

- Work with industry to compare IEQ and human and environmental costs in sets of buildings constructed with conventional least-cost decision making to sets of buildings constructed based on a life-cycle analysis.

Possible sets of materials, assemblies and systems with specific benefits in energy and indoor environmental quality could include: roofing systems including cool roofs and green roofs; high performance windows, daylighting control systems, and electric lighting systems; HVAC filtration; humidification systems; variable frequency HVAC components. The project can extend beyond the readily available materials, assemblies or systems with significant quality differences, to innovative assemblies such as new building envelope technologies/systems, HVAC micro-zoning or plug and play zones strategies. Early efforts should ensure that the effort captures the best available material from ESCOs, and DSM efforts, and produced by the manufacturing community. This effort should build on project 30 . The findings of this research would be broadly communicated in technical papers, conference presentations, and handbook chapters. A special effort should be made to communicate results to committees responsible for relevant standards.

\section{Explanation of Priority Status}

Least-cost decision making is pervasive in the built environment, regardless of public or private ownership and 10 or 50 year expected lives. Value engineering processes have become cost cutting efforts, frequently with well-known life cycle costs and environmental performance concerns voiced by the professionals. Clearly, the believability and quality of multiple year financial data are inadequate to convince clients to invest in products expected to enhance IEQ, health, comfort and productivity. Moreover, the client community does not recognize the benefits of quality differences in building materials, assemblies and systems, although $\$ 1000$ to $\$ 3000$ incremental investments in desktop computers are readily accepted, and consumers often accept $\$ 10,000$ $\$ 30,000$ increases in prices of automobiles. Clarification of quality differences that merit rethinking short term financial decision making, with persuasive or definitive financial arguments for a suite of 20-30 critical sets of materials, assemblies and systems for new and retrofit construction, will be invaluable for addressing energy, waste, health, productivity and other human and environmental costs.

\section{How research results would be used}

The results of this research would be used by architects, policy makers, and organizations responsible for standards in decisions about building designs and features of standards.

\section{Expected Research Products}

- Documents, presentations, and web site pages that quantify the full human and environmental costs of the current least-cost decision making practices for buildings

\section{Related R\&D goals}

- Identifying IEQ problems and opportunities

Related R\&D application categories

Commercial buildings, schools, New construction, Existing buildings 
Terms of R\&D Project area

Short term to mid term

\section{Co-funding or leverage opportunities}

Uncertain, possibly EPA Return to page 11 


\section{Project Area 34.}

Better quantify the productivity costs and investigation and remediation costs of SBS problems.

\section{Description}

Research in his project area would gather available economic and health information, use it to estimate the costs of SBS problems in different sectors, and define key data gaps impeding production of better estimates.

Research approaches might include the following:

- Identifying the key components of potential economic loss due to SBS from either acute or chronic IEQ problems, and the sources of best available information for estimating size of each loss component; e.g., large commercial landlords or property management firms, IEQ investigators, environmental attorneys, public health agencies, or researchers on indoor air quality, health, and performance. The focus will be on commercial and institutional buildings.

- Collect information on loss components of major interest, as feasible, from appropriate sources, public or private, including the insurance industry. Where necessary, estimate typical cost or range of costs for each type of loss (e.g., direct and indirect costs of investigating and remediation of office buildings with IEQ problems) and also proportion of building with that type of loss, to allow estimation of total costs across the building stock of each type.

- Report findings for acute losses from building investigation and remediation, including productivity losses, and for chronic losses from chronic SBS due to recognized or unrecognized IEQ deficiencies. Findings should be incorporated in handbooks, published in documents read by appropriate decision makers, including commercial realty executives, facility managers, and corporate executives.

\section{Explanation of priority status}

Current decision-making in buildings is based mostly on minimizing immediate costs, in part because of limited available data on long-term costs. This is particularly true of decisions that affect IEQ. Since the best current strategies for improving IEQ involve prevention through appropriate design, operation, and maintenance, and these decisions are economically-based, this project would provide a major boost in improving IEQ in actual buildings. By stimulating preventive measures, rather than reactive increases in ventilation rate or addition of air cleaners, the project could save energy.

\section{How the research results would be used}

Findings from this project would, by quantifying economic losses related to IEQ and allowing their consideration in economic decisions, would allow more appropriate decision-making in buildings. For instance, decisions on the design, operation, and maintenance of buildings could combine consideration of long-term costs and benefits of proactive IEQ-positive decisions with the desire to reduce immediate expenditures. To facilitate use of project results, summary articles would be prepared for the trade journals used by decision makers. In addition, results should be incorporated into decision making software.

\section{Expected Research Products}

- Documents, presentations, and web site pages that provide a more accurate (than currently available) quantification of the total economic losses associated with SBS symptoms

\section{Related R\&D goals}

- Identifying IEQ problems and opportunities

\section{Related R\&D application categories}

Commercial, Schools, New construction, Existing buildings

\section{Term of R\&D Project}

Short-term

Co-funding or leverage opportunities

EPA, NIOSH, GSA, ASHRAE Return to page 11 


\section{Project Area 35. \\ Develop financial incentives for the design and construction team that reward high IEQ and energy performance}

\section{Description}

Existing information about how to improve IEQ and energy performance is underutilized and is not affecting the design, construction, and operation of buildings as widely as it could be. Research in this project area, therefore, must focus on developing financial incentives for buildings that will both save energy and improve IEQ conditions.

The typical design and construction process in the U.S. building industry is too heavily focused on reducing first costs. This trend is seen throughout the design process, from pre-design to build out and through to occupancy. Architecture and engineering firms are paid for their services either a flat fee or a percentage of construction costs. As a result, there is a greater advantage to doing things fast, rather than well, and it is difficult for these firms to invest additional time on innovations that would lead to improvements in the building's operating efficiency or IEQ. During the bidding process contracts are typically awarded to the low bidder, rewarding first cost savings at the expense of building quality. Although building operators do have a financial incentive to reduce operational costs and enhance IEQ, they are often poorly equipped to effectively manage buildings, and there is little overlap between the design team who understand a building's optimal operation and the facilities management team who will actually operate the building. Under this fragmented system there is no inherent incentive for designing or constructing buildings that offer longer-term benefits such as reduced operating costs and higher quality environments.

A small number of leading edge designers, builders, and owners have experimented successfully with performance-based fees. In these cases performance has been based on occupant surveys or measured energy performance and design firms and contractors were then rewarded or required to refund fees after the performance was determined. These cases show that financial incentives can lead to the market transformation that until now has eluded the building industry.

Working in close collaboration with industry, this research project would develop and analyze the potential of a variety of financial incentive programs. These programs should be flexible enough to allow for the wide variety of possible contractual arrangements between building owners, architects, engineers, contractors, suppliers, construction managers, and others. The incentives should also recognize the varied concerns of these different players. Incentives for the owner might emphasize the marketing value of a building with improved IEQ and energy performance. Incentives for the architect or engineer need to directly address the increased time that might be required for high-IEQ or low-energy design, and incentives may be tied to IEQ or energy-related performance targets that would be paid after the building is completed and occupied. Incentives for the contractor can also be tied to performance targets, and should also include incentives for proper commissioning. To achieve the most optimized building designs, incentive programs should promote better integration and collaboration between the building owners, architects, engineers, contractors and the operations and maintenance staff, bringing greater information and experience to the start of the design process when it is possible to have the largest impact with the least effort and cost.

Specification of the quantifiable measures of IEQ performance, that would be used to assess incentive-related compensation, would be one of the major challenges in the development of these incentive programs. In theory, IEQ performance could be based on: a) measured IEQ conditions (temperatures within comfort zone, pollutant concentrations below limits; measured energy use; residual dust levels in ducts; HVAC produced noise); b) presence or absence of certain events (leaks of water through the roof); c) presence or absence of IEQ and energy features (high efficiency filters, measurement system for outside air; TAC system, floor area per thermal zone); d) occupant satisfaction or health complaints assessed via a questionnaire. However, the design and construction team has only partial control over these outcomes. Thus, acceptable and meaningful measures of IEQ performance that are controlled almost entirely by the designer and builder must be identified and utilized in incentive programs.

To facilitate use of the results of this work, model contract language covering financial incentives would be written and made broadly available to the appropriate businesses.

\section{Explanation of priority status:}

The way buildings are typically designed, constructed and operated offers little incentive for improved IEQ and energy efficiency. Although there are certainly gaps in our understanding about IEQ-related tools, technologies 
and practices, the currently available information is not sufficiently influencing current building practice.

Worldwide, over 3 billion square feel of new commercial buildings were constructed in the last decade, and that rate is expected to increase, with potentially enormous consequences for the energy efficiency and health and comfort of building occupants. It is essential that we develop financial incentives that can influence the ways in which buildings are bid, designed, constructed, and operated, so that the longer-term benefits of energy and IEQ are realized.

\section{How research results would be used}

The results of this research would be financial incentives incorporated into the contracts between building owners, architects, engineers, contractors, suppliers, construction managers, and others. These incentives would result in changes in designs, technologies, and practices that improve IEQ in an energy efficient manner.

\section{Expected Research Products}

- Model financial incentive programs, for example model contract language, that rewards building designers and the construction team for improvements in building IEQ and energy performance.

\section{Related R\&D goals}

- Stimulating or assisting implementation of energy efficient technologies or practices for improving IEQ.

\section{Related R\&D application category or categories}

New construction

\section{Term of R\&D Project}

Short to mid-term

\section{Co-funding or leverage opportunities}

EPA Return to page 11 


\section{Appendix 4. Original set of ten priority R\&D goals and full set of associated priority R\&D project areas.}

Goa1 1. Identify IEQ problem areas and opportunities to improve IEQ by filling critical gaps in information about IEQ and about IEQ-influencing characteristics within existing buildings.

\section{Project Areas:}

1a. Identify ventilation designs and actual airflow rates in schools.

1b. Survey and evaluate combustion safety problems in residences.

1c. Collect baseline data on IEQ conditions in both air-conditioned and naturally ventilated K-12 classrooms.

1d. Collect benchmark data on the distributions of indoor contaminants of key concern in schools

1e. Collect benchmark data on ventilation rates and IEQ in small $\left(<2500 \mathrm{~m}^{2}\right)$ commercial buildings.

1f. Determine, by climatic region, how well different types of HVAC deliver IEQ over time.

1g. Collect benchmark data on IEQ conditions, ventilation rates, and energy use in energy efficient and conventional new housing.

1h. Collect benchmark data on ventilation and air flow performance in existing buildings as a function of region, building type, HVAC system type.

1i Survey particle levels in existing buildings as a function of filtration efficiency and bypass.

1j. Assess quality and frequency of current test and balance practices in commercial buildings.

Goal 2. Advance knowledge of how to improve IEQ, health, comfort and productivity by improving our understanding of the relationship of these outcomes with building ventilation, infiltration, and uncontrolled airflows.

\section{Project Areas:}

2a. Investigate the effects of ventilation rates on productivity in schools

2b. Compare health outcomes among students and staff in schools with very high and very low ventilation rates.

$2 \mathrm{~d}$. Using SBS research data from office buildings, examine the validity of the ventilation rate equations proposed in addendum $n$ to ASHRAE Standard 62 and determine values for the occupant and building factors in these equations.

2e. Investigate the energy health and productivity effectiveness of natural ventilation as the only source of breathing air for extended periods of time in schools and offices.

$2 \mathrm{f}$. Relate ventilation rates in residences to health symptoms and to satisfaction with IAQ.

$2 \mathrm{~g}$. Quantify the energy and IEQ consequences of measures which reduce uncontrolled air flows.

2h. Quantify the influence of outside air ventilation rates on prevalences of communicable respiratory diseases.

2i. Investigate the influence of ventilation (natural and mechanical) on concentrations of contaminants from a diverse range of contaminant sources. 
Goal 3. Advance knowledge of how to improve health, comfort and productivity by improving our understanding of the relationship of these outcomes with IEQ conditions and associated building characteristics (other than ventilation, infiltration, and uncontrolled airflows which are addressed in goal 2).

\section{Project areas:}

3a. Identify and evaluate the health effects of combustion by-products especially low level carbon monoxide on health.

3b. Identify comfort and health impacts of low relative humidity in indoor spaces.

3c. Identify and quantify tradeoffs between optimum thermal comfort criteria from ASHRAE standard 55 and associated impacts on health, productivity and energy.

3d. Quantify the relationships between indoor chemical and biologic contaminants of greatest current concern and health effects on occupants.

3e. Quantify the relationships between outdoor air quality, ventilation rates and indoor air quality and their impacts on occupant health, comfort, productivity and total energy consumption.

3f. Identify and quantify the health, energy, comfort, productivity impact of access to fixed and operable windows.

3g. Evaluate the IEQ and health benefits of energy efficient IEQ improvement strategies and technologies currently believed to be beneficial.

3i. Quantify linkages between building characteristics and disease or health care costs.

3j. Determine the influence of occupant behavior on inter-individual differences in comfort, health, and productivity and building energy use.

$3 \mathrm{k}$. Evaluate the effects of thermal comfort parameters on health and comfort in commercial and institutional buildings, including comparisons between airconditioned and naturally ventilated buildings.

Goal 4. Advance knowledge and models of how important IEQ conditions depend on characteristics and operation of buildings, providing as basis for improvements in building design, operation and maintenance and associated guidelines, standards, and codes.

\section{Project areas:}

4a. Investigate uncontrolled air flows (UAFs) and ventilation rates in small commercial buildings including characterization of elements that contribute to UAFs such as envelope air tightness, pressure differentials, and unbalanced air flows.

4b. Investigate the influence of high performance building envelopes, including double skinned facades, on IEQ in office buildings.

4c. Based on health and comfort effects, determine, as a function of climate, if the use of economizer cycles can enable a reduction of minimum ventilation rates.

$4 d$. Identify the components and features of current HVAC technologies that are associated with harmful microbiologic exposures.

4e. In a number of climates, quantify the IEQ and energy impacts of deep floor plates, i.e., floors with interior areas far from windows, and of the systems that serve deep floor plates.

4f. Quantify the IEQ and energy impacts of building/HVAC maintenance and space cleaning.

4g. Quantify the impact of air flows, pressure differentials, ventilation rates, and HVAC system performance on indoor humidity levels and moisture problems in small commercial buildings located in humid climates, and develop associated remediation measures. 
Goal 5. To enable energy-efficient improvements in IEQ, identify indoor pollutant sources, quantify source strengths, and develop pollutant source reduction measures.

\section{Project areas:}

5a. For various climates, develop best ventilation and insulation technologies and practices for crawl spaces and attics to minimize moisture problems and energy waste.

5 b. Determine the pollutants and their source strengths emitted from common energy consuming office equipment such as copiers, printers, computers.

5c. Document pollutant emission characteristic for materials and equipment as used and maintained in residences.

5e. Develop standard labeling procedures for building materials and equipment for combined energy and IEQ environmental and energy performance.

5f. Advance understanding of pollutant emissions from HVAC systems and determine how to reduce these emissions.

5g. Develop models for predicting VOC emissions from building materials furnishings systems.

5i. Improve predictive models for indoor sources of chemical contaminants of concern to include generation, adsorption and transport.

$5 j$. Identify the dependence of microbiologic growth on buildings envelopes upon the materials used, airflows, humidity, moisture contents, condensation, and soiling; and develop strategies that minimize risk of microbiologic contamination, while maintaining energy efficiency.

Goal 6. Improve the IEQ performance of environmental control technologies and systems and develop new innovative technologies and systems for environmental control, including technologies and systems controlled by the building's occupants.

\section{Project areas:}

6a. Develop new and innovative HVAC system designs that provide improved IEQ at minimum life cycle cost.

6b. Develop HVAC systems with excellent dehumidification performance under full and part load conditions.

6d. Identify the components and features of current HVAC technologies posing risks, in actual use, of microbiologic contamination and dissemination.

6e. Develop mixed-mode HVAC strategies and design and operation guidelines to improve IEQ and save energy.

6f. Develop and evaluate task exhaust ventilation technologies for concentrated sources of heat and air pollutants.

6g. Develop and evaluate air cleaning technologies for removing gaseous pollutants from incoming outdoor air.

6h. Study contaminant removal efficiencies and energy consumption of air cleaners including consideration of integration with other building systems.

6i. Develop and evaluate strategies for micro-zoning while providing individual control, with a focus on spatial and temporal variability in IEQ conditions, on occupant interactions with the building [including its systems and environment] and on the resulting effects on health, comfort, productivity, and building energy use. 
Goal 7. To facilitate more efficient prevention or diagnosis of IEQ problems, develop practical measurement tools and diagnostic procedures for IEQ conditions of particular concern.

\section{Project areas:}

7a. Develop inexpensive yet accurate techniques for measuring outdoor air flow rates, in particular at mixed air plenums of packaged HVAC equipment.

7b. Develop and evaluate diagnostic testing/monitoring tools and protocols for diagnosing UAF and related IEQ failures or verifying building performance compliance.

7c. Develop inexpensive wireless sensor technologies to monitor local IEQ conditions and controlling factors, such as operable window position.

7d. Develop instruments for rapid and sensitive identification and measurement of highly irritant organic compounds.

7e. Develop inexpensive instruments for rapid and sensitive identification and measurement of indoor pollutants of concern.

7f. Develop effective, readily understood, data mining and graphic feedback mechanisms for communicating IEQ and energy performance of buildings.

7g. Develop diagnostic protocols and tools for failures of HVAC that deteriorate IEQ and energy efficiency.

7h. Evaluate and revise test and balance tools and methods to achieve improved air flow and building pressure characterization.

Goal 8. Develop IEQ performance metrics, guidelines, and standards that guide building design, construction, operation, and maintenance.

\section{Project areas:}

8a. Based on a cost/benefit analysis, determine the appropriate minimum ventilation rates in building codes.

8b. Integrate building science and IEQ information into building codes.

8d. Combine current scientific and practical information on health effects of building design operations and maintenance including ventilation into guidelines for best building practices.

8e. Investigate the interactions between and among multiple environmental factors and occupant responses.

8f. Integrate scientific information on IEQ and materials, with appropriate weighting factors, into the LEED Rating System for Green Buildings. Top22

8g. Use existing information to recommend maximum pollutant concentrations for pollutants and pollutant mixtures of particular concern.

8h. Develop and disseminate metrics based on a building ecology paradigm, considering the dynamic interdependence of the occupants, the building, and larger environment.

Goal 9. Develop and evaluate strategies and instruments to disseminate critical IEQ information, and decision-making tools that enable building professionals to improve IEQ in an energy efficient manner.

\section{Project areas:}

9a. Enhance the EnergyPlus building energy simulation program by adding models of IEQ factors and processes such as effective temperature and interzonal air and pollutant transport. 
9b. For design professionals, facility managers, and code officials, develop and deliver education programs in HVAC and building science related to best practice for IEQ.

9c. Develop a web-based tool illustrating strategies for maintaining thermal comfort within broader temperature ranges during energy curtailment periods.

9d. Identify key decision makers for IEQ and energy efficiency in buildings through the building life cycle, and develop effective information dissemination and decision making tools for IEQ and energy efficiency specifically targeted to these individuals.

9e. To improve design decisions for IEQ and energy, develop life cycle environmental impact assessment tools integrated with the CADD software used by architects and engineers.

9f. Create a consumer-reports style document that ranks the performance IEQ related building products in use.

9g. Develop a database of costs and economic benefits of energy efficient practices and technologies for improving IEQ.

Goal 10. To stimulate improvements in IEQ, develop financial incentives and remove barriers.

\section{Project areas:}

10a. Develop and implement IEQ practice competence certification for those designing, constructing, commissioning, and maintaining buildings.

10b. Develop and demonstrate life cycle cost analysis methods that include human and energy effects of IEQ.

10c. Develop financial incentive tools to stimulate energy-efficient or energyneutral improvements in IEQ in commercial and institutional buildings; such as model lease language, marketing strategies similar to the LEED rating system, model IEQ insurance policies, and model IEQ/energy efficiency disclosure requirements linked to sales.

10d. Document the full human and environmental cost of least cost decision making including health cost, energy consequences, productivity losses, and waste produced.

10e. Better quantify the productivity costs and investigation and remediation costs of SBS problems.

10f. Develop financial incentives for the design and construction team that reward high IEQ and energy performance.

10g. In both typical and cutting edge case-study buildings, document the full life cycle environmental and economic costs including those related to IEQ and energy efficiency. 